\title{
Feeding behaviour and digestive physiology in larval fish: current knowledge, and gaps and bottlenecks in research
} \author{
Clara Boglione ${ }^{6}$ \\ 1 Department of Biology, University of Bergen, Bergen, Norway \\ 2 Instituto de Ciencias Marinas de Andalucía (ICMAN-CSIC), Puerto Real, Cádiz, Spain \\ 3 Helmholtz Centre for Ocean Research Kiel - GEOMAR, Kiel, Germany \\ 4 Aquaculture Research Center of Portuguese Institute of Sea and Atmosphere, Olhão, Portugal \\ 5 National Institute of Nutrition and Seafood Research (NIFES), Bergen, Norway \\ 6 Department of Biology, University of Rome 'Tor Vergata', Rome, Italy
}

Ivar Rønnestad ${ }^{1}$, Manuel Yúfera² ${ }^{2}$ Bernd Ueberschär ${ }^{3}$, Laura Ribeiro ${ }^{4}, \emptyset y s t e i n ~ S æ l e^{5}$ and

\section{Correspondence}

Ivar Rønnestad, Department of Biology, University of Bergen, Pb 7803, 5020 Bergen, Norway. Email: ivar.ronnestad@bio.uib.no

Received 15 April 2012; accepted 23 August 2012.

Re-use of this article is permitted in accordance with the Terms and Conditions set out at http://wileyonlinelibrary.com/ onlineopen\#OnlineOpen_Terms

\begin{abstract}
Food uptake follows rules defined by feeding behaviour that determines the kind and quantity of food ingested by fish larvae as well as how live prey and food particles are detected, captured and ingested. Feeding success depends on the progressive development of anatomical characteristics and physiological functions and on the availability of suitable food items throughout larval development. The fish larval stages present eco-morpho-physiological features very different from adults and differ from one species to another. The organoleptic properties, dimensions, detectability, movements characteristics and buoyancy of food items are all crucial features that should be considered, but is often ignored, in feeding regimes. Ontogenetic changes in digestive function lead to limitations in the ability to process certain feedstuffs. There is still a lack of knowledge about the digestion and absorption of various nutrients and about the ontogeny of basic physiological mechanisms in fish larvae, including how they are affected by genetic, dietary and environmental factors. The neural and hormonal regulation of the digestive process and of appetite is critical for optimizing digestion. These processes are still poorly described in fish larvae and attempts to develop optimal feeding regimes are often still on a 'trial and error' basis. A holistic understanding of feeding ecology and digestive functions is important for designing diets for fish larvae and the adaptation of rearing conditions to meet requirements for the best presentation of prey and microdiets, and their optimal ingestion, digestion and absorption. More research that targets gaps in our knowledge should advance larval rearing.
\end{abstract}

Key words: absorption, digestion, gut, ingestion.

\section{Introduction}

The principal objectives of this review are (i) to analyse current knowledge, research trends and efforts in basic and applied aspects of the feeding behaviour and digestive physiology of fish larvae focusing primarily on marine species and (ii) to identify the gaps and bottlenecks that need to be tackled in future research on advanced and more efficient production of fish larvae.

Several recent reviews have covered various aspects of larval development, with emphasis on feed acquisition and digestive processes (i.e. Morais et al. 2007; Rønnes- tad et al. 2007b; Yúfera \& Darias 2007a; Rønnestad \& Morais 2008; Finn \& Kapoor 2008; Gisbert et al. 2008; Zambonino-Infante et al. 2008; Holt 2011). These reviews illustrate the advances made in knowledge from different perspectives, highlighting the essential role of feeding and digestive organs, as well as behaviour and the digestive machinery that enables rapid growth (larvae multiply their body mass to adult size by a factor of $10^{5}-10^{7}$; Finn et al. 2002), in addition to the anatomical status and transformations exhibited by fish during the first weeks of life. Although there is a substantial literature regarding the direct effect of some abiotic factors 
such as temperature on exogenous feeding activity, less attention has been paid to the impact of temperature, illumination and feeding protocol in a rhythmic or circadian perspective (Yoseda et al. 2008; Villamizar et al. 2009). The potential importance of environmental and endogenous rhythms and transient conditions on food uptake and feeding physiology is recognized but not well understood, as are even less so their implications for nutritional composition, growth rates and survival. Another important aspect that should be taken into account is the variety in ontogeny, feeding physiology and behaviour even within the same family. Thus, species-specific findings for a process or function in a model species cannot be extrapolated directly to other teleosts and specific validation studies are essential.

It is obvious that better knowledge of larval feeding behaviour and digestive physiology will contribute to the optimization of diets and feeding protocols and will eventually improve growth rates and survival, even in many common aquaculture species. An integrated understanding of the various factors and events interacting in food acquisition and digestion is necessary for the design of diets that meet the requirements for optimal ingestion, digestion and absorption. Not least, better knowledge in this area would mean reductions in the costs of fry production.

In comparison with earlier reviews of this field, this review focuses more tightly on identifying and describing the most significant gaps in our understanding of larval rearing that relate to feeding and digestion and on recommending future research strategies in the area.

\section{Feeding behaviour and appetite}

Good knowledge of the complexity of feeding behaviour and of the factors that modulate food detection, acquisition and processing is essential if we are to improve feeding protocols with live prey and to improve the design of microdiets to replace these. Successful food consumption depends, on the one hand, on a series of anatomical characteristics and physiological functions that should be ready to work at the appropriate time, and on the other, on the availability of appropriate food items. Given that the main activities of fish larvae are to eat and avoid being eaten, the differentiation of sensory organs, mouth and digestive elements and the capacity for locomotion is of primary importance (Osse \& van den Boogaart 1999; Boglione et al. 2003; Yúfera \& Darias 2007a).

Feeding behaviour comprises several activities that take place before and after consumption of a food item. In a hatchery scenario they can be summarized in terms of detection, capture and ingestion, and digestion and assimi- lation. This review discusses them according to this sequence.

\section{Detection}

Fish larvae receive information from their environment via their sensory organs. The type and intensity of their responses depend on the nature of the stimulus, the stage of development and the species. Food is detected via a wide range of chemical (olfaction and taste buds), visual (eyes) and mechanical (free neuromasts and lateral line) stimuli. Olfaction detects the most distant stimuli while touch and gustation detect the closest ones (Pavlov \& Kasumyan 1990). Vision plays the most prominent role in prey detection in the larvae of most fish species (Hunter 1981; Blaxter 1986). However, some species are capable of eating and growing independent of light, at low light intensities, in turbid waters or in the dark (Chesney 1989; Downing \& Litvak 2001; Mukai et al. 2008). These species can detect food with the help of the olfactory epithelium and taste buds (chemical stimuli), neuromasts and lateral line (mechanical) and/or electroreceptive ampullary (electrical) organs. Furthermore, scotopic (low light) vision varies among species and developmental stages and changes in the light spectrum may affect activity, feeding behaviour and larval growth (Villamizar et al. 2009; Blanco-Vives et al. 2010).

The timing and sequence of development of sensory tissues and organs differs among species. In most fish, the rudimentary sensory organs develop rapidly in the course of the first few days after hatching and permit prey to be detected at first feeding (O'Connell 1981; Fukuhara 1985; Evans \& Browman 2004; Pankhurst 2008). These organs continue to develop and new tissue appears in order to optimize prey detection in accordance with the body's new capabilities (O'Connell 1981; Fukuhara 1985; Osse \& van den Boogaart 1999).

The fish visual system is capable of wavelength discrimination, high spatial acuity, motion detection and both scotopic (low light intensity) and photopic (high light intensity) vision, but each species has its peculiar attributes. There is also significant inter- and intra-specific variation in the developmental trajectory of fish visual systems (Evans \& Browman 2004) and what we report here cannot be extended to all fish larvae. The fish larval eye is usually functional at the onset of feeding and in Atlantic halibut (Hippoglossus hippoglossus) (Helvik et al. 2001) at least, the retina is equipped with green-sensitive single cones as the only type of photoreceptor. This structure provides relatively good vision and object detection under bright light. Double and mosaic cone structures and rod photoreceptors generally appear later in development. With the structure of the retina complete the larvae can see at low light 
intensities and are able to detect movement (Kawamura et al. 1984; Higgs \& Fuiman 1996; Shand et al. 2002; Evans \& Browman 2004). As development progresses (according to species), the diameter of the eye increases, providing a wider angle of vision and longer-distance perception (Hunt von Herbing \& Gallager 2000; Chesney 2008).

Visual disorders and pathologies related to nutritional deficiencies have been described in several fish species (Hughes 1985): the importance of retinoic acid for retinal development in larval fish was demonstrated by MarshArmstrong et al. (1994) and Rønnestad et al. (1999). A lack of docosahexanoic acid affects rod formation (Bell \& Dick 1993; Shields et al. 1999) and reduced vision under this dietary deficiency has been reported in several species such as herring (Clupea harengus) (Bell et al. 1995), European sea bass (Dicentrarchus labrax) (Bell et al. 1996), Atlantic halibut (Shields et al. 1999) and gilthead seabream (Sparus aurata) (Benítez-Santana et al. 2007). Some recent trends in aquaculture are based on the use of $24 \mathrm{~h}$ artificial lighting or differently coloured tank walls in order to enhance the ingestion rates and growth of larvae and juveniles; if these practices are employed in the absence or ignoring of knowledge of larval ecology (i.e. larvae that develop in deep, dark waters or in surface waters), or the ocular structure and capacity of the species concerned, there is a possibility of increasing stress in the larvae and undermining the intention of the measure.

The first olfactory sensory cells generally differentiate at hatching, and olfaction plays an active role in prey detection in most larvae from first feeding (Dempsey 1978; Knutsen 1992; Kolkovski et al. 1997a). The olfactory organ comprises a number of different types of sensory cells (Hara \& Zielinski 1989; Hara 1993, 2005; Devitsina \& Kazhlayev 1995; Boglione et al. 2003). Olfaction, in combination with the detection of current direction by the lateral line system, enables the odour source to be located: olfactory stimuli trigger a feeding excitatory state that starts and maintains klinotactic swimming activity until the food is located (Valentinčič 2005). This is particularly relevant when live prey characteristics are to be mimicked in microdiets. Leaching hydrosoluble compounds such as amino acids from inert food particles after rehydration can improve their acceptability to larvae (Kolkovski et al. 2000). Therefore, although excessive nutrient leakage should be avoided, particles should not be completely hermetic.

Olfactory sensory cells differentiate very early. Thus, ciliated and/or microvillous receptors develop during the embryonic stages, and aggregate in two placodes or pits at hatching. However, the olfactory bulbs are believed to differentiate later in larval development, and only when they are connected with olfactory receptors do larvae acquire the ability to detect chemical stimuli. At present, data are lacking for most species. As larvae grow, the primordial placodes or pits continue to develop, becoming the nares and olfactory epithelium (Noakes \& Godin 1988; Tanaka et al. 1991; Boglione et al. 2003; Kawamura et al. 2003). As olfaction takes place in water, fish primarily perceive small water-soluble molecules. Most of the substances that stimulate olfactory and gustatory sensory cells are characterized by low molecular weight $(<1000 \mathrm{Da})$ non-volatility; they tend to be nitrogenous and amphoteric (Hara 1993). All these characteristics apply to amino acids, betaines, nucleotides and other substances similar to amino acids. The amino acids that stimulate the chemical senses of fish, even in mixture, are species-specific and exist in a large number of kinds and concentrations, without any identifiable pattern. Fish may be grouped according to the sensitivity of their olfactory cells to different amino acids: (i) wide response range species, which respond to a wide range of amino acids (e.g. channel catfish (Ictalurus punctatus), red sea bream (Pagrus major), black mullet (Mugil cephalus); (ii) limited response range species, sensitive to a limited number of amino acids (Salmonidae, Cyprinidae and other freshwater species) (Marui \& Caprio 1992; Hara 1993). Any diet administered to fish larvae should therefore take into account the species-specific sensitivity to and attractiveness of chemical substances in the diet, particularly if new candidate species for aquaculture are involved. Unfortunately, such data are currently only available for a few species.

The other chemoreceptors involved in feeding behaviour, the taste bud system, are extremely sensitive to a smaller number of chemical stimuli. These trigger reflex responses such as turning and biting/snapping (Valentinčič 2005). While the olfactory chemo-detection of food is involved in long-range detection, taste buds intervene in determining palatability; the external taste buds play a role in the preliminary determination of the suitability of food, intervening in the decision whether to seize or reject an item. The taste receptors located in the mouth are more sensitive (Kasumyan \& Kazhlayev 1993) and detect a wider range of substances than the inner buds, which are involved in the final verification of the quality of the prey seized (swallow or reject) (Pavlov \& Kasumyan 1990). Although taste buds may be present at the opening of the mouth in some species, they usually proliferate days or weeks after the onset of feeding (Boglione et al. 2003; Cobcroft \& Pankhurst 2006; Sánchez-Amaya et al. 2007); their implication in the food acceptation is thus more relevant at later stages, e.g. in Sparidae. In sharpsnout seabream (Diplodus puntazzo), the external and internal taste buds differentiate only during the post-larval phase (5-28.6 mm total length) (Boglione et al. 2003). The rainbow trout taste system is narrowly tuned, as it detects only a small number of amino acid stimuli and alone does not release feeding excitation, since either a visual or an olfactory input is also necessary 
(Valentinčič 2005). Very few data exist on the ontogenesis of taste buds in reared fish, and the individual ontogenetical stages of different types of taste bud still need to be defined.

Mechanical stimuli such as touching or water movements are detected by neuromasts, which may be either free-standing or sunk within the lateral line system. In larval fish, a few free neuromasts are already present at hatching, and these proliferate during growth and development (Higgs \& Fuiman 1996; Kawamura et al. 2003). Originating from the neural crest, they early differentiate near the auditory capsules in the lateral cephalic region soon after hatching, and then develop and migrate to the trunk and the head. Both the ratio of superficial neuromasts to those sunk in canals or in single pores and the pattern of the canal system differ according to species and during development. At first, they differentiate as free superficial neuromasts with a mucopolysaccharidic cupula that covers the stereo- (non sensory) and cnido- (sensory) cilia. They are involved not only in schooling, in the timing of responses to a predator stimulus, in detecting currents, in obstacle avoidance and in controlling swimming movements (Blaxter et al. 1983), but also in larval food detection (Mukai et al. 1994; Myrberg \& Fuiman 2002). In fact, neuromasts are able to detect a low range of frequencies (about $70 \mathrm{~Hz}$ vs $50-200 \mathrm{~Hz}$ ) and small velocities $\left(0.03 \mathrm{~mm} \mathrm{~s}^{-1}\right.$ vs $\left.0.3-20 \mathrm{~mm} \mathrm{~s}^{-1}\right)$ by organisms in the surrounding water: swimming and feeding movements of various types of zooplankton produce frequencies in the range of $10-50 \mathrm{~Hz}$ (Myrberg \& Fuiman 2002); motile particles can stimulate neuromasts from a relatively short distance, 0.5-3 mm (Appelbaum \& Riehl 1997; Harvey et al. 1992; Jones \& Janssen 1992; Poling \& Fuiman 1998; Webb 1989). Furthermore, the location of the free neuromasts on the head and trunk reveals the range within which the larvae can perceive prey movements; Iwai (1980) considered the symmetrical head arrangement of free neuromasts as typical of larvae that pursue their prey through the water column.

As the larvae develop, most of the free neuromasts move deeper into the derma, at first forming a groove and then becoming enclosed in the intradermal canal, opening to the exterior via canal pores. The canalization extends the sensitivity of this system to a wider range of frequencies and velocities. Unlike vision, the potential effects of nutritional deficiencies on olfactory epithelium, taste bud and neuromast development have yet to be explored.

\section{Capture and ingestion}

Both the mouth apparatus and swimming ability are important for the capture and ingestion of food. In most cultured species, teeth and the ability to bite appear during the later stages of the larval phase (Kohno et al. 1983;
Koumoundouros et al. 2000; Boglione et al. 2003) and therefore, larval fish ingest food primarily by swallowing directly the particle identified as food by the sensory organs. The selection of prey is mainly done by choosing sizes that can be swallowed as well as prey organisms that display inadequate escape behaviour. Mouth gape and oesophagus diameter are therefore defining factors in foodparticle preferences during development (Busch 1996; Yúfera \& Darias 2007a; Russo et al. 2009). More specifically, the prey size/mouth gape ratio determines the accessibility of a given prey. Thus, although fish larvae may ingest preys that are similar in size to the mouth gape (Russo et al. 2009), ratios ranging between $25 \%$ and $60 \%$ have been reported as positively selected in several species (Shirota 1970; Fernández-Díaz et al. 1994; Østergaard et al. 2005). When food items are considered as 3-D objects, it is found that width and depth tend to differ, and that depth is the usually smallest dimension. In this way, preys are ingested whose depth corresponds to the width of the mouth. This hypothesis is consistent with those of Hambright (1991) regarding largemouth bass (Micropterus salmoides), Blaxter (1965) for herring, Qin and Hillier (2000) for snapper (Pagrus auratus) and Economou (1991) for five gadoid species.

The range of accessible particle sizes increases as the larva grows. However, the ingested prey also needs to supply mass and energy. The growing larvae presumably try to ingest the maximum quantity of nutrients required for stable growth, while maintaining a favourable ratio between the energy gained by the ingestion of prey and that spent in capturing it (Hunt von Herbing et al. 2001; Puvanendran et al. 2004). Thus, the developing larvae gradually move to larger and more energy-rich prey. Yúfera et al. (1995), who tested a widely accepted experimental microdiet, found that gilthead seabream larvae ingested a greater mass of inert food than live prey, probably to compensate for the lower nutritional value of the microdiet.

In cultured larvae, suitable prey size is obtained by supplying progressively larger strains of rotifers, followed by Artemia nauplii and metanauplii (Polo et al. 1992; Olsen et al. 2000). In some species with very small mouths, other zooplankton species have been tested at first feeding, although not at industrial scale (Strøttrup \& Norsker 1997; Russo et al. 2009; Wullur et al. 2009). This is not a problem with microdiets, since a wide range of particle diameters can easily be produced.

Locomotory capacity during the early larval stages depends largely on the length and development of anatomical features such as the notochord (which becomes the vertebral column), fins and muscular system of the trunk. These structures gradually develop; total length increases, notochord flexion occurs, then the primordial finfold present at hatching is replaced within a few weeks by the lateral, 
median and caudal fins, differentiated vertebrae replace the notochord in sustaining the body, the swim-bladder is inflated, and the size and number of muscle white fibres also increases (Fukuhara 1985; Blaxter 1986; Webb \& Weihs 1986; Vegetti et al. 1990). Swimming capacity is also highly dependent on hydrodynamic conditions and larval body shape. The relationship between inertial and viscous forces in the water, characterized by the Reynolds number, depends on the size and shape of the growing larvae (Webb \& Weihs 1986). During the first days of feeding, when the total length of marine fish larvae ranges between 2 and $4 \mathrm{~mm}$, frictional forces dominate (Webb \& Weihs 1986; Batty \& Blaxter 1992) and the speed and duration of swimming episodes are limited (Hunt von Herbing \& Gallager 2000). The inertial forces become more relevant after notochord flexion and caudal fin development, usually occurring between 5 and $6 \mathrm{~mm}$ of total length. After these developmental events swimming resistance notably increases. As fish larvae grow, they develop better swimming performance (Webb \& Weihs 1986; Fuiman et al. 1999).

During the first days of feeding with limited locomotory capacity, the detection and capture of prey is highly dependent on encounter opportunities. As swimming capacity improves, the larvae can actively search for food and pursue prey, the maximum reaction distance increases as does the distance covered in burst pursuit of the prey (Blaxter 1986; Hunt von Herbing \& Gallager 2000; Chesney 2008). In other words, attack and feeding success rates rise as larvae grow.

Swimming work involves the rhythmic contractions of the segmentally arranged myotomes helped by fins (Johnston 2006). Restricted feeding and dietary imbalances negatively affect several of these structures, reducing locomotion and foraging capacity. The negative effects on ossification lead to abnormal bone development. Malformations in the spinal column and fin rays have been observed in several species fed on inadequate amounts of certain classes of lipids (Cahu et al. 2003a), vitamins A and D (Haga et al. 2002; Villeneuve et al. 2006; Fernández et al. 2008, 2009; Darias et al. 2010) or unbalanced amino acid composition (Akiyama et al. 1986; Saavedra et al. 2009). Nutritional effects on skeletal anomalies have been covered in recent reviews by Boglione (2012) and Hamre et al. (2012). Likewise, myotome structure is immediately affected by feeding restrictions: stunting can easily be observed in larvae kept without food after the opening of the mouth or poorly fed during growth (Margulies 1993; Yúfera et al. 1993; Gisbert et al. 2004). In some species, deficient lipid nutrition also appears to induce functional disorders in the swim-bladder (Kitajima et al. 1981; Katavić 1986). Irregular bladder inflation affects the larva's capacity to remain at the desired level in the water column, leading to higher energy expenditure and seriously interfering with feeding.

\section{Feeding rhythms}

As mentioned above, most fish larvae are visual feeders and thus depend on a minimum illumination level to detect and ingest prey. Day/night cycles thus mark feeding rhythmicity in larval fish. Some studies of wild populations have indicated that larval fish feed preferentially at sunrise and sunset (Kane 1984; McLaren \& Avendano 1995) and also show the highest digestive enzyme capacity at night (Ueberschär 1995). This may be attributed to the particular light intensity of these crepuscular hours and to nycthemeral migration of zooplankton. An adequate combination of the appropriate irradiance for the visual search and prey encounter rate has been suggested as a determinant of feeding success in larval Atlantic cod (Gadus morhua) (Fiksen \& Jørgensen 2011). Laboratory studies have also revealed a daily feeding pattern in spite of the continuous presence of prey (Dou et al. 2000; Ma et al. 2006; Kotani \& Fushimi 2011). These daily rhythms differ according to species. During the first week of life, most fish species feed during the day, while feeding ceases during the hours of darkness. Ingestion can be greater at sunrise and during the early hours of morning, at sunset or at both of these times of day (Shoji et al. 2001; Østergaard et al. 2005; Wang et al. 2008). This rhythmic feeding activity may be maintained even under continuous $24 \mathrm{~h}$ illumination (Yoseda et al. 2008), or may disappear (Dou et al. 2000). The daily feeding pattern may also change throughout development as observed in tongue sole (Cynoglossus semilaevis) (Ma et al. 2006) and loach (Misgurnus anguillicaudatus) (Wang et al. 2008). Feeding may thus be continuous, diurnal, nocturnal or preferentially crepuscular. The feeding pattern may change in the course of development and some species exhibit different pre-metamorphosis and postmetamorphosis patterns. Finally, the larvae may have endogenous rhythms that are strongly influenced by exogenous factors such as light level or the time at which food is more accessible.

\section{Neuroendocrine control of appetite and ingestion}

The physiological regulation of appetite and ingestion involves a complex integration of peripheral and central signals by the brain. As in mammals, the centre that regulates ingestion and energy homeostasis in fish seems to be located in the hypothalamus (Demski \& Northcutt 1983). The appetite-regulating hormones described in fish so far have been reviewed in several papers (Lin et al. 2000; Volkoff et al. 2005, 2009, 2010; Volkoff 2006). Many of the mammalian neuropeptides and hormones involved in the central regulation of appetite have homologues in fish, and several neuropeptides in goldfish have a regulatory effect on appetite similar to 
that described in mammals (e.g. Volkoff et al. 2009, 2010).

Satiety signals from the gastrointestinal tract (GI tract), including the stomach if present, have a major impact on appetite and meal size in both juvenile and adult stages. Studies of rainbow trout (Oncorhynchus mykiss), for instance, have shown that appetite returned when 80-90\% of the stomach content from the previous meal had been transferred downstream into the proximal gut (Grove et al. 1978). Several GI tract hormones seem to be involved together with neural pathways in this satiety feedback mechanism. Furthermore, the central regulator of appetite also receives afferent signals regarding the energy stored in the body. It has been suggested that leptin produced in the liver and fat plays an important role in this signalling function in fish (Murashita et al. 2011) (Table 1).

There are almost no studies of how neuropeptides and endocrine factors affect appetite and ingestion in larvae. In Atlantic cod, one study describes gene expression at the whole-larva level during ontogeny as well as the effects of the dietary regime (Kortner et al. 2011a,b), although analysis of whole larvae has limitations (see below). In adult fish, the list of appetite-regulating endocrine factors currently includes orexigenic factors such as neuropeptide Y (NPY), apelin and galanin, and a long list of anorexigenic factors such as cocaine-amphetamine-regulated transcript (CART), cholecystokinin (CCK) and amylin (Volkoff et al. 2010). The precise physiological role of each factor is not yet properly understood, and has been explored in only a few species. What we know of mammalian systems suggests that the list of endocrine factors that affect appetite and energy homeostasis in fish will be significantly extended and that it will include both central and peripheral signalling pathways. Adding to the complexity are the integration and interactions of the various factors involved. However, one of the key questions in larval stages is when these regulatory loops become functional. The fact that larvae continue to feed in spite of having a full gut suggests that satiety factors may play a relatively minor role, at least in the first feeding stages. Under natural feeding conditions, these larvae may never encounter prey densities that are high enough to permit ingestion rates equal to those in intensive culture. It is not yet known whether altricial fish larvae possess a system that regulates appetite and to what extent it depends on feedback from the digestive tract (for satiety) and/or from the body (nutrients/energy stored/ adiposity).

\section{Adaptation of feeding protocols to the feeding behaviour}

Larval feeding activity and digestion capacity define food preferences, daily ration and daily feeding rhythm. Good knowledge of all these processes, which are changing during the transition to the juvenile stage, is needed for the design of appropriate feeding protocols for each species. Identifying the optimum temporal sequence for the different prey types (usually rotifers and Artemia nauplii and metanauplii) during development has been the aspect of feeding behaviour most often examined in all reared species. Similarly, the questions of how much food should be offered and how often it should be supplied to the rearing tanks have been studied since the start of larvi culture. Providing sufficient food has been always a priority. Feeding protocols tend to maintain a permanent, or at least a better than minimum, prey density by supplying food twice or more often per day. However, 'when and how often' are important issues that have not been sufficiently studied. Protocols for supplying live planktonic prey tend to be adapted to working hours, or diurnal period. This protocol works for most species although obviously it can be optimized. Besides, as mentioned above, some species develop nocturnal habits. An inappropriate feeding schedule may limit ingestion, either because the larvae do not eat or do not detect the prey at feeding time or because they are already satiated. In both cases, the prey will spend hours in the tanks before being eaten, with a consequent drop in nutritional quality (Romero-Romero \& Yúfera 2012). On the other hand, in many species that tend to eat continuously during the early stages of life, an excess of food during the feeding period may shorten the gut passage time, while the prey are less efficiently digested (for details see section Gut transit rate vs dietary protein utilization).

\section{Digestive physiology}

Once larvae have captured and ingested their food, the role of the digestive system is to reduce it to very simple molecules (absorbable units) that are transported across the intestinal epithelium into the blood. Understanding the functions and limitations in processing capacity of the digestive system during early life stages continues to be a key area for aquaculture-related research on fish larvae.

\section{Ontogeny and plasticity of the digestive system}

An ample literature describes the gross morphological ontogeny of the fish digestive tract. In recent years, these descriptions have gradually gone into more detail as new tools become available to describe the embryogenesis of the GI tract and its associated organs. Recently, 3D models of the digestive tract at various developmental stages have started to become available (Fig. 1). Fish larvae are often categorized on the basis of the presence of a stomach: agastric fish will not develop a stomach, even in the adult stage, precocial fish have a functional stomach at the onset of first feeding, while altricial larvae develop a functional stomach 

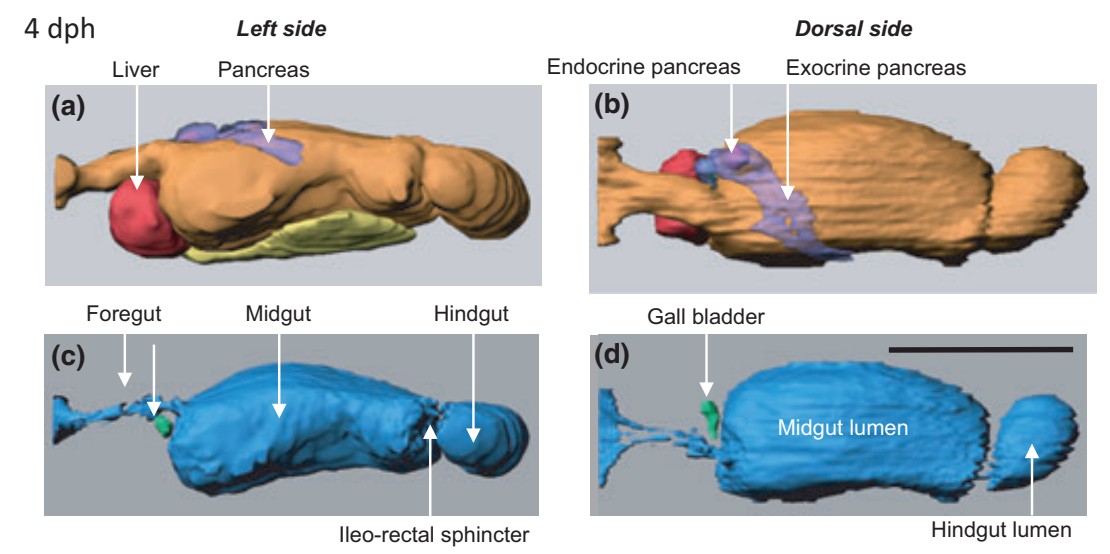

\section{$53 \mathrm{dph}$}
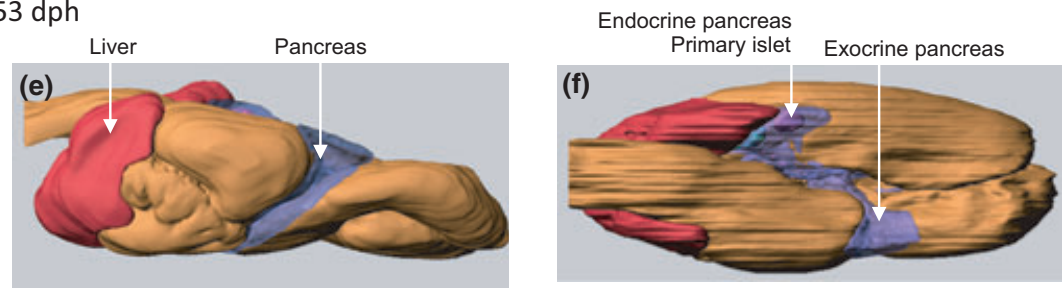

Figure 1 Three-dimensional model of the digestive tract with associated organs in Atlantic cod, an altricial fish that does not possess a stomach at first feeding. $4 \mathrm{dph}$, first feeding larvae; $53 \mathrm{dph}$, later stages of metamorphosis (modified from Kamisaka \& Rønnestad 2011).
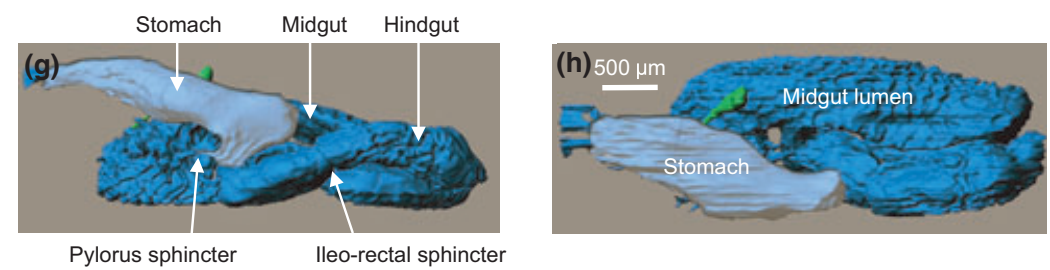

during metamorphosis. Most research on feeding-related physiology has targeted altricial larvae, among those most of the marine species common in aquaculture, since they present the largest challenge to successful rearing.

In altricial fish, the digestive tract gradually develops from a short and straight tube, often closed at both the mouth and anal ends in yolk-sac larvae, into a segmented and histologically differentiated tract in juvenile fish. At the onset of exogenous feeding the digestive tract has histologically and functionally distinct regions, the bucco-pharynx, oesophagus, stomach anlage, intestine and anus. Some authors use a different terminology and group these different regions into the foregut, midgut and hindgut. At the onset of exogenous feeding, the gut length is often less than half the body length. The midgut is individually separated from the foregut and hindgut by muscular sphincters. With few exceptions, the gut is coiled into a loop before exogenous feeding begins. In the subsequent phase of development, the digestive tract increases its absorptive capacity through elongation and mucosal folding. The wall of the tract also increases in thickness due to a thicker gut epithelium and maturation of enterocytes that includes development of the intestinal brush border with larger microvilli.
The shape of the midgut may differ from a narrow tube. A 3D model of the GI tract of the Atlantic cod shows the relatively large volume of the anterior midgut, resulting in a bulb-like appearance of this compartment (Kamisaka \& Rønnestad 2011; Fig. 1c,d). This feature probably increases the residence time of food and enables good mixing with secretions from the pancreas and bile that enter close to the oesophagus. Systematic studies linking morphology with functional studies of the digestion could provide valuable insight into the process, particularly at a general level.

During the transition period from larva to juvenile, the stomach epithelium becomes structurally differentiated, glands develop and by the end of this period gastric digestion has been established. However, the pyloric sphincter in Japanese flounder (Paralichthys olivaceus) for instance, seems to be functional before the onset of metamorphosis (Rønnestad et al. 2000b), which suggests that the stomach may start to function as a short-term reservoir before assuming its role as an acid proteolytic chamber. It has been suggested that the appearance of gastric glands acts as a marker to indicate the juvenile stage (Tanaka 1973). However, gastric glands may develop some days before $\mathrm{HCl}$ - and pepsinogen-secretion mechanisms are established 
(Douglas et al. 1999; Darias et al. 2005, 2007a), leading to a gap between gastric gland appearance and its secretory function.

Pyloric appendices (caeca) develop during metamorphosis, usually by the time that gastric glands develop. The caeca increase the volume of the anterior midgut and also the absorptive area of the digestive tract and may be important for protein and fat absorption. In some species, changes in enterocytes during ontogeny include enhanced brush border digestive capacity, due to increased activity of membrane-associated enzymes that contribute to a change in digestive abilities of the organism. In European sea bass, this shift occurs 3-4 weeks after hatching (ZamboninoInfante et al. 2008) and is believed to represent a shift to the adult mode of digestion. There is an elongation of the digestive tract during the larval stages, and this seems to continue for some species after metamorphosis. There are small changes in gut morphology after metamorphosis and these may include further increases in its relative length and, possibly, adaptation to changes in diet.

The anatomical and functional ontogeny of the digestive tract is similar in most teleosts once the above-mentioned differences between precocious and altricial, and gastric and agastric species are taken into account. However, there are important inter-species variations in the sequence of appearance of some tissues and enzymatic activities. The most relevant difference is probably the timing of stomach development. The point at which the first gastric glands appear ranges from a few days to several months after first feeding, even within the same family (Fig. 2). This event marks the beginning of the end of the larval mode of digestion. After the appearance of gastric glands and pepsin activity, the completion of the stomach and full acidic digestion capacity takes some weeks or months, depending on the species. However, in the Senegalese sole (Solea senegalensis) in spite of the presence of gastric glands, the acidification process has not been detected in either juveniles or adults (Yúfera \& Darias 2007b). The species differences are presumably evolutive adaptations to the diets they encounter in their natural environment and the apparently 'abnormal' functionality in sole might be explained by their diet of invertebrates that continues into the adult stage.

In conclusion, the ontogeny of the digestive tract has been described in a number of species by means of methods that have usually targeted gross morphology, histology and to a certain extent ultrastructure, often in combination with biochemical, immunochemistry or recently, molecular techniques. However, cellular changes, the differentiation and the turnover of intestinal cells as well as the underlying signalling pathways that control the genetically programmed development of different sections of the digestive tract during the early stages remain to be described. More attention also needs to be focused on understanding how, and to what extent, environmental and dietary factors induce effects (plasticity) on the digestive tract and digestive function.

\section{Accessory digestive organs}

The liver, pancreas and gallbladder with their outlets are differentiated as early as the embryo and yolk-sac stages, and are functional at the onset of exogenous feeding, which normally occurs some time before the yolk-sac has been absorbed completely (Sarasquete et al. 1995; Guyot et al. 1995, 1998; Ribeiro et al. 1999; Hoehne-Reitan \& Kjørsvik 2004; Micale et al. 2008). Taking Atlantic cod as an example, the pancreas is normally a distinct organ at the onset of first feeding (Kamisaka \& Rønnestad 2011; Fig. 1a,b). During ontogeny, the pancreas develops from a compact organ to an elongated and branched (but still not diffuse) organ along the posterior midgut (Fig. 1e,f). Most of the pancreas tissue is exocrine, but endocrine tissue can also be identified. The first islet of Langerhans can usually be observed from first feeding (Tanaka 1969; Sarasquete et al. 1993; Guyot et al. 1998). Additional islets appear later, although with a high interspecific variability. For instance, in red banded seabream (Pagrus auriga) the start of proliferation was detected at 21 days post-hatch (dph) (Sánchez-Amaya et al. 2007) while in Atlantic cod it becomes evident at 53 dph (Kamisaka \& Rønnestad 2011).

As in adult fish, the liver plays a role as an energy reservoir in fish larvae. Mature hepatocytes with accumulation of glycogen and protein granules in the cytoplasm have been observed in the liver of several species from first feeding (Tanaka 1969; Guyot et al. 1995; Micale et al. 2008). As development progresses and body size increases, the hepatic sinusoids and vacuolization proliferate. Glycogen is progressively stored in the liver with a species-specific time sequence (Hoehne-Reitan \& Kjørsvik 2004). In Senegalese sole liver glycogen deposition was observed at $7 \mathrm{dph}\left(19{ }^{\circ} \mathrm{C}\right.$; Ribeiro et al. 1999) and in Atlantic cod the visible storage of glycogen increases after yolk resorption (Kjørsvik et al. 1991). A key role for liver in digestion is to produce the bile that is required for proper lipid digestion. The synthesis of biliary products has been observed from the beginning of the trophic life of larval fish in European sea bass, gilthead seabream and pike-perch (Stizostedion lucioperca) (Diaz et al. 2002), but generally speaking, little is known about either the qualitative and quantitative aspects of this process in larvae, nor to what extent bile is recovered from the hindgut in the entero-hepatic pathway in larvae.

Most work related to the accessory digestive organs has focused on the production and the activity of pancreatic enzymes, particularly trypsin and how enzyme activities 


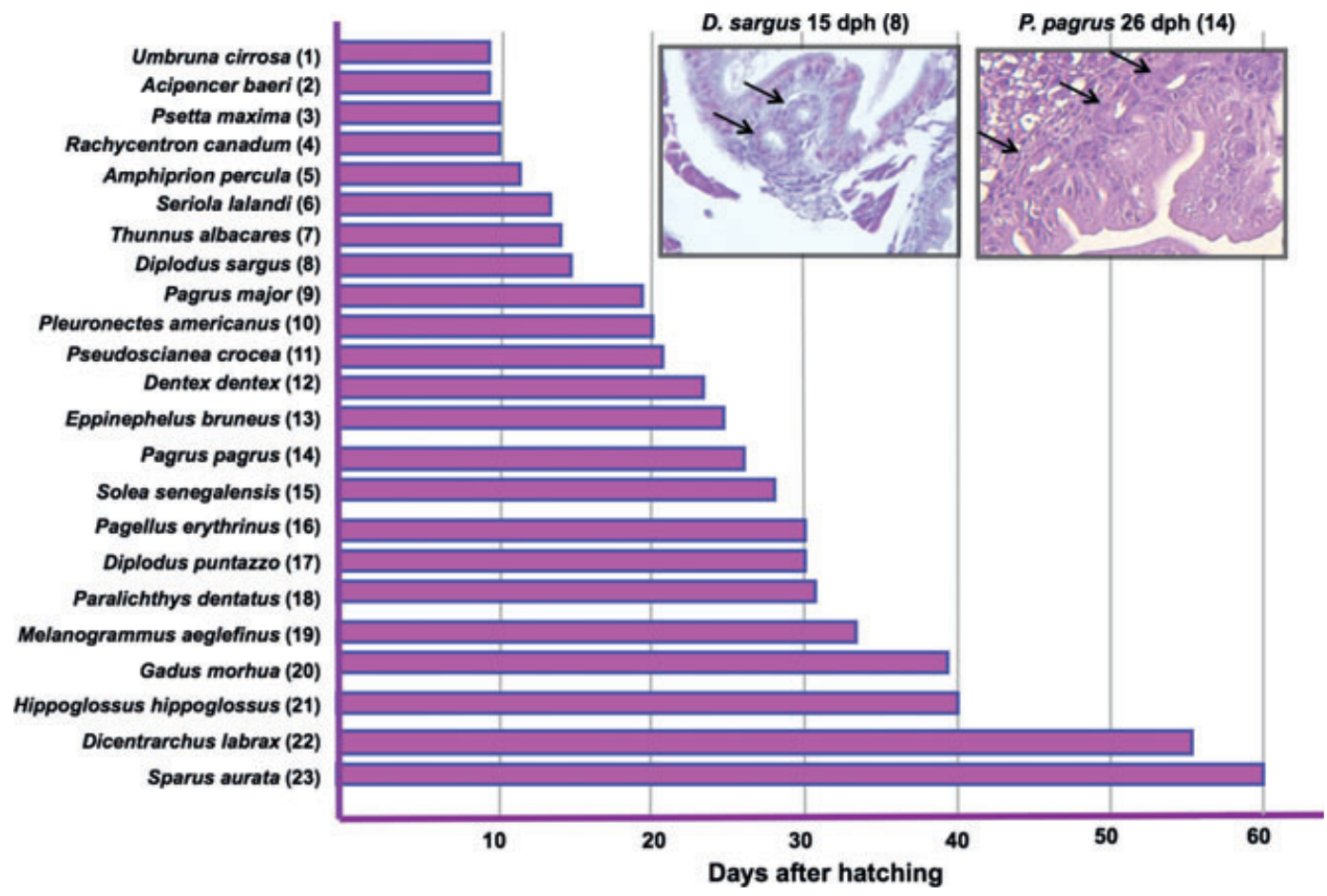

Figure 2 Age of detection of first gastric glands in various species of interest in aquaculture. Inserts show two examples of first developing gastric glands (arrows). (1) Zaiss et al. 2006; (2) Gisbert et al. 1999; (3) Cousin \& Baudin-Laurencin 1985; (4) Faulk et al. 2007; (5) Önal et al. 2008; (6) Chen et al. 2006; (7) Kaji et al. 1999; (8) Ortiz-Delgado et al. 2003; (9) Tanaka 1971; (10) Douglas et al. 1999; (11) Mai et al. 2005; (12) Santamaría et al. 2004; (13) Kato et al. 2004; (14) Darias et al. 2005; (15) Ribeiro et al. 1999; (16) Micale et al. 2006; (17) Micale et al. 2008; (18) Bisbal \& Bengtson 1995; (19) Hamlin et al. 2000; (20) Kamisaka \& Rønnestad 2011; (21) García-Hernández et al. 2001; (22) Elbal et al. 2004; (23) Luizi et al. 1999.

respond to diets. There is little in-depth knowledge of the digestive process and mechanisms by which the production, release and activity of enzymes are regulated by nutrients, either directly or via neuronal and hormonal factors. Likewise, we possess very little knowledge of the endocrine pancreas in early life or of the role of pancreatic hormones on post absorptive metabolism.

\section{Intestinal modelling and remodelling}

The intestinal epithelium is capable of continuous selfrenewal, providing the intestine with the plasticity it needs to adapt to changing feeding conditions and playing an essential role in organ homeostasis, tissue repair and regeneration (Henning 1979; Buddington et al. 1997; Shi et al. 2011). Intestinal development is mediated by preprogrammed intrinsic factors and external cues. However, inadequate dietary and environmental conditions may interfere with the complex regulation mechanisms involved in epithelial development, disrupting epithelial integrity and affecting its capacity for self-renewal (Buddington 1994). Weaning onto inert diets with inadequate dietary composition when gastrointestinal motility, digestion and absorption are not yet fully developed will usually result in epithelial disorders that depress growth and survival rates, as observed for fish larvae (Zambonino-Infante et al. 2008; Kamisaka et al. 2010) and other vertebrates, including rats, pigs and chickens (Henning 1979; Buddington 1994; Buddington et al. 1997; Zabielski et al. 2008). On the other hand, reduced proliferative capacity of the intestinal epithelium has been observed in Vimba bream larvae (Vimba vimba) fed diets based on free amino acids (FAA) and dipeptides than in larvae fed live food and a commercial microdiet (Ostaszewska et al. 2008). The identification of factors affecting the epithelium proliferation and intestinal maturation is therefore a task of primary importance for the prevention of developmental delays and future malformations and improvement of the quality of the produced juvenile.

In other vertebrates, such as mammals and especially anurans, this is a research area of intense activity, due to its importance for the treatment of human diseases and malformations (van der Flier \& Clevers 2009; Heimeier et al. 2010), but it is also extremely relevant to improvements in animal production (Rawdon 2001; Zabielski et al. 2008). Remodelling demands a continuous coordination of proliferation, differentiation and apoptosis. Mammalian intestinal stem cells are able to differentiate into the four types of cells present in the intestinal epithelium: enterocytes, 
entero-endocrine cells, mucous (goblet) cells and Paneth cells. Proliferative cells are located in the crypts of Lieberkühn, which are epithelial invasions into the underlying connective tissue (van der Flier \& Clevers 2009). The definitive intestine in mammals and adult amphibians is normally attained after intense, or even drastic, morphogenetic transformations that are associated with a drastic change in diet from suckling to solid food in mammals, or from herbivorous to carnivorous in amphibian (Henning 1979; Buddington 1994; Ramalho-Santos et al. 2000; Shi \& Ishizuya-Oka 2001; Zabielski et al. 2008; Schreiber et al. 2009; Heimeier et al. 2010). Complex molecular pathways coordinate and regulate intestinal remodelling in mammals and amphibians. In mammals, stem cell proliferation seems to be via the Wnt and Notch molecular pathways, respectively responsible for the secretory and absorptive lineages (van der Flier \& Clevers 2009). Furthermore, the selfrenewal system appears to be dependent on endogenous thyroid hormone (triiodothyronine - T3) levels, which are high during amphibian metamorphosis and around birth in mammals (Shi et al. 2011).

During development, the intestine is lined by a monolayer of rapidly renewing cells, in which cellular proliferation and apoptosis are coordinated and regulated by cellsignalling events between the epithelial and mesenchymal layers (Theise 2005; Shi \& Ishizuya-Oka 2001; RamalhoSantos et al. 2000; van der Flier \& Clevers 2009). Adult epithelial cells have been identified as small islets of undifferentiated cells in the transition layer between epithelium and connective tissue (Shi \& Ishizuya-Oka 2001). In mammals, the number of proliferative cells falls during embryonic development and rises again after birth in the crypts of Lieberkühn (Henning 1979; van der Flier \& Clevers 2009). In anurans, it is still not clear whether the larval epithelium as a whole (Schreiber et al. 2005) or a subpopulation of adult stem cells (Ishizuya-Oka \& Shi 2005) are the progenitors of the adult epithelium. Studies in larval stages of the rosy barb, a cyprinid (Barbus conchonius) and zebrafish (Danio rerio) demonstrated that these species exhibited a comparable pattern of gastrointestinal development, since proliferative cells along the intestine are observed. However, these cells tend to be restricted to small bundles at the base of the epithelial folds (Rombout et al. 1984; Ng et al. 2005; Wallace et al. 2005), resembling the Lieberkühn crypts of mammals, although some proliferative cells can also be identified in other fold levels (Stroband \& Debets 1978). No such cell agglomerations were observed in the intestine of larval lampreys (Petromyzon marinus) during the transition from larval to adult epithelium (Youson \& Horbert 1982), suggesting that other mechanisms are in operation.

The use of zebrafish as a model organism for several lines of biomedical research has revealed similarities in several aspects of development and physiology between mammals and this small teleost (Hölttä-Vuori et al. 2010). The information available on the zebrafish digestive tract shows some differences in the sequence of events of digestive tract morphogenesis, but that it is similar to that of mammals in terms of its development, organization and function, indicating conserved cellular mechanisms ( $\mathrm{Ng}$ et al. 2005; Wallace \& Pack 2003; Wallace et al. 2005). The first signs of digestive tract morphogenesis in the zebrafish were observed during gastrulation, and $21 \mathrm{~h}$ post-fertilization (hpf), and until hatching (48-72 hpf) organization and polarization of the columnar epithelium occurred (Wallace \& Pack 2003). Between hatching and mouth opening (74 hpf) the formation of epithelial junctions, the elaboration of dense brush border microvilli, and the differentiation of the three cell lineages - absorptive enterocytes, secretory goblet and enteroendocrine cells - were observed, while the anus opened later at $96 \mathrm{hpf}$ ( $\mathrm{Ng}$ et al. 2005; Wallace et al. 2005). The gut was fully functional by day 5 postfertilization (dpf), a regular pattern of spontaneous motility is clearly visible, and exogenous feeding commences (Holmberg et al. 2004). This pattern of gastrointestinal development is identical to what is described for marine fish larvae (this review).

The expression of the intestinal fatty acid-binder protein (I-FABP) mRNA is regarded as a useful marker of intestinal development (Shi \& Ishizuya-Oka 2001). However, in zebrafish I-FABP mRNA expression has been demonstrated in tissues other than intestine during embryogenesis. This indicates the existence of physiological differences between species (Sharma et al. 2004). In zebrafish, I-FABP was detected after hatching ( $3 \mathrm{dpf}$ ) (André et al. 2000). Sharma et al. (2004) detected the expression of this gene as early $11 \mathrm{hpf}$ (beginning of somatogenesis) in other tissues, such as the syncytial layer. Some hours later these authors observed expression in the intestinal bulb (36 hpf) and in the liver and the pancreas primordium cells (48 hpf). I-FABP belongs to the intracellular lipid-binding family, whose functions have been suggested to be involved in dietary fatty acid uptake and intracellular lipid transport (Baier et al. 1996; Levy et al. 2001). These authors showed that genes involved in mammal gut morphogenesis, such as faust/gata-5 (functional orthologue of gata-4) and sonic hedgehog, are also essential for the formation of the teleost digestive system.

An understanding of clues to epithelium proliferation and remodelling in the gut of developing fish is important for the design of appropriate feeds and feeding protocols. During development, feeding habit changes from strictly zooplanktivorous to carnivorous, herbivorous and mostly to omnivorous, with more or less of a preference for flesh or plant material. In fact, adaptation to a changing food spectrum offered by the habitat is a characteristic of many 
fish species. Studies that use model species such zebrafish are contributing to our knowledge in this still poorly understood process. Nevertheless, it is important to take into account that the zebrafish is an agastric fresh water species and have other feeding habits and preferences than target teleost marine species. It is therefore necessary to study this process in other species in order to build up a more complete picture of the factors and mechanisms involved in gut maturation and in the capacity to adapt to different foods, particularly to inert microdiets.

\section{Digestion: an overview}

The digestive process involves a series of events that require the coordination of a range of basic processes in the digestive tract (Fig. 3), starting with ingestion of the food, and including the secretion of enzymatic and fluid secretions, digestion via mechanical and enzymatic processes, absorption, motility (including evacuation) and finally regulation of the different processes. The efficiency of the digestive processes determines the delivery of nutrients to the rapidly growing larval tissues. As mentioned above, the gut also acts as an important primary barrier to prevent the entry of unwanted agents into the body tissues. The last topic is outside the scope of this review, but has been dealt with in a recent review by Vadstein et al. 2012 (accepted for Reviews in Aquaculture).

\section{Digestion of proteins and peptides}

\section{Pancreatic enzymes}

Proteolytic enzymes from the pancreas are regarded as being particularly significant in the early life stages of precocious and altricial fish because of the absence of a functional stomach with its acid protease, pepsin. There is a wealth of literature describing the activities of the major pancreatic enzymes during ontogeny and/or their response to various nutritional conditions in a variety of teleosts (e.g. Hjelmeland et al. 1988; Ueberschär et al. 1992; Cahu \& Zambonino-Infante 1995; Moyano et al. 1996; Martínez et al. 1999; Ribeiro et al. 1999, 2002; Srivastava et al. 2002; Ma et al. 2005; Rathore et al. 2005; Ueberschär 2006; Cara et al. 2007; Fujii et al. 2007; Lamarre et al. 2007; Lazo et al. 2007; Kamaci et al. 2010; Buentello et al. 2011; Galaviz et al. 2011; Kortner et al. 2011a). Such studies have demonstrated that proteolytic enzymes are produced and secreted from the pancreas at the onset of first feeding, although the enzyme activities vary between species. For instance, in yellowfin tuna (Thunnus albacares), the activity levels of several enzymes were much greater than in similarly aged/sized marine fish of other species (Buentello et al. 2011). This has been explained as an evolutionary adaptation of scombrid fish larvae (Tanaka et al. 1996; Kaji et al. 1999) that exhibit early piscivory habits and remarkably higher growth rates than most other marine species. Further comparative studies that take the life history of each species into account should be performed, in order to provide a better understanding of differences in the proteolytic capacity of each species, as this is believed to be important for further optimization of the nutrient supply in the early larval stages.

Figure 4 depicts the development of tryptic enzyme capacity in six species in order of increasing size. In order to accommodate the comparison within a single graph, different age ranges had to be employed. There is some coincidence of species with rapid development of trypsin capacity (turbot, European sea bass, Atlantic cod) with their success in aquaculture (except for gilthead seabream in this example).

It is a generally accepted that trypsin is the most important proteolytic enzyme in the early stage of marine fish larvae (Fig. 5). Trypsin is a serine protease found in the digestive system of many vertebrates, where it hydrolyses proteins and also plays a key role in activating other
Figure 3 The digestive tract is a multifunctional organ. Digestion includes a range of closely orchestrated processes that are integrated in ways that is believed to optimize efficiency and maximize absorption in feeding larvae under natural conditions. See text for more information.

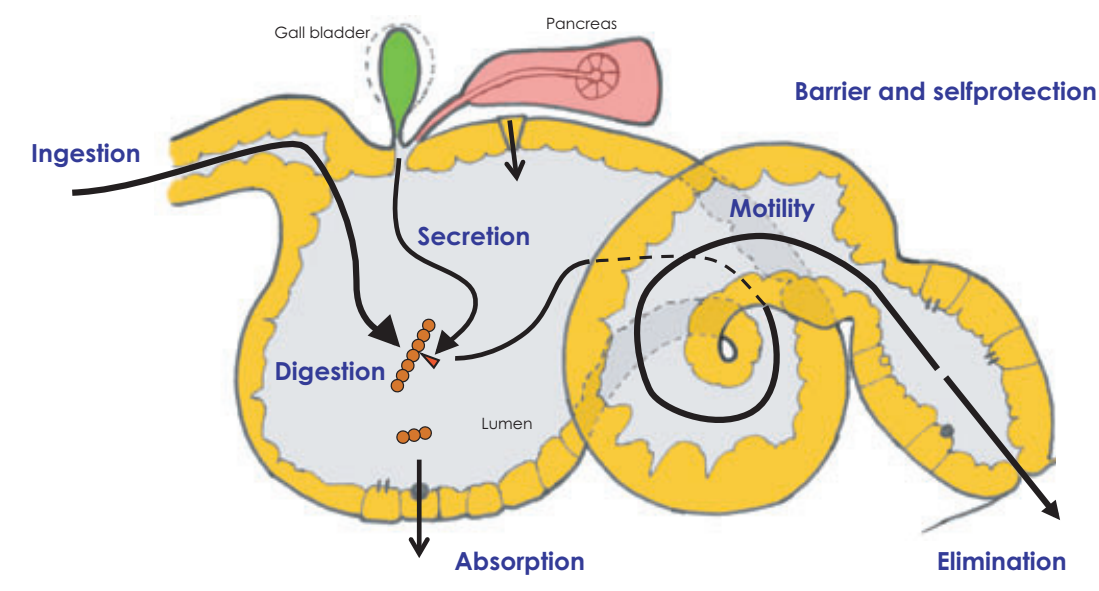



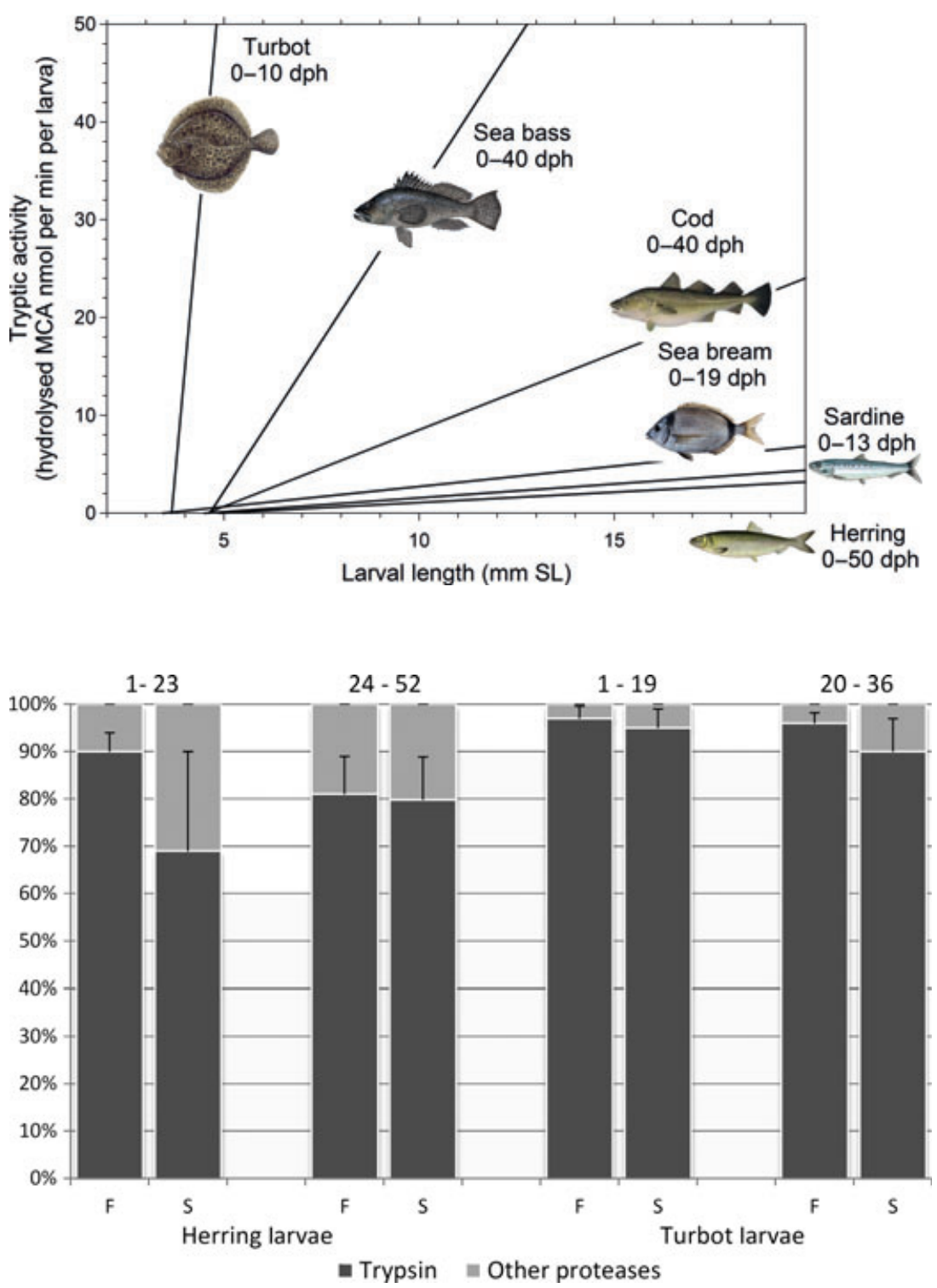

Figure 4 Increase in tryptic activity with increasing larval size. Comparison of six species reared under laboratory conditions. The regression line was calculated within the given lifespan in days after hatching. Age-dependent variability of tryptic activity was not considered here (re-drawn from Ueberschär 2006).
Figure 5 Significance of tryptic activity compared with total alkaline proteolytic activity in 1- to 52-day-old laboratory-reared herring (Clupea harengus) and I-36 day old turbot (Psetta maxima) larvae ( $\mathrm{F}$, fed larvae; $\mathrm{S}$, starving larvae). Mean values with error bars ( \pm SD) of two time intervals are shown (adapted from Ueberschär 1993). ( $\square$ ) Trypsin; ( $\square$ ) Other proteases. pancreatic enzymes in the gut lumen. Trypsin is produced in the pancreas as the inactive precursor trypsinogen and cleaves peptide chains, mainly on the carboxyl side of the amino acids lysine or arginine.

Considering the development of trypsin-like enzyme capacity in early larval stages, a 'four-phase model' of the ontogenetic development of tryptic activity in marine fish larvae from hatching to metamorphosis has been suggested (Ueberschär 1993). In Phase I, at the yolk-sac stage and beyond at commencement of exogenous feeding, the trypsin level increases; in Phase II, which is regarded as a 'critical' stage with decreasing tryptic activity, poor growth and high mortality rates may occur; in Phase III, sufficient production of trypsin (at optimal food supply) and high growth rates can be observed; in Phase IV, at the beginning of metamorphosis, tryptic activity decreases again since it is in the course of being partly replaced by the activity of pepsin in the developing stomach. Although this is a rather schematic approach, this pattern has been observed in a number of species (Ueberschär 1993, 1995, 2006). Figure 6 depicts a typical example that demonstrates the postulated four different ontogenetic stages related to the development of tryptic enzyme capacity in larval common pandora (Pagellus erythrinus). The related pepsin activity (Fig. 7) demonstrates that tryptic activity is decreasing in the late larval stages, when the stomach is becoming functional and peptic activity is gradually increasing.

The PCR analyses have shown that mRNA transcripts of several proteolytic enzymes including trypsin are present already from hatching, which for most species takes 


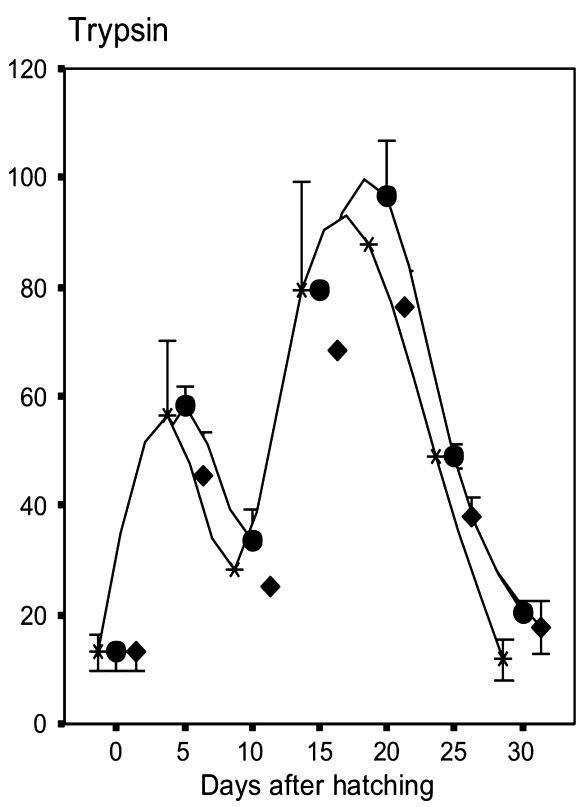

Figure 6 Development of tryptic activity in experiments on larvae from common pandora (Pagellus erythrinus). Newly hatched larvae were fed rotifers from day 3. Tryptic activity was measured in individual larvae and shown with standard deviations. Re-used from Suzer et al. (2006). (*) Group A; (•) Group B; (•) Group C.

place several days before the onset of exogenous feeding (Srivastava et al. 2002; Lo \& Weng 2006; Perez-Casanova et al. 2006; Drossou et al. 2006; Darias et al. 2007b). As far as trypsin is concerned, there appear to be temporal differences between the expressions of the various enzymatic paralogues. In winter flounder (Pseudopleuronectes americanus), for instance trypsin 2 expression was detected from $5 \mathrm{dph}$, while trypsin 1 levels of expression only became significant in the late larval stages and during metamorphosis and trypsin 3 showed expression only after 20 dph (Murray et al. 2004). Whether these ontogenetic differences in mRNA expression of individual paralogues have functional implication for protein digestion is not known.

It is still not clear why tryptic enzyme activity decreases shortly following the onset of first feeding before increasing again. This phenomenon warrants further in-depth study.

Chymotrypsin is another pancreatic proteolytic enzyme of significance in the larval intestine. Like trypsin, chymotrypsin is a serine alkaline protease produced in the pancreas and secreted as its precursor chymotrypsinogen into the lumen of the intestine. The activation is catalysed by cleavage of a small peptide chain. Chymotrypsin displays a substrate-specific pattern of activity like trypsin and hydrolyses peptide bonds on the carboxyl side of the aromatic side-chains of tyrosine, tryptophan and phenylal-

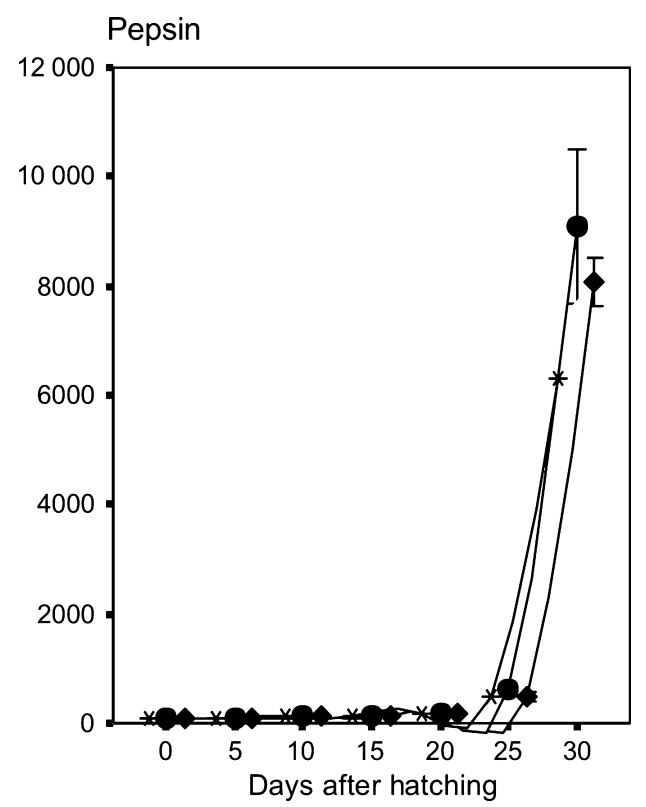

Figure 7 Development of pepsin activity in experiments using larvae from common pandora (Pagellus erythrinus). Pepsin was detected on day 25 in connection with stomach formation and a sharp increase until 30 dph. Re-used from Suzer et al. (2006). (*) Group A; (•) Group B; (•) Group C.

anine, and of large hydrophobic residues such as methionine. Its activity is complementary to that of trypsin, which cleaves peptide chains mainly on the carboxyl side of lysine or arginine. Aktulun et al. (2008) observed that chymotrypsin was present immediately after hatching in sharpsnout seabream larvae and continuously increased during the larval period. In red drum (Sciaenops ocellatus) larvae too, chymotrypsin activity was detected before the onset of exogenous feeding (Applebaum et al. 2001). Total chymotrypsin activity increased with age and standard length. Specific activity was greatest on day 10 post-hatch. These results confirm that chymotrypsin contributes to protein digestion also in the early stages of larval development. However, considering the quantitative significance of trypsin and chymotrypsin in early stages of marine larvae, it was shown that trypsin is the most important alkaline protease in the early life stages (Fig. 5). Compared with trypsin, our current knowledge about chymotrypsin and its dynamics in the early larval stages is still limited, as is its significance in the digestive processes during these stages.

Chymotrypsin has also been regarded as an appropriate indicator of the nutritional condition of marine larvae (Applebaum \& Holt 2003). The approach to using the tryp$\sin$ /chymotrypsin ratio as an indicator was suggested by e.g. Cara et al. (2007) for European sea bass larvae close to and beyond the weaning stage. The idea here is that the 
ratio might indicate the extent to which chymotrypsin is activated by trypsin and that this in turn might indicate the growth potential of the fish. The higher the trypsin/chymotrypsin ratio, the higher is the absorption rate of essential amino acids for protein synthesis and growth potential. However, this approach has its limitations, since trypsin usually decreases significantly at the onset of a functional stomach with gastric digestion established, while chymotrypsin apparently continues to increase (compare the four-phase model mentioned above). Further, trypsin and chymotrypsin activation is also catalysed by the enzyme enterokinase, which is produced in the intestinal enterocytes. This mechanism was not considered in the abovementioned experiments. Obviously, more research is needed on the dynamic and the role of chymotrypsin.

Pepsin is found in the functional stomach and is active in an acidic environment with $\mathrm{pH}$ as low as 1.5-2.0. In fish that lack a functional stomach in the early stages, pepsinlike enzyme activities and acidification capacity develop slowly during metamorphosis (Yúfera et al. 2004; Darias et al. 2007a; Yúfera et al. 2012b). For example, the first record of significant pepsin-like activity in larval barramundi started at $17 \mathrm{dph}$, coinciding with the acidification of the developing stomach (Walford \& Lam 1993), while in turbot larvae, peptic activity not was observed before day 22 post-hatch (Ueberschär 1993). Moreover, in this experiment it was observed that the peptic level reacts to food deprivation by a decrease in activity. In common pandora, peptic activity began to rise between 20 and 24 days post hatch (Suzer et al. 2006; compare Fig. 7). Nevertheless, the measurements of pepsin activity in fish have been done at pH 2 instead of buffering at the actual gastric $\mathrm{pH}$ with the consequent overestimation of this activity in developing larvae (Márquez et al. 2012; Yúfera et al. 2012b). Unlike chymotrypsin and trypsin, which have specific sites of action (Keil 1971; Blow et al. 1972; Blow 1976), pepsin has a broad range of active sites (Fruton 1970). Pepsin digestion yields polypeptides of very diverse sizes, but few FAA (Lied \& Solbakken 1984; Espeland 2006). The combined effects of $\mathrm{HCl}$ and pepsin make the stomach a highly efficient organ for degrading complex proteins such as collagen-rich connective tissues (Gildberg 2004). As a consequence, tryptic activity, as described above, decreases when the stomach becomes functional (Fig. 6). The digestive processes that combine pepsin and pancreatic enzyme activity are thus likely to hydrolyse proteins to a greater extent than when pepsin is missing. The acquisition of functional proteolytic digestion in the stomach thereby allows a wider range of ingredients to be incorporated in fish diets. At the same time the absence of a functional stomach and its associated acid-pepsin-mediated digestion, could be a limiting influence on the digestibility of dietary proteins in the youngest stages of marine fish larvae (e.g.
Tonheim et al. 2005; Rønnestad et al. 1999, 2007b). Based on the aforementioned points, considerable efforts are being put into assessing protein digestibility by both in vivo and in vitro methods and also into establishing protocols for efficient treatments and handling of dietary protein ingredients to optimize amino acid (AA) bioavailability at different life stages (Tonheim et al. 2007; Fox \& Lawrence 2009; Hansen et al. 2009; Johnson et al. 2009; Nordgreen et al. 2009; Saenz de Rodrigañez et al. 2011). This important work needs to be kept in focus.

In conclusion, the weak ability of early larval stages efficiently to digest currently available microdiets (compared with live food) may be attributed to the lack of denaturizing and proteolytic cleavage of food proteins by combined peptic and acid activity. This is one of the main challenges that remain to be tackled when formulated feeds are used as first feed for the young stages of marine fish larvae (see General protein-processing capacity).

\section{Enzymes in the mucosal layer}

Enzymes associated with the enterocytes also contribute to the final digestion of proteins and peptides. The brushborder membrane (BBM) enzymes are located in the apical cell membrane facing the gut lumen. These enzymes are aminopeptidases that hydrolyse small peptides that are the result of cleaving by pancreatic proteases, into FAA and small peptides that are small enough to be absorbed. The activities of BBM enzymes such as the leucine aminopeptidase (LAP) of the enterocytes in Atlantic cod and Atlantic halibut are at a low level at first feeding, but increase during larval development (Kvåle et al. 2007). The activity of cytosolic (intracellular) peptidases such as leucine-alanine peptidase which, it has been suggested, participate in protein degradation after pinocytosis, are high in some species around first-feeding but tend to decrease as larvae develop, concurrent with rising levels of alkaline phosphatase (Cahu \& Zambonino-Infante 2001; Kolkovski 2001). This picture is less clear in cod than in halibut, which have a stable level of LAP activity throughout the start-feeding period, apart from a peak in activity around day 35 after the start of feeding (Kvale et al. 2007).

It has been suggested that the ontogenetic pattern of trypsin, membranous and cytosolic peptidase activity during larval development reflect changes in the mode of larval digestion, which is believed to become increasingly dependent on luminal digestion and less so on intracellular digestion (Cahu \& Zambonino-Infante 2001).

\section{Exogenous enzymes}

In the past, it was argued that first-feeding marine fish larvae had insufficient endogenous digestive enzyme capacity and therefore rely on exogenous enzymes originating from 
their prey. Lauff and Hofer (1984) concluded for freshwater coregonid species that external enzymes obtained from zooplankton might contribute $70-80 \%$ of the total enzyme activity in the fish digestive tract, supporting the earlier results of Dabrowski and Glogowski (1977). Consequently, it was assumed that compound diets result in poor growth and survival in the earliest larval stages, since no exogenous enzymes were supplied with the artificial diets. This led to the supply of exogenous enzymes in compound diets (Kolkovski et al. 1997c) but this approach has never been introduced in routine feeding protocols in fish culture (Kolkovski 2001).

Related research in the course of the past two decades has disclosed that the marine species studied to date possess sufficient levels of endogenic digestive enzymes to allow the digestion of suitable live prey and well-designed artificial diets from first feeding (for trypsin, e.g. Ueberschär 1993; Cahu \& Zambonino-Infante 1994). Results regarding comparisons of the quantity of endogenous and exogenous enzymes specifically in herring larvae allow the conclusion to be drawn that the exogenous enzymes that are ingested with live food (e.g. rotifers, Artemia nauplii, copepod nauplii), are of minor significance for the overall digestive capacity of marine fish larva (Hjelmeland et al. 1988; Pedersen \& Hjelmeland 1988; Pedersen \& Andersen 1992; Ueberschär 1995). In recent experiments, it was demonstrated that exogenous enzymes from live food (Brachionus sp., Acartia tonsa, Temora sp., newly hatched Artemia nauplii) contributes only $1-2 \%$ of the total tryptic enzyme activity measured in young herring larvae (Ueberschär, unpublished).

\section{Absorption}

\section{Free amino acids}

It has been suggested that dietary proteins, peptides and free amino acids (FAA) in larval fish are absorbed primarily by the midgut (Rønnestad \& Conceição 2005). However, our understanding of the mechanisms and ontogenetic changes involved in protein, peptide and FAA absorption in larvae is still limited. Amino acid absorption involves a number of transport processes, some of them with overlapping functions. The in vivo transport rates reported for free amino acids (Rønnestad et al. 2000a,b; Applebaum \& Rønnestad 2004) will depend on several elements, including the luminal concentration of AA, the transport affinity and capacity of each amino acid transporter (AAT), and the amount of each AAT in the brush border membrane. It is also important to emphasize that these data represent transintestinal absorption rates and reflect the net flux of free amino acids from the midgut lumen, across the digestive tract cells, and into the body. In their studies Applebaum and Rønnestad (2004) failed to find a saturable component for free amino acid absorption for luminal concentrations up to $20 \mathrm{~mm}$ for the four amino acids tested; dispensable (alanine, glutamate) and indispensable (arginine, lysine). Further studies need to be performed to improve our understanding of the absorption kinetics of individual amino acids and of interactions between various amino acids.

In mammals, there is a range of functional systems that mediate amino acid transport in the apical and basolateral membranes of epithelial cells. Each system accepts groups of amino acids rather than individual amino acids, and most of them have several genetic representatives. For instance, in mammals more than four separate systems are involved in transepithelial transport of the cationic amino acids lysine and arginine in the GI tract. Some AAT are heterodimeric and thus consist of two subunits and genes. Molecular studies of the AAT that were described on the basis of their functional characteristics have identified the genes involved that are now classified into solute carrier families (slc). While many of the genes coding for AATs have been cloned in mammals, such efforts have only started in fish (Narawane 2011; Pinto et al. 2012). In zebrafish, several of the transporters for cationic amino acids have been identified (Narawane 2011). This list includes the presence of system $b^{0,+}$ and $y^{+}$. Zebrafish system $b^{0,+}$, which is a heterodimeric transporter that comprises members of the solute carrier family members slc3a1 and slc7a9 and displays conservation of the essential features that determine its functions and interactions. Analysis of the zebrafish system $\mathrm{y}^{+}$transporter slc7al also revealed conservation of essential functional features and a high affinity for cationic amino acids. Both slc3al and slc7a9 were expressed in the developing intestine as well as in the proximal tubule segments of the nephrons (Narawane 2011). Due to the ubiquitous distribution in tissue of some of these AAT, functional studies in larval stages will be a challenge. Narawane (2011) demonstrated that slc7al is widely expressed in the developing eyes, somites, distal nephrons and branchial arches of zebrafish. Gene-specific morpholino-mediated knockdown that induces loss of gene function had major effects on early zebrafish embryos and these AAT are essential for normal embryonic development and organogenesis during endogenous feeding. However, due to the temporary effect of the morpholino technique used (which ceases to work around the time of first feeding), combined with the abundant expression of these AAT, these studies have yet to provide any specific information regarding the role of these transporters in the digestive tract.

A recent study by Pinto et al. (2012) has described the cloning and ontogenetic expression of the taurine transporter (TauT; slc6a6) in Senegalese sole. The results showed a high degree of similarity between TauT in Senegalese sole and other vertebrates, but some differences in TauT amino 
acid sequences may be indicative of modifications in the characteristics of taurine transport between mammals and fish. TauT was expressed early, and the authors suggested that sole can absorb dietary taurine prior to the onset of first feeding. In juveniles, TauT was more expressed in stomach and hindgut, indicating that dietary taurine is rapidly absorbed when digestion begins and taurine conjugated in bile salt may be recycled in the caudal end of the digestive tract. These results thus suggest an enterohepaticrecycling pathway for taurine in Senegalese sole, a process that may be important for the maintenance of body taurine levels.

\section{Peptides}

Protein digestion may not be complete prior to absorption, and recent studies of a number of vertebrate species clearly indicate that peptide entry across the apical membrane of the enterocytes is an important route of absorption of digested proteins (Daniel 2004; Gilbert et al. 2008; Verri et al. 2010, 2011). Peptide absorption has also aroused the interest of scientists working on the larval and juvenile stages of fish (see e.g. Zambonino Infante et al. 1997; Dabrowski et al. 2003, 2005; Tesser et al. 2005; Zhang et al. 2006; Bakke et al. 2010; Ostaszewska et al. 2010). Data in mammals support the hypothesis that peptides transported over the brush border membrane are hydrolysed by cytoplasmatic peptidases to FAA, which are transported out of the basal membrane of the enterocytes and into the portal circulation. However, small peptides that are resistant to hydrolysis may enter the systemic circulation, some of them also being potentially biologically active in teleost fishes (Rønnestad et al. 2010). Peptide transport may therefore be an important route of absorption of both dietary proteins and peptides in teleost fishes, also in their early stages of life.

While vertebrate enterocytes express an assortment of AAT, only one transporter has been described for peptides in the digestive tract; the oligopeptide transporter 1 (PepT1; Nielsen \& Brodin 2003; Daniel 2004). In teleosts, current data suggest that the PepT1 transporter is expressed at hatching in both zebrafish (Verri et al. 2003) and Atlantic cod (Rønnestad et al. 2007a; Amberg et al. 2008). In zebrafish, PepT1 is highly expressed in the proximal intestine, similarly to what has been observed in European sea bass (Terova et al. 2009). In Atlantic cod, PepT1 mRNA is expressed prior to the onset of exogenous feeding and PepT1 is expressed in the enterocytes throughout the digestive system, except in the oesophagus and sphincter regions (Fig. 8; Amberg et al. 2008). Functional analysis by in vitro expression systems categorized the zebrafish, European sea bass and Atlantic salmon PepT1 as classical low-affinity/ high-capacity systems (Verri et al. 2003; Sangaletti et al. 2009; Rønnestad et al. 2010). In zebrafish and Atlantic salmon, the data show that PepT1 is an $\mathrm{H}^{+}$-dependent pep-

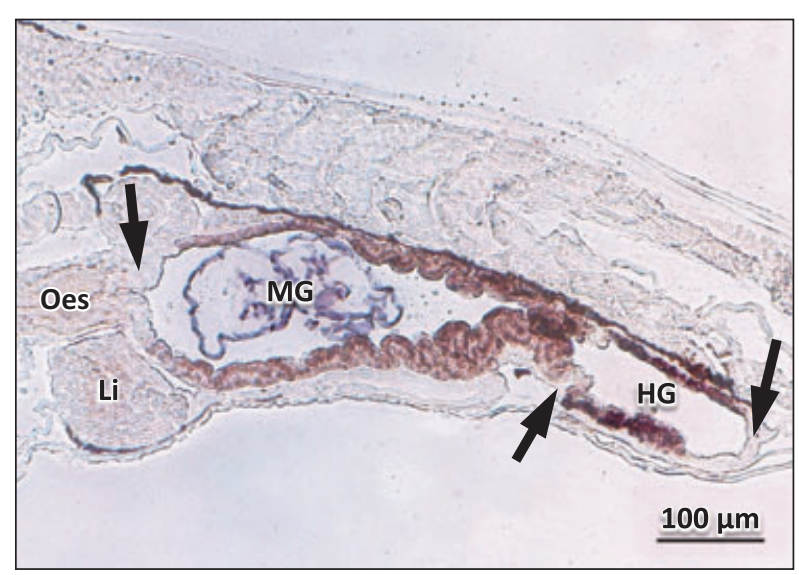

Figure 8 Expression pattern of PepT1 mRNA in the digestive tract of Atlantic cod larvae fed natural zooplankton at $4 \mathrm{dph}$. Arrowheads point to sphincter regions with no PepT1 expression. Oes, oesophagus; Li, liver; MG, midgut; HG, hindgut (modified from Amberg et al. 2008).

tide co-transporter, but in contrast to higher vertebrates, in which the maximum transport activity is independent of extracellular $\mathrm{pH}$, the maximum transport rates rise when extracellular $\mathrm{pH}$ is alkaline (Verri et al. 2003; Rønnestad et al. 2010). However, in sea bass the data show that, as in higher vertebrates, the maximum transport activity of PepT1 is almost independent of extracellular pH (Sangaletti et al. 2009), which suggests the occurrence of speciesspecific adaptations in the functional behaviour of the transporter.

\section{Whole proteins}

Visual observations show that fish larvae absorb large molecules, including proteins, by endocytosis followed by intracellular digestion in the hindgut mucosa (Watanabe 1984; Luizi et al. 1999; Yúfera \& Darias 2007a). On the basis of these findings, it has been suggested that low intestinal proteolytic capacity in the larval stages may be compensated for by protein endocytosis and subsequent digestion (Rust et al. 1993). Watanabe (1984) showed that in larvae of pond smelt (Hypomesus olidus), a protein absorbed by hindgut pinocytosis took from 10 to $24 \mathrm{~h}$ to be degraded intracellularly. Rønnestad et al. (2001a, 2007b) argued that such processing rates of dietary proteins are much too low to supply the amino acids required to maintain the high metabolic and anabolic demands of rapidly growing fish larvae. Other authors have suggested that intracellular digestion is an important route of amino acid absorption at least at the onset of first feeding and in the early post-first feeding stages (Gabaudan 1984; Rust et al. 1993). It has not been possible to quantify this route of amino acid absorption experimentally; its dietary importance thus remains unknown and needs further study. 


\section{General protein-processing capacity}

The experimental challenges involved in performing in vivo studies of digestive function in fish larvae have limited the number of studies. The results of experiments based on tube feeding with radio-labelled amino acids show that small sized peptides and FAA are absorbed two to three times as rapidly as intact protein in fish larvae (Tonheim et al. 2004, 2005; Rønnestad et al. 2000c). As discussed by Tonheim et al. (2004) the ${ }^{14} \mathrm{C}$-methylated bovine serum albumin $\left({ }^{14} \mathrm{C}\right.$-BSA) that was used in some of the early studies (Rønnestad et al. 1999; Rojas-García \& Rønnestad 2003) are not suitable as model proteins in metabolic studies due to modification of their ${ }^{14} \mathrm{C}$-methylated lysine residues that makes them resistant to trypsin degradation. These authors therefore produced a radioactive soluble model protein $\left({ }^{14} \mathrm{C}\right.$-SSP $)$ by administration of uniformly labelled amino acids to Atlantic salmon followed by blood sample withdrawal and purification (Tonheim et al. 2004). The digestibility of this model protein tested in vivo using Atlantic halibut was found to be ca $60 \%$.

So far, the data suggest that both essential and nonessential amino acids are absorbed rapidly and efficiently if they are supplied in free form (Rønnestad et al. 2001a). Even when FAA are introduced into the gut in saturation concentrations, losses of intact amino acids to the surrounding water appear to be low (Rojas-García \& Rønnestad, unpublished data).

Recent data support earlier assumptions that the ability of larvae to digest protein improves after metamorphosis. In Atlantic halibut, administration of ${ }^{14} \mathrm{C}$-SSP as a single pulse via tube feeding demonstrated absorption efficiency at $<30 \%$ in the larval stage, while after metamorphosis, absorption efficiency for the same protein had risen to $60 \%$. This study also showed that about $60 \%$ of the model protein was absorbed at the larval stage if it had been prehydrolysed with pepsin (Tonheim et al. 2005). The total processing capacity (including digestion and absorption of protein-bound amino acids) diminished as the amount of protein in the gut rose. These findings may be related both to digestive capacity and/or to the residence time in the gut; i.e. transit rates (see below). The tube-feeding technique used in the studies mentioned above has some known limitations: these include administration of the nutrient(s) as a single dose and that the handling has adverse effects. However, with standardized design and the use of a model protein, comparative studies can provide valuable results (Conceição et al. 2007, 2008, 2011). Recently a dynamic mechanistic model that simulates amino acid metabolism of fish larvae has been developed. This model also assists in the interpretation of results obtained using labelled nutrients and single dose administration (Rønnestad \& Conceição 2012). The model aims to improve the understanding of larval digestion and absorption of dietary amino acids, and the postprandial amino acid metabolism and growth.

Studies have shown that lipid absorption affects amino acid absorption to a small degree. Methods for labelling amino acids in Artemia (largely protein) with isotopes have been developed, enabling studies to be performed that quantify the rate of amino acid uptake from ingested prey during active feeding, as well as studies of the transfer and metabolism of amino acids in tissues. In Senegalese sole larvae, about $30 \%$ of the amino acids in Artemia were absorbed and transferred to tissue within an hour of being consumed (Morais et al. 2004a,b; Rønnestad \& Conceição 2012). In sole fry around $55 \%$ of the amino acids had been transferred within the same period of time. This shows that the digestion of live feed is more efficient in post metamorphic sole, although the difference is less than might have been expected.

Some larvae fed on formulated feed have higher survival rates when some of the protein in the feed is given in the form of hydrolysate. When as much as $40 \%$ of the protein was given as pepsin hydrolysate to Atlantic cod, survival rates rose in line with the proportion of hydrolysate (Kvåle et al. 2007). In other species, such as Atlantic halibut, a gradual decline in survival rates was noted when the proportion of pepsin hydrolysate in the feed protein was raised to $40 \%$ (Kvåle et al. 2007). In European sea bass, the addition of a protein hydrolysate in a weaning diet facilitated intestinal maturation (Cahu \& Zambonino-Infante 1995). Some of these results are not in agreement with a positive effect of hydrolysis on the uptake of tube-administered protein by fish larvae (see above), but some of the observations can probably be explained by the leaching of water-soluble protein from feeds that contain a high proportion of hydrolysate. In some cases, leaching can be very rapid (Nordgreen et al. 2009), sometimes with losses of more than $90 \%$ in 2 min (Lopez-Alvarado et al. 1994). Larvae of some species, e.g. Atlantic halibut, some groupers and first-feeding gilthead seabream are slow to ingest diets that are fed into the water, and the feed particles remain suspended for a long time before they are consumed. Other fish such as Senegalese sole, on the other hand, are rapid feeders, with the result that there is less leaching to the water.

\section{Gut transit rate vs dietary protein utilisation}

Gut transit rate is an important factor in determining the utilization of ingested dietary proteins. The gut transit is a function of rates of ingestion, evacuation and absorption and the gut volume. It is not clear how, and to what extent, the intestinal transit time is regulated in fish larvae, particularly in the early stages. In some species first-feeding larvae 
may continue to ingest feeds without any apparent satiety signal from gut fullness (e.g. Atlantic halibut, Harboe et al. 2009; see also below). Short and variable passage times have been reported in fish larvae (Govoni et al. 1986) and a reduced gut transit time has been found to reduce the efficiency of digestion and absorption of the ingested feed (Werner \& Blaxter 1980, 1981; Govoni et al. 1986).

One of the main problems of a fast gut passage is the short time available for efficient digestion and absorption of proteins from the ingested feeds. Slowly digestible proteins (or other slowly digested nutrients) may therefore be lost in the faeces in larvae that have a short gut retention time, while in larvae with a longer transit time these proteins may be properly digested and absorbed. As discussed by Rønnestad et al. (2007b) and Harboe et al. (2009), the problems associated with rapid gut transit in a continuously feeding (and evacuating) larva may potentially also include lowering luminal proteolytic activity due to overloading of the enzyme-producing capacity of the exocrine pancreas. Quantification of trypsin in herring larvae showed that in digested, defaecated copepods about $1 \%$ of larval intestinal enzyme was excreted along with one to three copepods (Pedersen \& Hjelmeland 1988). Although this remains to be verified and demonstrated in more species, it is evident that a too rapid gut transit may limit any recovery of the enzymes, as well as bile, from the chyme.

Analysis of the gut evacuation in halibut larvae indicated that a poor protein utilization was correlated with fast gut transit (Tonheim et al. 2005). In some larvae more than half of the administered protein had been evacuated by $4 \mathrm{~h}$ post-administration. At this time the processes of digestion and absorption were far from complete (Tonheim et al. 2005). This indicates that gut evacuation is a critical factor in the utilization of slowly digested and absorbed dietary proteins, while it will have a lower effect on the utilization efficiency of rapidly absorbed feed constituents such as free amino acids, peptides and pre-hydrolysed protein. Light condition and feeding strategy (meal vs continuous feeding) strongly affects feed ingestion (Harboe et al. 2009). In Atlantic halibut, continuous light results in continuous feeding and high rates of feed ingestion, while combinations of light and darkness periods produce different daily feeding patterns, since the larvae of most species apparently stop feeding in the dark. These authors suggested that fast gut transit in continuously feeding larvae may cause essential but slowly digestible compounds to be lost in the faeces, while in larvae on a meal-based feeding regime, a longer transit time increases the absorption of nutrients that are critical for development.

However, more than gut transition time is important for efficient protein digestion in the early larval stages. Digestive capacity, in terms of proteolytic enzyme synthesis and secretion, is another important concern. It has been demonstrated in the early stages of turbot and herring larvae that the ability to react to a meal by secreted trypsinogen is limited. An example is shown here for turbot larvae (Fig. 9), which were fed three times a day (9:30, 13:00 and 15:30) with rotifers. The larvae reacted to the first two meals with immediate trypsinogen secretion, but there was no response to the third meal in the afternoon. It appears that the digestive capacity in young turbot is limited, and these results may help to optimize feeding schedules for

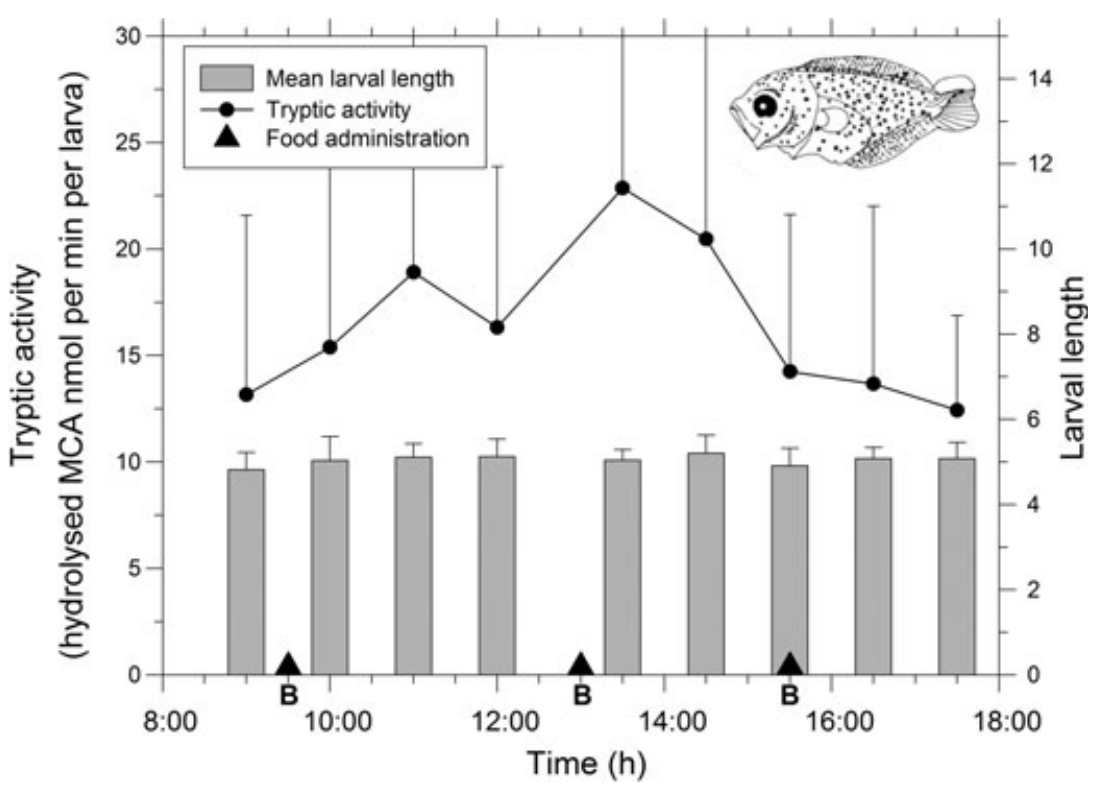

S76
Figure 9 Diurnal pattern of tryptic enzyme activity in relation to food and feeding time in laboratory-reared and continuously fed 12 day-old (dph) turbot larvae (Psetta maxima). Arrows indicate when food was supplied (Brachionus plicatilis, 5 ind $\mathrm{ml}^{-1}$ ). Data points with positive error bars (SD) are means of 1015 individually measured larvae. Bars indicate mean larval length $(\square)$ Mean larval length; $(\rightarrow-)$ Tryptic activity; ( $\mathbf{\Delta})$ Food administration. 
early stages of marine fish larvae in cultivation. Since the production and administration of live food in aquaculture is labour-intensive and costly, optimization could help to reduce costs without interfering with larval growth (Ueberschär 1995, 2006).

Further work is necessary to determine the effects of gut transit time of feeding regimes combined with prey availability in rearing systems. Studies will also need to focus on the bioavailability of different nutrients at different gut transit rates and on age/size dependency in providing the necessary proteolytic enzyme capacity.

\section{Lipids}

Lipids are a diverse group of molecules that comprise the following eight sub-groups; fatty acyls, sphingolipids, sterol lipids, prenol lipids, saccharolipids, polyketides, glycerolipids and glycerophospholipids (Fahy et al. 2005). Here we focus on the glycerophospholipids, often referred to as phospholipids (PL) and a subclass of glycerolipids, namely the triacylglycerols (TAG). The triacylglycerols consist of a glycerol backbone with three fatty acids and is used for energy storage. Phospholipids (except sphingomyelin) have a glycerol backbone with two fatty acids, which comprise the lipophilic part. The hydrophilic part consists of a phosphate group with an organic molecule such as choline, inositol or ethanolamine. Phospholipids are vital for energy, structure of membranes, posttranscriptional regulation of proteins and as messenger molecules (Fahy et al. 2005; Lodish et al. 2000). Phospholipid is also nutritionally the most important lipid class in young fish larvae. The dietary phospholipid requirement is high when marine fish larvae start feeding and decreases when they approach the juvenile stage (reviewed by Coutteau et al. 1997; Tocher et al. 2008).

\section{Pre-intestinal digestion of lipids}

In mammals, lipid digestion starts in the mouth where lingual lipase is mixed with food as it is being chewed. The stomach contains gastric lipase that continues fat hydrolysation. In humans, these lipases account for 30\% of lipid hydrolysation. The presence of gastric lipase activity in fish has been suggested by Xiong et al. (2011), who described lipase activity in the stomach tissue of the catfish (Glyptosternum maculatum) that had a lower $\mathrm{pH}$ optimum $(\mathrm{pH} 6)$ than that found in intestinal tissue ( $\mathrm{pH} 8)$. Since the assays were performed on stomach tissue and not the digesta itself, there is a possibility that the enzymatic activity described was due to lysosomal acid lipase/cholesteryl ester hydrolase, present in most tissues rather than from true gastric lipase (Anderson \& Sando 1991). Murray et al. (2003) characterized a lipase in winter flounder with more similarities to lysosomal acid lipase than gastric lipase.
Their conclusion was that lipolytic activity found in the oesophagus and gastric tissues probably came from lysosomal gastric lipase. Current data do not describe any gastric lipases in teleosts.

\section{Intestinal lipid digestion}

Dietary lipids that enter the intestine are emulsified with the help of bile salts and phospholipids (Fig. 10). Both these molecules have hydrophilic and hydrophobic sides that help to form and stabilize micelles. Neutral lipases hydrolyse the ester bonds of triacylglycerol to monoacylglycerol (MAG) and free fatty acids (FFA). These products of triacylglycerol hydrolysation are then absorbed by the enterocytes located on the gut epithelial wall. The sn-2-specific pancreatic enzyme PLA 2 hydrolyses phopholipids. The products are one lyso-PL molecule and one free fatty acid, both of which are absorbed by the enterocytes. Here the lipids are re-esterified in two pathways: the monoglyceride pathway in the smooth endoplasmatic reticulum (ER), which produces triacylglycerol, and the $\alpha$-glycerophosphate pathway in the rough and smooth ER, which produces both triacylglycerol and phopholipids (Mansbach 2000). The $\alpha$-glycerophosphate pathway appears to be the major pathway responsible for lipid re-esterification in teleosts (Oxley et al. 2007). Remodelling of lyso-PL to PL is superior to new synthesis in Atlantic cod larvae (Hamre et al. 2011).

The most important neutral lipase in mammals is the pancreatic lipase, which is inhibited by bile acids and needs co-lipase to function (Brockman 2001). There are two proteins closely related to pancreatic lipase, namely lipaserelated protein 1 (PLRP1) and pancreatic lipase-related protein 2 (PLRP2). The latter is important for lipid digestion in suckling infants, while the function of PLRP1 remains unknown. The other neutral lipase, produced in the pancreas and excreted in the intestine is the carboxyl

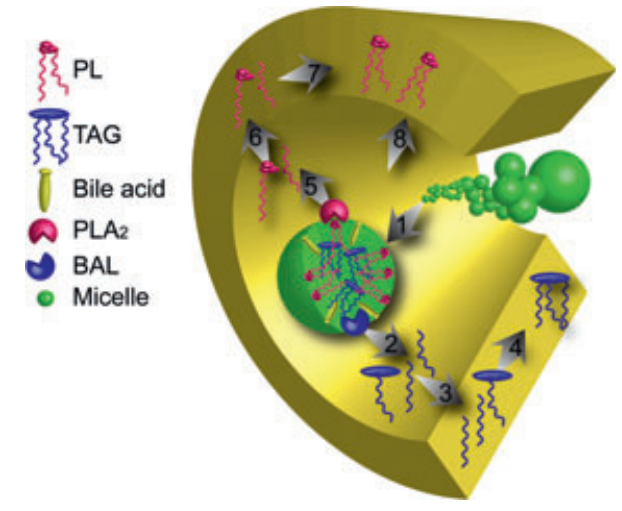

Figure 10 Lipid digestion in fish larvae. (1) Lipids form micelles with the emulsifying effect of bile acids and PLs. (2) BAL hydrolyses TAG and (3) hydrolysed products are absorbed in the enterocytes. (4) TAG is synthesized. (5) PLs are hydrolysed by PLA $\mathrm{A}_{2}$ and (6) products are absorbed. (7) Lyso-PL is remodelled to PL. (8) Intact PL is absorbed by enterocytes. 
ester lipase, usually referred to as bile-activated lipase (BAL) in the fish literature. This enzyme is also important for the hydrolysis of a wide range of lipids such as glycerophospholipids, cholesterol esters and lipid-soluble vitamins.

Lie and Lambertsen (1985) found that neutral lipase activity in Atlantic cod is stimulated by bile and appears to preferentially hydrolyse polyunsaturated fatty acids, regardless of position on the glycerol backbone. Gjellesvik et al. (1992) were the first to isolate bile-activated lipase in fish, and they suggested that teleosts did not have phospholipid and co-lipase. Sæle et al. (2010) found later that teleosts apparently do not possess a functional pancreatic lipase but a related protein to the mammalian PLRP1, whose function is still unknown. It has been shown in mammals that pancreatic lipase is not particularly efficient at hydrolysing TAG with PUFA. On the other hand, bile-activated lipase is more suitable for these lipids (Chen et al. 1990; Hernell et al. 1993); pancreatic lipase may thus not be a suitable enzyme for marine organisms.

Although bile-activated lipase may hydrolyse PL, phospholipase A2 $\left(\mathrm{PLA}_{2}\right)$ is the most important enzyme. Phospholipase A2 hydrolyses the fatty acid ester bond at the sn-2 position of the PL molecule, leaving a lyso-PL and an FFA. Phospholipase A2 is a member of a large group of 19 enzymes that share substrate specificity. These enzymes are found in all types of cells and are either secretory $\left(\mathrm{sPLA}_{2}\right)$ or cytosolic $\left(\mathrm{cPLA}_{2}\right)$. The sPLA 2 produced in the pancreas, which is involved in $\mathrm{PL}$ digestion, is recognized by the 'pancreatic loop' and is called sPLA2 group IB (Murakami \& Kudo 2002).

It is difficult to assess the ability of marine larvae to digest lipids. Lipase activity has been detected from first feeding in several species, where it either diminishes or remains stable during the early larval period (Izquierdo et al. 2000; Gawlicka et al. 2000; Hoehne-Reitan et al. 2001a; Izquierdo et al. 2000; Murray et al. 2006, 2003; Perez-Casanova et al. 2004, 2006; Darias et al. 2007b).

Table 1 Ranking of lipase activity from the most active part of the Gl tract (1) to the least active (4)

\begin{tabular}{lccll}
\hline & Stomach & Anterior & Mid & Posterior \\
\hline Turbot* & 4 & 3 & 1 & 2 \\
Catfish $\dagger$ & 4 & 1 & 2 & 2 \\
Pompano† & 4 & 2 & 1 & Not tested \\
Atlantic cod* & 4 & 1 & 2 & 3 \\
\hline
\end{tabular}

In turbot (Psetta maxima) (Izquierdo \& Henderson 1998), catfish (Glyptosternum maculatum) (Xiong et al. 2011), pompano (Trachinotus ovatus) (Ou et al. 2011) and Atlantic cod (Gadus morhua) (Lie et al. 1987). *Analysis of digesta.

$\uparrow$ Analysis of gastric/intestinal tissue with digesta.
According to the rate of neutral lipase activity in whole larvae homogenates, BAL activity is present from first exogenous feeding, although several studies have pointed to the low tolerance for dietary TAG in young larvae. European sea bass larvae fed compound diets that included high levels of dietary PL from first feeding displayed better maturation of the digestive tract, better survival, better growth and fewer malformations than larvae fed low levels of phospholipids (Cahu et al. 2003b; Fontagné et al. 1998; Geurden et al. 1995). The conclusion of these studies was that sea bass are more efficient in utilizing dietary PL than neutral lipids. However, Uematsu et al. (1992) did not find PLA 2 in the acinar cells of the hepatopancreas in red sea bream until 13 $\mathrm{dph}$. The intensity of the labelling became stronger between 20 and $30 \mathrm{dph}$, indicating an increase in $\mathrm{PLA}_{2}$ production. The mRNA (qPCR) and protein (western blot) expression of $\mathrm{PLA}_{2}$ IB in Atlantic cod is low at start of feeding and does not increase until the development of the pyloric caeca (Sæle et al. 2011). As pointed out above, BAL may be important for the digestion of phospholipidss as well as neutral lipids. It has also been demonstrated in $\mathrm{PLA}_{2}$-deficient mice that phosholipids are digested (Richmond et al. 2001).

Many marine larvae are quite small when they start feeding e.g. $4.5 \mathrm{~mm}$ standard length Atlantic cod (Sæle et al. 2010); gilthead seabream $\sim 3.7 \mathrm{~mm}$ TL (Rodríguez et al. 1998). As a result, most studies of digestive enzyme activity have been performed on homogenates of whole larvae. Interpreting such data is rather problematic because lipase activity is present in several tissues that have nothing to do with lipid digestion (Chesley 1934; Lazo et al. 2000; Chatzifotis et al. 2008). To complicate this further, the relationship between lipolytic activity in the digestive organs and lipolytic activity in non-digestive organs varies during development (Sæle et al. 2010, 2011). The analysis of gene or protein expressions where the specific gene or protein of interest may be singled out is therefore a more suitable method of characterizing the ontogeny of lipases in wholelarva homogenates. This is illustrated during the ontogeny of Atlantic cod larvae, where a correlation between mRNA and protein expression was found, but not with enzyme activity (Sæle et al. 2011).

Two factors, although they are controversial, might explain how young larvae deal with lipid digestion with a low production of endogenous lipase. The contribution of lipolysis from live prey (e.g. copepods, rotifers and Artemia) may be important. Lipase activity in rotifer homogenates has been shown to be 10 times as high as in homogenates of Atlantic cod larvae. Since larvae at this point do not possess an acid stomach, exogenous enzymes will survive for longer in the intestine (Hoehne-Reitan et al. 2001b). 
Secondly there are the findings of (Farber et al. 2001; Hama et al. 2009) who demonstrated absorption of intact phosholipid in the posterior part of the intestine in young zebrafish larvae. This is probably linked to the pinocytotic activity that may contribute to protein absorption (see section on absorption of whole proteins). To facilitate this, the emulsifying effect of bile would be important, and it has been shown that the gallbladder is present at mouth opening in common pandora about 3 days prior to yolk exhaustion (Micale et al. 2006). There seems to be bile production and secretion from the start of feeding in European sea bass, gilthead seabream, and pike-perch as well (Diaz \& Connes 1997; Diaz et al. 1997a,b). The dietary contribution of exogenous lipases and pinocytosis is still unknown and needs further study.

\section{Overall processing capacity for lipids}

The high requirement of phosholipid relative to triacylglycerol in the larval diet may be due to a poor ability to synthesize PLs de novo (Coutteau et al. 1997). This may also explain the accumulation of lipid droplets in enterocytes of larvae fed on diets with a low PL/TAG ratio (Salhi et al. 1999). Lipids are assembled in lipoprotein particles such as chylomicrons and very low density lipoproteins (VLDL) in the enterocytes, which distribute the lipids to the body (Mansbach et al. 2000). A limited supply of PL may thus inhibit the assembly of these particles and consequently cause TAG to accumulate in the intestinal epithelium. However, if the PL/TAG ratio is adequate, larvae appear to process both TAG and PL without difficulty. It has been shown that cod larvae of $\sim 15 \mathrm{~mm}$ SL absorbed $85 \%$ or more of ingested lipid present in a formulated diet, with $15 \%$ total lipid and a 60/40 TAG/PL ratio, when the larvae ate $3.4-5.2 \%$ of their dry body weight, regardless of lipid class. When up to $2.1 \%$ lipid was consumed all the lipid was transported from the gut, while following consumption of up to $2.4 \%$ of PL and $2.9 \%$ of TAG, all the lipid was catabolized. When the larvae ingested more lipid, TAG and PL were stored in the body, but more dietary PL was retained than dietary TAG (Hamre et al. 2011).

\section{Digestion of carbohydrates}

The ability of fish to digest carbohydrates (mono-, diand polysaccharides) differs according to their feeding habits, ranging from herbivorous to strict carnivorous, of the individual species. Larvae ingest mainly zooplankton and later, microalgae. Reared larvae are also provided with compound feeds towards the end of the stage. The carbohydrates in these feeds are present in different amount and forms.

Information about the digestion and absorption of carbohydrates by fish larvae is relatively scarce. The role of car- bohydrases in the digestion processes during the fish early stages has received less attention than proteases and lipases. This situation may be partly due to the low carbohydrate content of the planktonic prey (Dhont \& Van Stappen 2003; Hamre 2006). However, the activity of $\alpha$-amylase, a key enzyme for the digestion of complex carbohydrates, has been determined in the larvae of several fish species (Cahu \& Zambonino-Infante 1994; Moyano et al. 1996; Cara et al. 2003; Ma et al. 2005; Suzer et al. 2007b; Gisbert et al. 2009). The fish do not have salivary glands, and $\alpha$-amylase is only synthesized in the pancreas. Accordingly, $\alpha$-amylase has been detected from the moment the pancreas starts to be functional during the yolksac stage. Different patterns of activity have been observed in the course of larval development. The most common pattern described for the specific activity determined biochemically is a high level after first feeding that tends to decrease during the following weeks as development progresses. This has been observed for instance in walleye pollock (Theragra chalcogramma) (Oozeki \& Bailey 1995), gilthead seabream (Moyano et al. 1996), Senegalese sole (Martínez et al. 1999; Ribeiro et al. 1999), Asian sea bass (Lates calcarifer) (Ma et al. 2001), white bream (Diplodus sargus) (Cara et al. 2003), European sea bass (Suzer et al. 2007a,b,c) and blackspot seabream (Ribeiro et al. 2008). In other cases, the maximum activity has been measured in the middle of the larval stage, to disappear at the end of this stage with the transition to juvenile, as has been observed in Pacific threatfin (Polydactylus sexfilis), bluefin travalli (Caranx melampygus) (Kim et al. 2001), California halibut (Paralichthys californicus) (Alvarez-González et al. 2006), yellowtail kingfish (Seriola lalandi) (Chen et al. 2006), spotted sand bass (Paralabrax maculatofasciatus) (Alvarez-González et al. 2008) and common dentex (Gisbert et al. 2009). A second increase in amylase activity at the end of larval stage has also been described in red drum (Sciaenops ocellatus) (Lazo et al. 2000), yellow croaker (Pseudosciaena crocea) (Ma et al. 2005) and some sturgeons (Babaei et al. 2011; Sanz et al. 2011). Finally, a continuous increase of $\alpha$-amylase activity during the development has been described in lipped grey mullet (Chelon labrosus) (Zouiten et al. 2008). A similar variety of patterns has been found at the transcriptional level (Péres et al. 1998; Douglas et al. 2000; Ma et al. 2001; Darias et al. 2006; Sánchez-Amaya et al. 2009; Kortner et al. 2011a). All these different patterns probably reflect the interspecific differences in feeding habits of the forthcoming juvenile as well as differences in feeding protocols, with different live prey or inert diets being supplied at different larval ages. Species with more carnivorous habits tend to reduce amylase activity when the stomach is becoming functional, while herbivorous and omnivorous species seem to exhibit an increase in activity as they approach the juvenile stage. 
The function of amylase in these first moments of larval life, during which very low or negligible amount of carbohydrates are being ingested, remains unclear. It has been hypothesized that its relatively high level of activity is related to the necessity to digest efficiently potential sources of carbohydrate in order to optimize the energy obtained from the food, needed to support rapid growth in this critical period. In fact, ingestion of microalgae has been described from the very first moment at which external water enters the digestive tract (Reitan et al. 1997) and microalgal cells are also present in the digestive tract of the ingested zooplankton.

Some studies have reported that $\alpha$-amylase activity is somehow independent of diet being genetically programmed (Péres et al. 1998; Zambonino-Infante \& Cahu 2001), as supported by the fact that it is detected, even at high level, as early as the yolksac stage and after the onset of exogenous feeding. However, this is stimulated by starch and glycogen (Péres et al. 1998) and several studies show a clear effect of dietary carbohydrates, particularly with the starch content of microdiets (Cahu \& Zambonino-Infante 1994; Péres et al. 1998; Ribeiro et al. 2002; Suzer et al. 2007c).

The presence of other carbohydrases in larval fish has hardly been examined. The pattern of activity of maltase, a disaccharidase present in the brush border of the enterocytes, has been examined in common dentex (Gisbert et al. 2009), remaining at an almost constant level during the larval stage following an initial increase after first feeding. On the other hand, the mRNA expression of chitinase, which is involved in the digestion of the crustaceans exoskeleton, has been detected in the gastric glands of Japanese flounder, spotted halibut (Verasper variegatus), seven-band grouper (Epinephelus septemfasciatus) and greater amberjack (Seriola dumerili) (Kurokawa et al. 2004; Wu et al. 2011) at the same time as pepsinogen.

\section{Regulatory systems of digestion}

Digestive systems evolved to maximize nutrient absorption from foods available under natural conditions. This process involves the spatial and temporal coordination of a remarkably complex system that includes neural, endocrine and local control mechanisms. Much of our understanding is based on mammalian studies and a few on juvenile and adult fish. As in other vertebrates, regulation in fish larvae is believed to occur via the enteric nervous system and gastrointestinal hormones. In most adult vertebrates, processing of a meal is tightly regulated and involves cephalic, gastric and intestinal phases (Silverthorn 2004).

The cephalic phase is initiated by sight, smell or taste and acts as a feed-forward reflex to initiate digestion and to prepare the digestive tract for the anticipated arrival of feed by stimulating secretion and motility in the GI tract and accessory organs. The presence of a cephalic phase in the larval stages of gilthead seabream was reported by Kolkovski et al. (1997a,b). These authors demonstrated that combinations of visual and chemical signals from Artemia nauplii raised ingestion rates of microparticulate diets, and they suggested that the response was regulated by the hormone bombesin. Larval fish also respond to specific feed attractants (Døving et al. 1995; see below). Organic components in microdiets such as protein hydrolysates, phospholipids and polyamines stimulate appetite (Browman 2005; Kvåle et al. 2006; Rocha et al. 2008). However, there are no specific studies of neural and hormonal responses of fish larvae during the cephalic phase (Webb \& Rønnestad 2011).

During the gastric phase, the stomach handles the control of digestion. This phase is initiated by distention and by chemical signals from the food in the stomach lumen. The lack of a functional stomach in agastric and precocial larval fish suggests that the fully operational regulatory patterns common in the gastric phase develops at a later stage of maturation. In most carnivorous fish the stomach plays an important role as a storage chamber and the gastric phase is primarily focused on digesting food in the stomach and controlling the flux of chyme through the pyloric sphincter. However, as mentioned above, some fish larvae possess a stomach anlage that appears to serve as a reservoir before the gastric glands are differentiated, and parts of a gastric phase may already be functional as early as first feeding (Webb \& Rønnestad 2011).

Gastrin-producing cells that are immunoreactive to gastrin antibodies can be observed at $4 \mathrm{dph}$ in the anterior intestine of the African catfish (Clarias gariepinus), which has a short larval period (Verreth et al. 1992). This suggests the early appearance of a functional gastric phase in this freshwater species. In marine larva such as Japanese flounder, there is no evident expression of the gastrin preprohormone mRNA until the larva enters metamorphosis at 35 dph (Kurokawa et al. 2003), which coincides with the development of functional gastric glands and an acidic $\mathrm{pH}$ in the stomach (Rønnestad et al. 2000a). As gastrin plays an important role in the regulation of the gastric phase, the lack of gastrin mRNA expression until around the time of the initiation of gastric activity suggests that there is no significant gastric phase in these larvae (Webb \& Rønnestad 2011).

The intestine is the key regulator of digestion during the intestinal phase. In precocial and agastric larvae this phase is probably predominant (Webb \& Rønnestad 2011). Differences between the intestinal regulatory systems of digestion before and after the stomach becomes functional have not been studied. The intestinal phase is initiated as chyme 
enters the midgut through the pyloric sphincter from the stomach. In agastric and altricial fish larvae, food enters the gut directly via the mouth and oesophagus, followed by water that is engulfed along with the food particles. In both cases, this stimulates the secretions from pancreas and gallbladder. The neuronal networks and regulatory peptides that are necessary for adequately control of this phase probably become active either slightly before or just at the onset of exogenous feeding. This is evident in red drum larvae, in which there is a dramatic increase in trypsin and chymotrypsin activity at $3 \mathrm{dph}$, before the larvae begin to feed (Lazo et al. 2000; Applebaum et al. 2001).

In Atlantic herring larvae fed with inert polystyrene spheres, there was a small but detectable increase in intestinal trypsin response, suggesting that gut distension alone is capable of initiating secretion (Fig. 11; Hjelmeland et al. 1988). This could be explained by reflexes initiated by stretch receptors as part of the digestive phase or as a feedforward system forming part of the cephalic phase. However, Hjelmeland et al. (1988) also demonstrated that trypsin secretion was higher when the larvae were fed live

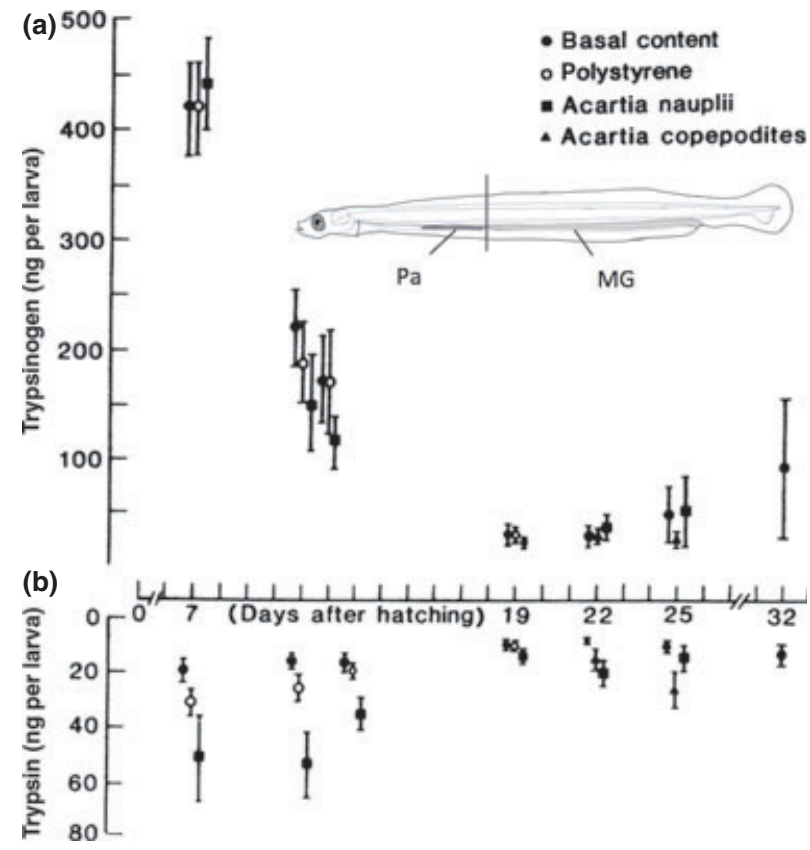

Figure 11 Effect of ingesting live prey and inert spheres on trypsinogen (inactive enzyme stored in pancreas) and trypsin (active enzyme present in midgut) in Atlantic herring. Adapted from Hjelmeland et al. (1988) and drawing by I. Rønnestad. The insert shows that pancreas (Pa) can easily be separated from the midgut (MG) in herring larvae by a section just prior to the anterior part of the midgut as indicated by the line. This location is clearly visible in live specimens due to the transparency that makes this larva a good model for such studies. (•) Basal content; (০) Polystyrene; ( $\mathbf{\square})$ Acartia nauplii; ( $\mathbf{\Delta}$ ) Acartia copepodites. prey rather than inert spheres (Fig. 11), suggesting the possible presence of other active intestinal phase mechanisms.

A fully functional regulatory system for digestion utilizes negative feedback loops that are expected to prevent overfeeding (and thus flooding and saturation of the intestinal digestive enzyme system) by affecting appetite and ingestion, and also to contribute to fine-tuning of the release of digestive secretions in response to available substrates in the content of the lumen. The fact that many fish larvae continue to eat even with a full gut suggest that the inhibitory satiety signals from the GI tract, as seen in adults, are not fully functional in early larval stages. It may be that the encounter rate of prey in the natural environment is so low that satiety signals from the digestive tract are normally not required to prevent overfeeding. These larvae may have evolved into feeding machines that engulf everything that is perceived as food, so that the continuous light and high availability of feeds in intensive culture systems results in overfeeding. This implies the absence of a proper feedback signalling system in the larvae for the negative feedback loop.

\section{Gastrointestinal tract hormones}

A number of studies on vertebrates have suggested that gastrointestinal regulatory molecules include paracrine and endocrine hormones, neuropeptides and cytokines. In adult fish, peptide hormones have been shown to regulate gut motility and bile and enzyme secretions, but very limited information is available regarding the involvement of regulatory peptides during the larval stages. The ontogeny of some of the regulatory peptides in the digestive tract has been described in some fish larvae (eg. Kurokawa et al. 2000 and reviews by Zambonino-Infante et al. 2008; Webb \& Rønnestad 2011), but to what extent the endocrine systems that control digestion differ from the adult stages is still unclear. The stomach requires the feedback regulatory systems to gradually become operational during metamorphosis and the differentiation phases of development. This process also needs to be integrated with the regulatory system already in operation in the mid- and hindgut.

Cholecystokinin (CCK) is the most studied gut peptide hormone in fish larvae to date. In adult mammals, CCK has been shown to have a key regulatory effect on the intestinal phase of digestion, where it participates in regulating gallbladder contraction, pancreatic enzyme secretion, inhibition of gastric acid production, regulation of gastric emptying (delaying) and gut motility (peristalsis) (Liddle 1997). Studies based on teleosts suggest that there are clear differences in the distribution pattern of CCK-producing cells and in the timing of their appearance along the gut during ontogeny. In larvae that develop from pelagic eggs and species that possess a coiled gut at onset of exogenous feeding (e.g. Atlantic halibut and bluefin tuna, Thunnus 
thynnus), the presence of CCK-producing cells in the gut is difficult to demonstrate until some time after the larvae have started feeding (Kamisaka et al. 2001, 2002; Hartviksen et al. 2009; Webb et al. 2010). In such species, these cells initially appear in the anterior midgut, and are rarely found in the rear two-thirds of the gut, although for one investigated species (sharpsnout sea bream, Diplodus puntazzo) significant numers are also found in the hindgut (Micale et al. 2010). Keeping in mind the role of CCK in gut regulation, it is still an open question on how well digestive processes are controlled during the start-feeding phase in these species. In larvae with a straight gut, such as herring and ayu (Plecoglossus altivelis), CCK-producing cells are present before start-feeding and throughout the whole length of the gut (Kamisaka et al. 2003, 2005). CCK mRNA and protein expression demonstrates transcription and translation of the gene during the early phases of development. However, the importance of CCK in the regulation of digestion needs to be established via studies of its function. A more recent in vivo study in zebrafish using fluorescent reporters for protein and lipid digestion combined with CCK inhibitors indicated that CCK only acquires an active role in the regulation of digestion 1 day after the onset of first feeding (Hama et al. 2009). This supports previous suggestions that CCK regulation may not be fully operational at the onset of exogenous feeding.

The available data suggest that CCK is involved in the secretion of trypsin in larval fish. In Atlantic herring, the administration of proteins into the digestive system led to higher levels of CCK in the gut of larvae, while FAA did not have the same effect (Koven et al. 2002). A higher level of CCK is correlated with a rise in trypsin activity. Administration of a saline control had only minor effects on the level of CCK. This indicates that distension of the gut wall via stretched receptors may cause trypsin release without involving CCK. A high level of inclusion of dietary protein hydrolysate in European sea bass larvae lowered trypsin secretion and CCK levels (Cahu et al. 2004). Taken together, these data indicate that dietary protein content, in combination with protein and peptide chain lengths and intraluminal proteolytic activity, regulates CCK levels.

There are some conflicting data regarding how the regulatory loop of CCK and trypsin is affected by fasting, starvation and feeding regime. It is possible that some of these differences can be explained by the resolution of the analysis, i.e. it is possible that CCK might have paracrine effects that no studies so far have been able to resolve. In a study of Senegalese sole (Ribeiro et al. 2009) involving the replacement of live prey with microdiets, there were large differences in growth, but CCK followed a similar pattern of development in all treatments.
The CCK levels in the gut were higher in fed than fasted herring larvae (Rojas-García et al. 2011). This study also demonstrated a marked drop in relative gut CCK levels and a concurrent increase in the CCK carcass to gut ratio, 1 hour after the introduction of food followed by a return to pre-feeding levels after 2 hours. This response probably results from the release and re-synthesis of CCK in the gut after feeding started. The data do not indicate that CCK has a circadian rhythm independent of feeding.

Drossou (2006) demonstrated an antagonistic feedback mechanism between CCK and tryptic activity in cod larvae (Fig. 12). High CCK levels corresponded to low tryptic activities and vice versa. The author described short- and long-term patterns of action for CCK and tryptic activity and suggested that the presence or absence of sufficient food modifies the feedback regulation between CCK and trypsin secretion. Drossou's data also support the existence of a CCK-releasing factor, as postulated by other researchers (Rønnestad 2002; Cahu et al. 2004). However, knowledge of the role of CCK in fish larvae is still rather basic and much remains to be discovered with respect to its synthesis, release and actions (Rojas-García et al. 2001; Rønnestad 2002; Rønnestad et al. 2003; Webb 2008; Webb \& Rønnestad 2011; Micale et al. 2010).

Since many GI-tract hormones are also found in the brain, whole-larva levels of CCK cannot be regarded as representative of intestinal CCK. For instance, at the onset of first feeding in Atlantic herring, CCK in the digestive system represented $<10 \%$ of what was detected in whole larvae (Rojas-García et al. 2011), while in Atlantic halibut, intestinal CCK represented only $2 \% 1$ week after the onset of exogenous feeding. This level steadily rose to about $62 \%$ after about 4 weeks (Rojas-García \& Rønnestad 2002).

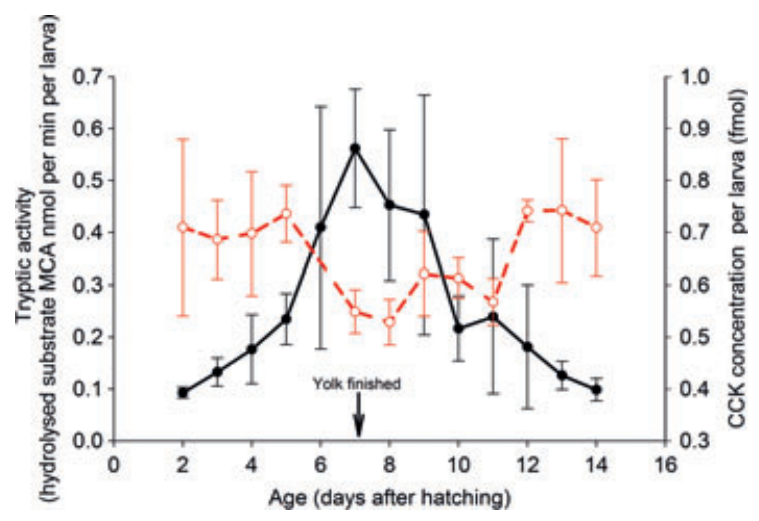

Figure 12 Natural variability in tryptic activity and CCK level (CCK-8s) in young cod larvae. The graph depicts the antagonistic behaviour of trypsin and CCK concentration, indicating the existence of a feedback mechanism. $(\bullet)$ Tryptic activity; $(-)$ CCK. 


\section{Other gastrointestinal tract hormones}

The gastrointestinal tract is the largest endocrine organ in the vertebrate body, and a number of other peptide hormones and neuropeptides are found in the GI tract of many vertebrates and adult fish. It has been suggested that the evolutionary signalling pathways and molecules involved are conserved among vertebrates, with some data suggesting species-specific differences in fish (Buddington \& Krogdahl 2004). An incomplete list of hormones that need to be further explored in fish larvae includes bombesin, ghrelin, vasointestinal peptide (VIP), glucagon-like peptide-1 (GLP-1), peptide YY(PYY) and motilin. Our knowledge of these peptides in larval stages of fish is very limited, and the few studies that do exist mainly involve semi-quantitative descriptions of their localization or expression, with some related to a particular experimental treatment (Kolkovski 2001; Ribeiro et al. 2009; Kortner et al. 2011a).

\section{Enteric nervous systems}

The enteric nervous system (ENS) takes the form of two neural plexi in the submucosal and muscularis layers. It regulates gut motility and blood flow, coordinates secretion and absorption and modulates immune and endocrine functions reflexively (Silverthorn 2004). Thanks to short reflexes mediated by the ENS, the GI tract can perform spontaneous motor activity independent of control by the brain or spinal cord. This ability enables functional in vitro experiments to be carried out, in which the digestive tract is dissected and mounted in Ringer's solution. Using this approach in post-metamorphotic Atlantic halibut, Rønnestad et al. (2000b) documented several types of spontaneous motor activity in the isolated gastrointestinal tract.

The role played by the enteric nervous system in gut motility has been well described in adult vertebrates. Electrical slow waves are generated spontaneously and spread from the interstitial cells of Cajal, stimulating smooth muscle contraction in the gut (Holmberg et al. 2008). The ENS regulates feeding-induced peristalsis and thereby determines the rate at which food passes. Studies of zebrafish larvae have suggested that these rhythmic contractile properties are established before the onset of exogenous feeding (Holmberg et al. 2003, 2004, 2008). These peristaltic movements transport the food bolus along the digestive tract and the motility appears to be controlled by cholinergic nerves in the intestine. In addition to the anterograde peristaltic waves, retrograde waves have also been observed in Atlantic halibut (Rønnestad et al. 2000b) and zebrafish (Holmberg et al. 2004). It is believed that rather than moving food through the gut, the retrograde motion serves to mix the digestive secretions into the food bolus/chyme and also to fill the pyloric caeca (Rønnestad et al. 2000b). However, we do not know how well the ENS can cope with the high ingestion rates observed in intensive rearing systems during larval stages.

Data on zebrafish based on IHC support the idea that the enteric innervation is well developed before the onset of feeding and that there is a correlation between the growth of innervation and more regular and complicated patterns of motility (Olsson et al. 2008). Such studies demonstrate the advantages of using fish as models for vertebrates to understand the underlying mechanisms of ENS development and function. The combination of new methods such as forward and reverse genetic approaches with the visualization of cell populations, specific gene expression, etc., in living transparent embryos have made the zebrafish an attractive model. As discussed by Shepherd and Eisen (2011), recent work on this species that describes the development and organization of the ENS has revealed details of cellular, molecular and genetic mechanisms that also provide new insights into human ENS diseases.

\section{Future research strategies for studies in feeding behaviour and digestive physiology to advance larval rearing of marine fish}

Our knowledge of many aspects of food acquisition and digestion in fish larvae has increased enormously during the past few decades, but there are still many gaps that require further research in order to improve the rearing of marine fish larvae.

In relation to food detection we still need to develop an overall picture of the sensory systems throughout development. Not all types of sensory cell are present in individual species, and those present in adult stages are often different from those observed in larvae and juveniles. Furthermore, some sense organs (e.g. solitary chemosensory cells) are very poorly described and only in some species, and no or few data on their physiological functions are available. Broader and deeper knowledge of sense organs ontogenesis, morphology and physiology in larvae, juveniles and adults of reared species will greatly help us to optimize feeding protocols and replace live prey with inert microdiets. This will permit species-specific optimization of administration of prey/food item sequences based on organoleptic properties, dimensions, detectability (i.e. via mechanical or chemical clues), the type and speed of movements or buoyancy.

Another issue that needs attention is the problem of sense organ anomalies that has been described in some reared fish (Mana \& Kawamura 2002). If this situation is confirmed in other reared species, it will have strong implications for sampling for ontogenetic studies, including reference material needing to be collected from wild populations or fish having to be reared in extensive systems with natural plankton in order to elucidate the normal pattern of development. This would also imply that under 
cultivation conditions, fish larvae rely on impaired or even missing sensory organs for food detection, evaluation and ingestion.

In spite of numerous studies on gut development in fish, we still possess little knowledge of details of the structural changes that occur during intestinal epithelium development, including the complex molecular pathways involved in gastrointestinal organogenesis and the concomitant changes in functionality. Very little is known about the mechanisms that underlie proliferation and differentiation in the gut at cellular, tissue and integrated organ level and how these are influenced by endogenous and exogenous factors, including microbiota and diets. This knowledge will contribute to the design of stage-specific diets for individual species as well as to achieving appropriate intestinal maturation on species-specific diets and in consequence, more efficient food digestion.

Although several studies exist regarding the role of proteolytic enzymes and particularly trypsin in larval digestive physiology, most of the results are of academic character, rather than being of practical value for mass rearing of marine fish larvae. It is widely accepted that marine fish larvae provide endogenic trypsin at the onset of feeding and beyond, a few studies also demonstrate that the larvae of many marine species are deficient in tryptic activity beyond the first feeding stage. This is usually accompanied by significant mortality even when sufficient food is provided. More studies that deal with this apparent ontogenetic deficiency are needed, as these would help to identify the underlying reasons for the deficiencies in larval digestive physiology during this critical period. Such knowledge will be useful for overcoming the lack of proteolytic capacity, for example by identifying the factors that facilitate the production and secretion of sufficient trypsin, and which may eventually also be added to the food. It is also unknown whether ontogenetic differences in the various trypsin paralogues have functional implications for protein digestion. The roles played in the early stages of marine larvae by other proteolytic enzymes such as chymotrypsin and pepsin have not been investigated sufficiently. An area that is virtually unexplored in larval fish is that of the mechanisms of absorption of nutrients such as proteins, peptides and amino acids, and since these systems are important for the supply line of energy and building blocks into the growing tissues such knowledge is of key importance.

Our understanding of feeding rhythms is far from complete and does not permit a global view of the digestive function in the course of a full day. The available data, which cover a few species, cover partial examination of the gut content and feeding incidence. Likewise, other important aspects such as gut passage time and digestive enzyme activity during a $24 \mathrm{~h}$ cycle have been only partially studied, again in only a few species (Ueberschär 1995;
Mackenzie et al. 1999; Rojas-García et al. 2011). In spite of the importance of the photoperiod in synchronizing the physiological cycles, the time of day at which food is offered also plays a role in establishing and maintaining the daily pattern of the feeding activity and digestive function, and this needs to be explored in many species. A variety of strategies employed in marine hatcheries relate to the feeding schemes for early larval stages. Practical protocols in commercial hatcheries range from natural light cycle and a limited number of meals per day to $24 \mathrm{~h}$ of light and continuous food supply. The functional digestive processing capacity at specific developmental stages is still poorly examined. However, with some feeding schemes, the digestive capacity is quite clearly overwhelmed. In order to match the larva's digestive capacity at different developmental stages, studies that deal with the diurnal and nocturnal rhythm in digestive capacity are also needed. Such studies need to take into account the proteolytic capacity, but they should also take a holistic view of the concerted action of the whole digestive process. Since it has been suggested that the capacity varies from one species to another, species-specific experiments are necessary, and the nature of the feed offered will have to be paid attention.

Species-specific knowledge of feeding regimes is also of importance for lipid digestion, and future studies will also need to focus on the mechanisms that underlie lipid packaging and transport from the enterocytes to the body. Triacylglycerol and phospholipid synthesis pathways apparently have very different capacities in early larval life, while the dynamics of these pathways also change during ontogeny. These are issues that need to be elucidated in order to improve the design of larval diets with respect to lipids.

Our information regarding the digestion of carbohydrates during the larval stage is still very fragmentary, nor have carbohydrate absorption processes been studied in fish larvae. We thus still lack a clear picture of the role played by carbohydrates and of the potential importance of supplying them in appropriate quality and quantity in the diet.

Although the endocrine and neural control of both appetite and digestion is known to be very complex in adult vertebrates, our knowledge in larval fish is virtually nonexistent. A few descriptions exist for certain hormones and neuropeptides, and these may include cloning and expression, but there is almost no knowledge of regulation at the biochemical, molecular and integrating levels. Cholecystokinin has been most studied, but knowledge about the dynamics and the precise role of CCK in fish larvae is still rather basic and much remains to be discovered with respect to its synthesis, release and actions. There are some conflicting data regarding how the regulatory CCK and trypsin loop is affected by fasting, starvation and feeding regime. The first feeding stages in particular, where CCK 
appears to be insufficient to regulate trypsin secretion, need more attention in research.

The extremely small and delicate nature of fish larvae is the source of a number of methodological challenges. How to take representative samples without affecting the normal development of a population in a rearing tank has been a recurrent problem in larviculture research. The amount of biomass required to perform reliable biochemical analyses has also been a constant constraint on performing complete temporal series during development. Fortunately, important advances have been made in some respects. Modern analytical techniques for quantifying enzyme activity enable us accurately to measure a given enzyme in a whole-body homogenate. These techniques also enable these analyses to be performed using only one larva. Used in conjunction with biochemical assays, these molecular tools also allow the identification, localization and quantification of specific gene transcripts for enzymes, (Douglas et al. 1999; Murray et al. 2004, 2006; Marza et al. 2005; Perez-Casanova et al. 2004, 2006 Darias et al. 2007a,b). For instance, in the studies of hormone and neuropeptide expression, further dissections and compartmentalizations are needed. As discussed for CCK (Rojas-García et al. 2011), there are significant populations of CCK-producing cells in both the brain and the gut, and in the early stages the levels in the head are much higher than in the gut. Thus, the individual CCK pool needs to be assessed separately for any discussion of their effects on appetite and digestion.

On the other hand, digestive function cannot be considered separately from the other biological, nutritional and metabolic processes that occur during development. Global genomic approaches are particularly useful as a means of obtaining an integrative perspective (Mazurais et al. 2011). In this sense, current EST databases in fish species will need to be enriched to cover the larval developmental period and the transition to juvenile stages (Douglas et al. 2007; Yúfera et al. 2012a).

A complete and global picture of the main key processes involved in the feeding and digestion of reared fish larvae will be difficult to obtain, due to the wide range of patterns of development and feeding habits in teleosts. An adequate combination of model and reared target species could be a valuable pathway to this goal. A few key model species such as medaka and zebrafish, for which sophisticated molecular and experimental toolboxes are already available, could provide in-depth knowledge of specific and general processes related to feeding and digestion. It is evident that many of the most important mechanisms are conserved even at vertebrate level. However, it is still important to perform parallel studies of the species targeted for culture, since the variety of teleost adaptations will have evolved mechanisms that are unique for the ecology and natural conditions appropriate to each species.

\section{Acknowledgements}

This study benefited from participation in LARVANET COST action FA0801 (EU RTD framework Programme). I.R. received funding from the Research Council of Norway (CODE- 199482 and GutFeeling- 190019) and the EC FP7 (LIFECYCLE- 222719). M.Y. received financial support from the Spanish Ministry of Science and Innovation MICINN + FEDER/ERDF (projects AGL2007-64450-C02-01 and Consolider Ingenio 2010 Program-project Aquagenomics CSD2007-0002). C.B. received funding from the Italian Ministry of Agricultural, Forestry and Alimentary Policy (Law 41/82) (projects 5C49-6C138).

\section{References}

Akiyama T, Murai T, Nose T (1986) Oral administration of serotonin against spinal deformity of chum salmon fry induced tryptophan deficiency. Bulletin of the Japanese Society of Scientific Fisheries 52: 1249-1254.

Aktulun S, Suzer C, Kamaci HO, Coban D, Saka S, Firat K (2008) Activity of the digestive protease, chymotrypsin, in larvae of the cultured sharpsnout seabream (Diplodus puntazzo) larvae. Israel Journal of Aquaculture Bamidgeh 60: 82-88.

Alvarez-González CA, Cervantes-Trujano M, Tovar-Ramírez D, Conklin DE, Nolasco H, Gisbert E et al. (2006) Development of digestive enzymes in California halibut Paralichthys californianus larvae. Fish Physiology and Biochemistry 31: 83-93.

Alvarez-González CA, Moyano-López JF, Civera-Cerecedo R, Carrasco-Chávez V, Ortiz-Galindo JL, Dumas S (2008) Development of digestive enzyme activity in larvae of spotted sand bass Paralabrax masculatofasciatus. 1. Biochemical analysis. Fish Physiology and Biochemistry 34: 373-384.

Amberg JJ, Myr C, Kamisaka Y et al. (2008) Expression of the oligopeptide transporter, PepT1, in larval Atlantic cod (Gadus morhua). Comparative Biochemistry and Physiology B 150: 177-182.

Anderson RA, Sando GN (1991) Cloning and expression of cDNA-encoding human lysosomal acid lipase cholesteryl ester hydrolase - Similarities to gastric and lingual lipases. Journal of Biological Chemistry 266: 22479-22484.

André M, Ando S, Ballagny C et al. (2000) Intestinal fatty acid binding protein gene expression reveals the cephalocaudal patterning during zebrafish gut morphogenesis. International Journal of Developmental Biology 44: 249-252.

Appelbaum SL, Riehl R (1997) Scanning electron microscopic observations of the chemo and mechanoreceptors of carp larvae (Cyprinus carpio) and their relationship to early behaviour. Aquatic Living Resources 10: 1-12.

Applebaum SL, Holt GJ (2003) The digestive protease, chymotrypsin, as an indicator of nutritional condition in larval red drum (Sciaenops ocellatus). Marine Biology 142: 1159-1167.

Applebaum SL, Rønnestad I (2004) Absorption, assimilation and catabolism of individual free amino acids by larval Atlantic halibut (Hippoglossus hippoglossus). Aquaculture 230: 313-322. 
Applebaum SL, Perez R, Lazo JP, Holt GJ (2001) Characterization of chymotrypsin activity during early ontogeny of larval red drum (Sciaenops ocellatus). Fish Physiology and Biochemistry 25: 291-300.

Babaei SS, Kenari AA, Nazari R, Gisbert E (2011) Developmental changes of digestive enzymes in Persian sturgeon (Acipenser persicus) during larval ontogeny. Aquaculture 318: $138-144$.

Baier LJ, Bogardus C, Sacchettini JC (1996) A polymorphism in the human intestinal fatty acid binding protein alters fatty acid transport across Caco-2 cells. Journal of Biological Chemistry 271: 10892-10896.

Bakke S, Jordal A-EO, Gomez-Requeni P et al. (2010) Dietary protein hydrolysates and free amino acids affect the spatial expression of peptide transporter PepT1 in the digestive tract of Atlantic cod (Gadus morhua). Comparative Biochemistry and Physiology B 156: 48-55.

Batty RS, Blaxter JHS (1992) The effect of temperature on the burst swimming performance of fish larvae. Journal of Experimental Biology 170: 187-201.

Bell MV, Dick JR (1993) The appearance of rods in the eyes of herring and increased di-docosahexaenoyl molecular species of phospholipids. Journal of the Marine Biological Association of the United Kingdom 73: 679-688.

Bell MV, Batty RS, Dick JR, Fretwell K, Navarro JC, Sargent J (1995) Dietary deficiency of docosahexanoic acid impairs vision at low light intensities in juvenile herring (Clupea harengus L.). Lipids 30: 443-449.

Bell MV, McEvoy LA, Navarro JC (1996) Deficit of didocosahexaenoyl phospholipid in the eyes of larval sea bass fed an essential fatty acid deficient diet. Journal of Fish Biology 49: 941-952.

Benítez-Santana T, Masuda R, Juárez Carrillo E et al. (2007) Dietary n-3 HUFA deficiency induces a reduced visual response in gilthead seabream Sparus aurata larvae. Aquaculture 264: 408-417.

Bisbal GA, Bengtson DA (1995) Development of digestive tract in larval summer flounder. Journal of Fish Biology 47: 277291.

Blanco-Vives B, Villamizar N, Ramos J, Bayarri MJ, Chereguini O, Sánchez-Vázquez FJ (2010) Effect of daily thermo- and photo-cycles of different light spectrum on the development of Senegal sole (Solea senegalensis) larvae. Aquaculture 306: 137-145.

Blaxter JHS (1965) The feeding of herring larvae and their ecology in relation to feeding. California Cooperative Oceanic Fish Investigation Report 10: 79-88.

Blaxter JHS (1986) Development of sense organs and behaviour in teleost larvae with special reference to feeding and predation avoidance. Transations of the American Fisheries Society 115: 98-114.

Blaxter JHS, Danielssen D, Moksness E, Øiestad V (1983) Description of the early development of the halibut Hippoglossus hippoglossus and attempts to rear the larva past first feeding. Marine Biology 73: 99-107.
Blow DM (1976) Structure and mechanism of chymotrypsin. Accounts of Chemical Research 9: 145-152.

Blow DM, Ruhlmann A, Wright CS, Steigema W, Huber R, Kukla D (1972) Model for association of bovine pancreatic trypsin-inhibitor with chymotrypsin and trypsin. Journal of Molecular Biology 69: 137-144.

Boglione C, Giganti M, Selmo C, Cataudella S (2003) Morphoecology in larval fin-fish: a new candidate species for aquaculture, Diplodus puntazzo (Sparidae). Aquaculture International 11: $17-41$.

Boglione C, Gavaia P, Koumoundouros G et al. (2012a) A review on skeletal anomalies in reared European fish larvae and juveniles. Part 1: normal and anomalous skeletogenic processes. Reviews in Aquaculture 5: s99-s120.

Boglione C, Gisbert E, Gavaia P et al. (2012b) A review on skeletal anomalies in reared European fish larvae and juveniles. Part 2: main typologies, occurrences and causative factors. Reviews in Aquaculture 5: s121-s167.

Brockman H (2001) Pancreatic lipase. In: Mansbach CM II, Tso P, Kuksis A (eds) Intestinal Lipid Metabolism, pp. 61-73. Kluwer Academic, New York.

Browman HI (2005) Applications of sensory biology in marine ecology and aquaculture. Marine Ecology: Progress Series 287: 266-269.

Buddington RK (1994) Nutrition and ontogenic development of the intestine. Canadian Journal of Physiology and Pharmacology 72: 251-259.

Buddington RK, Krogdahl A (2004) Hormonal regulation of the fish gastrointestinal tract. Comparative Biochemistry and Physiology A 139: 261-271.

Buddington RK, Krogdahl A, Bakke McKellep AM (1997) The intestines of carnivorous fish: structure and functions and the relations with diet. Acta Physiologica Scandinavica 161: 67-80.

Buentello JA, Pohlenz C, Margulies D et al. (2011) A preliminary study of digestive enzyme activities and amino acid composition of early juvenile yellowfin tuna (Thunnus albacares). Aquaculture 312: 205-211.

Busch A (1996) Transition from endogenous to exogenous nutrition: larval size parameters determining the start of external feeding and size of prey ingested by Ruegen spring herring Clupea harengus. Marine Ecology Progress Series 130: 39-46.

Cahu CL, Zambonino-Infante JL (1994) Early weaning of sea bass (Dicentrarchus labrax) larvae with a compound diet: effect on digestive enzyme. Comparative Biochemistry and Physiology A 109: 213-222.

Cahu CL, Zambonino-Infante JL (1995) Maturation of the pancreatic and intestinal digestive functions in sea bass (Dicentrarchus labrax): effect of weaning with different protein sources. Fish Physiology and Biochemistry 14: 431-437.

Cahu C, Zambonino-Infante J (2001) Substitution of live food by formulated diets in marine fish larvae. Aquaculture 200: 161-180.

Cahu C, Zambonino-Infante JL, Takeuchi T (2003a) Nutritional components affecting skeletal development in fish larvae. Aquaculture 227: 245-258. 
Cahu CL, Zambonino-Infante JL, Barbosa V (2003b) Effects of dietary phospholipid levels and phospholipids: neutral lipid value on the development of sea bass (Dicentrarchus labrax) larvae fed a compound diet. British Journal of Nutrition 90: 21-28.

Cahu C, Rønnestad I, Grangier V, Zambonino-Infante JL (2004) Expression and activities of pancreatic enzymes in developing sea bass larvae (Dicentrarchus labrax) in relation to intact and hydrolyzed dietary protein; involvement of cholecystokinin. Aquaculture 238: 295-308.

Cara JB, Moyano FJ, Cárdenas S, Fernández-Díaz C, Yúfera M (2003) Assessment of digestive enzyme activities during larval development of white bream. Journal of Fish Biology 63: 4858.

Cara B, Moyano FJ, Zambonino-Infante JL, Fauvel C (2007) Trypsin and chymotrypsin as indicators of nutritional status of post-weaned sea bass larvae. Journal of Fish Biology 70: 1798-1808.

Chatzifotis S, Polemitou I, Divanach P, Antonopouiou E (2008) Effect of dietary taurine supplementation on growth performance and bile salt activated lipase activity of common dentex, Dentex dentex, fed a fish meal/soy protein concentratebased diet. Aquaculture 275: 201-208.

Chen Q, Sternby B, Akesson B, Nilsson A (1990) Effects of human pancreatic lipase-colipase and carboxyl ester lipase on eicosapentaenoic and arachidonic-acid ester bonds of triacylglycerols rich in fish oil fatty-acids. Biochimica et Biophysica Acta 1044: 111-117.

Chen BN, Qin JG, Kumar MS, Hatchinson W, Clarke S (2006) Ontogeny development of the digestive system in yellowtail kingfish Seriola lalandi larvae. Aquaculture 256: 489-501.

Chesley LC (1934) The concentrations of proteases, amylase, and lipase in certain marine fishes. Biological Bulletin 66: 133144.

Chesney EJ Jr (1989) Estimating the food requirements of striped bass larvae Morone saxatilis: effect of light, turbidity and turbulence. Marine Ecology Progress Series 53: 191200.

Chesney EJ (2008) Foraging behaviour of bay anchovy larvae, Anchoa mitchilli. Journal of Experimental Marine Biology and Ecology 362: 117-124.

Cobcroft JM, Pankhurst PM (2006) Visual field in cultured striped trumpeter Latris lineata (Teleostei) feeding in rotifer prey. Marine and Freshwater Behaviour and Physiology 39: 193 -208 .

Conceição LEC, Morais S, Rønnestad I (2007) Tracers in fish larvae nutrition: a review of methods and applications. Aquaculture 267: 62-75.

Conceição LEC, Morais S, Dinis MT, Rønnestad I (2008) Tracer studies in fish larvae. In: Cyrino JEP, Bureau D, Kapoor BG (eds) Feeding and Digestive Functions in Fishes, pp. 349-392. Science Publishers, Enfield, NH.

Conceição L, Aragão C, Rønnestad I (2011) Proteins. In: Holt GJ (ed.) Larval Fish Nutrition, pp. 83-116. John Wiley \& Sons, Chichester.
Cousin JCB, Baudin-Laurencin F (1985) Morphogénêse de l'appareil digestif de la vessie gazeuse du turbot, Scophthalmus maximus L. Aquaculture 47: 305-319.

Coutteau P, Geurden I, Camara MR, Bergot P, Sorgeloos P (1997) Review on the dietary effects of phospholipids in fish and crustacean larviculture. Aquaculture 155: 149-164.

Dabrowski K, Glogowski J (1977) Studies on role of exogenous proteolytic-enzymes in digestion processes in fish. Hydrobiologia 54: 129-134.

Dabrowski K, Lee K-J, Rinchard J (2003) The smallest vertebrate, teleost fish, can utilize synthetic dipeptide-based diets. Journal of Nutrition 133: 4225-4229.

Dabrowski K, Terjesen BF, Zhang YF, Phang JM, Lee KJ (2005) A concept of dietary dipeptides: a step to resolve the problem of amino acid availability in the early life of vertebrates. Journal of Experimental Biology 208: 2885-2894.

Daniel H (2004) Molecular and integrative physiology of intestinal peptide transport. Annual Review of Physiology 66: 361384.

Darias MJ, Murray HM, Martínez-Rodríguez G, Cárdenas S, Yúfera M (2005) Gene expression of pepsinogen during the larval development of red porgy (Pagrus pagrus). Aquaculture 248: 245-252.

Darias MJ, Murray HM, Gallant JW et al. (2006) Characterization of a partial $\alpha$-amylase clone from red porgy (Pagrus pagrus): expression during larval development. Comparative Biochemistry and Physiology B 143: 209-218.

Darias MJ, Murray HM, Gallant JW, Douglas SE, Yúfera M, Martínez-Rodríguez G (2007a) Ontogeny of pepsinogen and proton pump expression in red porgy (Pagrus pagrus): determination of stomach functionality. Aquaculture 270: 369-378.

Darias MJ, Murray HM, Gallant JW, Douglas SE, Yúfera M, Martínez-Rodríguez G (2007b) The spatiotemporal expression pattern of trypsinogen and bile salt-activated lipase during the larval development of red porgy (Pagrus pagrus, Pisces, Sparidae). Marine Biology 152: 109-118.

Darias MJ, Mazurais D, Koumoundouros G et al. (2010) Dietary vitamin D3 affects digestive system ontogenesis and ossification in European sea bass (Dicentrarchus labrax, Linnaeus, 1758). Aquaculture 298: 300-307.

Dempsey CH (1978) Chemical stimuli as a factor in feeding and intraspecific behaviour of herring larvae. Journal of the Marine Biological Association of the United Kingdom 58: 739-747.

Demski LS, Northcutt RG (1983) The terminal nerve - a new chemosensory system in vertebrates. Science 220: 435-437.

Devitsina GV, Kazhlayev AA (1995) Chemosensory systems and their heterochronous morphogenesis in the sturgeon fry. Biophysics (English Translation of Biofizika) 40: 153-157.

Dhont J, Van Stappen G (2003) Biology, tank production and nutritional value of Artemia. In: Støttrup JG, McEnvoy LA (eds) Live Feeds in Marine Aquaculture, pp. 65-121. Blackwell Publishing, Oxford, UK.

Diaz JP, Connes R (1997) Ontogenesis of the biliary tract in a teleost, the sea bass Dicentrarchus labrax L. Canadian Journal of Zoology-Revue Canadienne de Zoologie 75: 740-745. 
Diaz JP, Guyot E, Vigier S, Connes R (1997a) First events in lipid absorption during post-embryonic development of the anterior intestine in gilt-head sea bream. Journal of Fish Biology 51: 180-192.

Diaz JP, Mani-Ponset L, Guyot E, Connes R (1997b) Biliary lipid secretion during early post-embryonic development in three fishes of aquacultural interest: Sea bass, Dicentrarchus labrax L, sea bream, Sparus aurata L, and pike-perch, Stizostedion lucioperca (L). Journal of Experimental Zoology 277: 365-370.

Diaz JP, Mani-Ponset L, Blasco C, Connes R (2002) Cytological detection of the main phases of lipid metabolism during early post-embryonic development in three teleost species: Dicentrarchus labrax, Sparus aurata and Stizostedion lucioperca. Aquatic Living Resources 15: 169-178.

Dou S, Seikai T, Tsukamoto K (2000) Feeding behaviour of Japanese flounder larvae under laboratory conditions. Journal of Fish Biology 56: 654-666.

Douglas SE, Gawlicka A, Mandla S, Gallant JW (1999) Ontogeny of the stomach in winter flounder: characterization and expression of the pepsinogen and proton pump genes and determination of pepsin activity. Journal of Fish Biology 55: 897-915.

Douglas SE, Mandla S, Gallant JW (2000) Molecular analysis of the amylase gene and its expression during the development in the winter flounder Pleuronectes americanus. Aquaculture 190: 247-260.

Douglas SE, Knickle LC, Kimball J, Reith ME (2007) Comprenhensive EST analysis of Atlantic halibut (Hippoglossus hippoglossus), a commercially relevant aquaculture species. BMC Genomics 8: 144, doi:10.1186/1471-2164-8-144.

Døving KB, Mårstøl M, Andersen JR, Knutsen JA (1995) Experimental-evidence of chemokinesis in newly-hatched cod larvae (Gadus morhua L). Chemical Senses 20: 172-173.

Downing G, Litvak MK (2001) The effect of light intensity and spectrum on the incidence of first feeding by larval haddock. Journal of Fish Biology 59: 1566-1578.

Drossou A (2006) CCK concentration and tryptic activity in early stages of finfish larvae. PhD thesis. Leibniz Institut für Meereswissenschaften IFM-GEOMAR, Christian-AlbrechtsUniversität Kiel.

Drossou A, Ueberschär B, Rosenthal H, Herzig K-H (2006) Ontogenetic development of the proteolytic digestion activities in larvae of Oreochromis niloticus fed with different diets. Aquaculture 256: 479-488.

Economou AN (1991) Food and feeding ecology of live gadoid larvae in the larvae in the northern North Sea. Journal du Conseil/Conseil International pour l'Exploration de la Mer. 47: 339-351.

Elbal MT, García-Hernández MP, Lozano MT, Agulleiro B (2004) Development of the digestive tract of gilthead sea bream (Sparus aurata L.). Light and electron microscopic studies. Aquaculture 234: 215-238.

Espeland S (2006) Postprandial changes in intestinal, plasma, urine, and bile free amino acids of Atlantic cod (Gadus morhua) fed a pelleted commercial feed. Master thesis. University of Bergen, Bergen, Norway.
Evans BI, Browman HI (2004) Variation in the development of fish retina. American Fisheries Society Symposium 40: 145166.

Fahy E, Subramaniam S, Brown HA et al. (2005) A comprehensive classification system for lipids. Journal of Lipid Research 46: 839-861.

Farber SA, Pack M, Ho SY et al. (2001) Genetic analysis of digestive physiology using fluorescent phospholipid reporters. Science 292: 1385-1388.

Faulk CK, Benninghoff AD, Holt GJ (2007) Ontogeny of the intestinal tract and selected digestive enzymes in cobia Rhachycentron canadum (L.). Journal of Fish Biology 70: 567583.

Fernández I, Hontoria F, Ortiz-Delgado JB et al. (2008) Larval performance and skeletal deformities in farmed gilthead sea bream (Sparus aurata) fed with graded levels of vitamin A enriched rotifers (Brachionus plicatilis). Aquaculture 283: 102115.

Fernández I, Pimentel M, Ortiz-Delgado JB et al. (2009) Effect of dietary vitamin A on Senegalese sole (Solea senegalensis) skeletogenesis and larval quality. Aquaculture 295: 250-265.

Fernández-Díaz C, Pascual E, Yúfera M (1994) Feeding behaviour and prey size selection of gilthead seabream, Sparus aurata L., larvae fed on inert and live food. Marine Biology 118: 323-328.

Fiksen $\varnothing$, Jørgensen C (2011) Model of optimal behaviour in fish larvae predicts that food availability determines survival but not growth. Marine Ecology Progress Series 432: 207-219.

Finn RN, Kapoor BG (2008) Fish Larval Physiology. Science Publishers, Enfield, NH.

Finn RN, Rønnestad I, van der Meeren T, Fyhn HJ (2002) Fuel and metabolic scaling during the early life stages of Atlantic cod Gadus morhua. Marine Ecology Progress Series 243: 217234.

van der Flier LG, Clevers H (2009) Stem cells, self-renewal, and differentiation in the intestinal epithelium. Annual Review of Physiology 71: 241-260.

Fontagné S, Geurden I, Escaffre AM, Bergot P (1998) Histological changes induced by dietary phospholipids in intestine and liver of common carp (Cyprinus carpio L.) larvae. Aquaculture 161: 213-223.

Fox JM, Lawrence AL (2009) Evaluation of in vitro apparent protein digestibility by shrimp using gut enzyme extracts. Journal of the World Aquaculture Society 40: 325-336.

Fruton JS (1970) Specificity and mechanism of pepsin action. Advances in Enzymology and Related Subjects of Biochemistry 33: 401-443.

Fuiman LA, Smith ME, Malley VM (1999) Ontogeny of the routine swimming speed and startle responses in red drum, with a comparison of responses to acoustic and visual stimuli. Journal of Fish Biology 55 (Suppl. A): 215-226.

Fujii A, Kurokawa Y, Kawai Si et al. (2007) Diurnal variation of tryptic activity in larval stage and development of proteolytic enzyme activities of malabar grouper (Epinephelus malabarieus) after hatching. Aquaculture 270: 68-76. 
Fukuhara O (1985) Functional morphology and behaviour of early life stages of red sea bream. Bulletin of the Japanese Society of Scientific Fisheries 51: 731-743.

Gabaudan J (1984) Posthatching Morphogenesis of the Digestive System of Striped Bass. Ph.D Dissertation. Auburn University, Auburn, AL, USA.

Galaviz MA, García-Gasca A, Drawbridge M, Alvarez-González CA, Lopez LM (2011) Ontogeny of the digestive tract and enzymatic activity in white seabass, Atractoscion nobilis, larvae. Aquaculture 318: 162-168.

García-Hernández MP, Lozano MT, Elbal MT, Agulleiro B (2001) Development of the digestive tract of sea bass (Dicentrarchus labrax L). Light and electron microscopic studies. Anatomy and Embryology 204: 39-57.

Gawlicka A, Parent B, Horn MH, Ross N, Opstad I, Torrissen OJ (2000) Activity of digestive enzymes in yolk-sac larvae of Atlantic halibut (Hippoglossus hippoglossus): indication of readiness for first feeding. Aquaculture 184: 303-314.

Geurden I, Coutteau P, Sorgeloos P (1995) Dietary phospholipids for European sea bass (Dicentrarchus labrax L.) during first ongrowing. European Aquaculture Society Special Publication 24: $175-178$.

Gilbert ER, Wong EA, Webb KE (2008) Board-invited review: peptide absorption and utilization: implications for animal nutrition and health. Journal of Animal Science 86: 21352155.

Gildberg A (2004) Digestive enzyme activities in starved preslaughter fanned and wild-captured, Atlantic cod (Gadus morhua). Aquaculture 238: 343-353.

Gisbert E, Sarasquete MC, Williot P, Castelló-Orvay F (1999) Histochemistry of the development of the digestive system of Siberian sturgeon during early ontogeny. Journal of Fish Biology 55: 596-616.

Gisbert E, Conklin DB, Piedrahita RH (2004) Effects of delayed first feeding on the nutritional condition and mortality of California halibut larvae. Journal of Fish Biology 64: 116-132.

Gisbert E, Ortiz-Delgado JB, Sarasquete C (2008) Nutritional cellular biomarkers in early life stages of fish. Histology and Histopathology 23: 1525-1539.

Gisbert E, Giménez G, Fernández I, Kotzamanis Y, Estévez A (2009) Development of digestive enzymes in common dentex Dentex dentex during early ontogeny. Aquaculture 287: 381387.

Gjellesvik DR, Lombardo D, Walther BT (1992) Pancreatic bilesalt dependent lipase from cod (Gadus morhua) - purification and properties. Biochimica et Biophysica Acta 1124: 123-134.

Govoni JJ, Boehlert GW, Watanabe Y (1986) The physiology of digestion in fish larvae. Environmental Biology of Fishes 16: 59-77.

Grove DJ, Loizides LG, Nott J (1978) Satiation amount, frequency of feeding and gastric-emptying rate in Salmo gairdneri. Journal of Fish Biology 12: 507-516.

Guyot E, Diaz JP, Connes R (1995) Organogenesis of liver in seabream Sparus aurata. Journal of Fish Biology 47: 427-437.
Guyot E, Diaz JP, Romestand B, Connes R (1998) Insulin during the early postembryonic development of gilt-head sea bream, Sparus aurata: ultrastructural, himmunohistochemical, and biochemical studies. General and Comperative Endocrinology 110: 146-156.

Haga Y, Suzuki T, Takeushi T (2002) Retinoic acid isomers produce malformations in the postembryonic development of the Japanese flounder, Paralichthys olivaceus. Zoological Science 19: 1105-1112.

Hama K, Provost E, Baranowski TC et al. (2009) In vivo imaging of zebrafish digestive organ function using multiple quenched fluorescent reporters. American Journal of Physiology - Gastrointestinal and Liver Physiology 296: G445-G453.

Hambright KD (1991) Experimental analysis of prey selection by largemouth bass: role of predator mouth width and prey body depth. Transactions of the American Fisheries Society 120: 500508.

Hamlin HJ, Hunt von Herbing I, Kling LJ (2000) Histological and morphological evaluations of the digestive tract and associated organs of haddock throughout post-hatching ontogeny. Journal of Fish Biology 57: 716-732.

Hamre K (2006) Nutrition of cod (Gadus morhua) larvae and juveniles. ICES Journal of Marine Science 63: 267-274.

Hamre K, Lukram IM, Rønnestad I, Nordgreen A, Sæle $\varnothing$ (2011) Pre-digestion of dietary lipids has only minor effects on absorption, retention and metabolism in larval stages of Atlantic cod (Gadus morhua). British Journal of Nutrition 105: 846-856.

Hamre K, Yúfera M, Rønnestad I, Boglione C, Conceição LEC, Izquierdo M (2012) Fish larval nutrition and feed formulation - knowledge gaps and bottlenecks for advances in larval rearing. Reviews in Aquaculture 5: s26-s58.

Hansen JM, Lazo JP, Kling LJ (2009) A method to determine protein digestibility of microdiets for larval and early juvenile fish. Aquaculture Nutrition 15: 615-626.

Hara TJ (1993) Chemoreception. In: Evans DH (ed.) The Physiology of Fish, pp. 191-218. CRC Press, Boca Raton.

Hara TJ (2005) Olfactory responses to amino acids in rainbow trout: revisited. In: Reutter K, Kapoor BG (eds) Fish Chemosenses, pp. 31-64. Science Publishers, Inc. Enfield, NH.

Hara TJ, Zielinski B (1989) Structural and functional development of the olfactory organs in teleosts. Transactions of the American Fisheries Society 118: 183-194.

Harboe T, Mangor-Jensen A, Moren M, Hamre K, Rønnestad I (2009) Control of light condition affects the feeding regime and enables successful eye migration in Atlantic halibut juveniles. Aquaculture 290: 250-255.

Hartviksen MB, Kamisaka Y, Jordal AEO, Koedijk RM, Rønnestad I (2009) Distribution of cholecystokinin-immunoreactive cells in the gut of developing Atlantic cod Gadus morhua L. larvae fed zooplankton or rotifers. Journal of Fish Biology 75: 834-844.

Harvey R, Blaxter JHS, Hoyt RD (1992) Development of superficial and lateral line neuromasts in larvae and juveniles of plaice (Pleuronectes platessa) and sole (Solea solea). Journal of 
the Marine Biological Association in the United Kingdom 72: 651-668.

Heimeier RA, Das B, Buchholz DR, Fiorentino M, Shi YB (2010) Studies on Xenopus laevis intestine reveal biological pathways underlying vertebrate gut adaptation from embryo to adult. Genome Biology 11: R55.

Helvik JV, Drivenes $\varnothing$, Harboe T, Seo HC (2001) Topography of different photoreceptor cell types in the larval retina of Atlantic halibut (Hippoglossus hippoglossus). Journal of Experimental Biology 204: 2553-2559.

Henning SJ (1979) Biochemistry of intestinal development. Environmental Health Perspectives 33: 9-16.

Hernell O, Blackberg L, Chen Q, Sternby B, Nilsson A (1993) Does the bile salt-stimulated lipase of human-milk have a role in the use of the milk long-chain polyunsaturated fatty-acids. Journal of Pediatric Gastroenterology and Nutrition 16: 426431.

Higgs DM, Fuiman LA (1996) Ontogeny of visual and mechanosensory structure and function in Atlantic menhaden Brevoortia tyrannus. Journal of Experimental Biology 199: 2619-2629.

Hjelmeland K, Pedersen BH, Nilssen EM (1988) Trypsin content in intestines of herring larvae, Clupea harengus, ingesting inert polystyrene spheres or live crustacea prey. Journal of Marine Biology 98: 331-335.

Hoehne-Reitan K, Kjørsvik E (2004) Functional development of the liver and exocrine pancreas in teleost fish. American Fisheries Society Symposium 40: 9-36.

Hoehne-Reitan K, Kjørsvik E, Gjellesvik DR (2001a) Development of bile salt-dependent lipase in larval turbot. Journal of Fish Biology 58: 737-745.

Hoehne-Reitan K, Kjørsvik E, Reitan KI (2001b) Development of the $\mathrm{pH}$ in the intestinal tract of larval turbot. Marine Biology 139: 1159-1164.

Holmberg A, Schwerte T, Fritsche R, Pelster B, Holmgren S (2003) Ontogeny of intestinal motility in correlation to neuronal development in zebrafish embryos and larvae. Journal of Fish Biology 63: 318-331.

Holmberg A, Schwerte T, Pelster B, Holmgren S (2004) Ontogeny of the gut motility control system in zebrafish Danio rerio embryos and larvae. Journal of Experimental Biology 207: 4085-4094.

Holmberg A, Holmgren S, Olsson C (2008) Enteric control. In: Finn RN, Kapoor BG (eds) Fish Larval Physiology, pp. 553 572. Science Publishers, Enfield, NH.

Holt GJ (2011) Larval Fish Nutrition. John Wiley and Sons, Chichester, UK.

Hölttä-Vuori M, Salo VT, Nyberg L et al. (2010) Zebrafish: gaining popularity in lipid research. Biochemical Journal 429: 235-242.

Hughes SG (1985) Nutritional eye diseases in salmonids: a review. The Progressive Fish-Culturist 47: 81-85.

Hunt von Herbing I, Gallager SM (2000) Foraging behavior in early Atlantic cod larvae (Gadus morhua) feeding on a protozoa (Balanion sp.) and a copepod nauplius (Pseudodiaptomus sp.). Marine Biology 136: 591-602.
Hunt von Herbing I, Gallager SM, Halteman W (2001) Metabolic cost of pursuit and attack in early larval Atlantic cod. Marine Ecology Progress Series 216: 201-212.

Hunter JR (1981) Feeding ecology and predation of marine fish larvae. In: Lasker R (ed.) Marine Fish Larvae: Morphology, Ecology, and Relation to Fisheries, pp. 33-77. Washington Sea Grant Program, Seattle.

Ishizuya-Oka A, Shi YB (2005) Molecular mechanisms for thyroid hormone-induced remodeling in the amphibian digestive tract: a model for studying organ regeneration. Development, Growth and Differentiation 47: 601-607.

Iwai T (1980) Sensory anatomy and feeding of fish larvae. In: Bardach JE, Magnuson JJ, May RC, Reinhart JM (eds) Fish Behavior and Its Use in the Capture and Culture of Fishes. ICLARM Conference Proceedings 5, International Centre for Living Aquatic Resources Management, pp. 124-145, Manila, Philippines.

Izquierdo MS, Henderson RJ (1998) The determination of lipase and phospholipase activities in gut contents of turbot (Scophthalmus maximus) by fluorescence-based assays. Fish Physiology and Biochemistry 19: 153-162.

Izquierdo MS, Socorro J, Arantzamendi L, Hernández-Cruz CM (2000) Recent advances in lipid nutrition in fish larvae. Fish Physiology and Biochemistry 22: 97-107.

Johnson RB, Cook MA, Nicklason PM, Rust MB (2009) Determination of apparent protein digestibility of live Artemia and a microparticulate diet in 8-week-old Atlantic cod Gadus morhua larvae. Aquaculture 288: 290-298.

Johnston IA (2006) Environment and plasticity of myogenesis in teleost fish. Journal of Experimental Biology 209: 2249-2264.

Jones WR, Janssen J (1992) Lateral line development and feeding behavior in the mottled sculpin, Cottus bairdi (Scorpaeniformes: Cottidae). Copeia 2: 485-492.

Kaji T, Tanaka M, Oka M et al. (1999) Growth and morphological development of laboratory-reared yellowfin tuna Thunnus albacares larvae and early juveniles, with special emphasis on the digestive system. Fisheries Science 65: 700-707.

Kamaci HO, Suzer C, Coban D, Saka S, Firat K (2010) Organogenesis of exocrine pancreas in sharpsnout sea bream (Diplodus puntazzo) larvae: characterization of trypsin expression. Fish Physiology and Biochemistry 36: 993-1000.

Kamisaka Y, Rønnestad I (2011) Reconstructed 3D models of digestive organs of developing Atlantic cod (Gadus morhua) larvae. Marine Biology 158: 233-243.

Kamisaka Y, Totland GK, Tagawa M et al. (2001) Ontogeny of cholecystokinin-immunoreactive cells in the digestive tract of Atlantic halibut, Hippoglossus hippoglossus, larvae. General and Comparative Endocrinology 123: 31-37.

Kamisaka Y, Kaji T, Masuma S et al. (2002) Ontogeny of cholecystokinin-immunoreactive cells in the digestive tract of bluefin tuna, Thunnus thynnus, larvae. Sarsia 87: 258-262.

Kamisaka Y, Fujii Y, Yamamoto S et al. (2003) Distribution of cholecystokinin-immunoreactive cells in the digestive tract of the larval teleost, ayu, Plecoglossus altivelis. General and Comparative Endocrinology 134: 116-121. 
Kamisaka Y, Drivenes Ø, Kurokawa T et al. (2005) Cholecystokinin mRNA in Atlantic herring, Clupea harengus - molecular cloning, characterization, and distribution in the digestive tract during the early life stages. Peptides 26: 385-393.

Kamisaka Y, Jordal A-EO, Edvardsen RB, Kryvi H, Otterlei E, Rønnestad I (2010) A case report on the distended gut syndrome (DGS) in cultured larvae of Atlantic cod (Gadus morhua). Aquaculture 309: 38-48.

Kane J (1984) The feeding habits of co-occurring cod and haddock larvae. Marine Ecology Progress Series 16: 9-20.

Kasumyan AO, Kazhlayev AA (1993) Behavioral responses of early juveniles of Siberian sturgeon, Acipenser baeri, and stellate sturgeon, A. stellatus (Acipenseridae). Journal of Ichthyology 33: 85-97.

Katavić I (1986) Diet involvement in mass mortality of sea bass (Dicentrarchus labrax) larvae. Aquaculture 58: 45-54.

Kato K, Ishimaru K, Sawada Y et al. (2004) Ontogeny of the digestive and immune system organs of larval and juvenile kelp grouper Epinephelus bruneus reared in the laboratory. Fisheries Science 70: 1061-1069.

Kawamura G, Tsuda R, Kumai H, Ohashi S (1984) The visual cell morphology of Pagrus major and its adaptive changes with shift from pelagic to benthic habitats. Bulletin of the Japanese Society of Scientific Fisheries 50: 1975-1980.

Kawamura G, Masuma S, Tezuka N, Koiso M, Jimbo T, Namba $\mathrm{K}$ (2003) Morphogenesis in sense organs in the bluefin tuna Thunnus orientalis. In: Browman HJ, Skiftesvik AB (eds) The Big Fish Bang. Proceedings of the 26th Annual Larval Fish Conference, pp. 123-135. Institute of Marine Research, Bergen.

Keil B. (1971) Trypsin. In: Boyer PD (ed) The Enzymes, Vol. III, 3rd edn, pp. 249-275 (BU). Academic Press Inc., New York and London.

Kim BG, Divakaran S, Brown CL, Ostrowski AC (2001) Comparative digestive enzyme ontogeny in two marine larval fishes: Pacific threadfin (Polydactylus sexfilis) and bluefin trevally (Caranx melampygus). Fish Physiology and Biochemistry 24: 225-241.

Kitajima C, Tsushima Y, Fujita S, Yone Y (1981) Relationship between uninflated swimbladders and lordotic deformity in hatchery reared red sea bream (Pagrus major). Bulletin of the Japanese Society of Scientific Fisheries 47: 1289-1294.

Kjørsvik E, van der Meeren T, Kryvi H, Arnfinnson J, Kvenseth PG (1991) Early development of the digestive tract of cod larvae, Gadus morhua L, during start-feeding and starvation. Journal of Fish Biology 38: 1-15.

Knutsen JA (1992) Feeding behaviour of North Sea turbot (Scophthalnus maximus) and Dover sole (Solea solea) larvae elicited by chemical stimuli. Marine Biology 113: 543-548.

Kohno H, Taki Y, Ogasawara Y, Shirijo Y, Taketomi M, Inoue M (1983) Development of swimming and feeding functions in larval Pagrus major. Japanese Journal of Ichthyology 30: 4760.

Kolkovski S (2001) Digestive enzymes in fish larvae and juveniles - implications and applications to formulated diets. Aquaculture 200: 181-201.
Kolkovski S, Arieli A, Tandler A (1997a) Visual and chemical cues stimulate microdiet ingestion in sea bream larvae. Aquaculture International 5: 527-536.

Kolkovski S, Koven W, Tandler A (1997b) The mode of action of Artemia in enhancing utilization of microdiet by gilthead seabream Sparus aurata larvae. Aquaculture 155: 193-205.

Kolkovski S, Tandler A, Izquierdo MS (1997c) Effects of live food and dietary digestive enzymes on the efficiency of microdiets for seabass (Dicentrarchus labrax) larvae. Aquaculture 148: 313-322.

Kolkovski S, Szesny S, Dabrowski K (2000) Use of krill hydrolysate as feed attractant for fish larvae and juvenile. Journal of the World Aquaculture Society 31: 81-88.

Kortner TM, Overrein I, Øie G, Kjørsvik E, Arukwe A (2011a) The influence of dietary constituents on the molecular ontogeny of digestive capability and effects on growth and appetite in Atlantic cod larvae (Gadus morhua). Aquaculture 315: 114120.

Kortner TM, Overrein I, Øie G et al. (2011b) Molecular ontogenesis of digestive capability and associated endocrine control in Atlantic cod (Gadus morhua) larvae. Comparative Biochemistry and Physiology A 160: 190-199.

Kotani T, Fushimi H (2011) Determination of appropriate feeding schedule from diel feeding rhythm in finfish larviculture. Aquaculture 315: 104-113.

Koumoundouros G, Divanach P, Kentouri M (2000) Development of the skull in Dentex dentex (Ostheichthyes: Sparidae). Marine Biology 136: 175-184.

Koven W, Rojas-García CR, Finn RN, Tandler A, Rønnestad I (2002) Stimulatory effect of ingested protein and/or free amino acids on the secretion of the gastro-endocrine hormone cholecystokinin and on tryptic activity, in earlyfeeding herring larvae, Clupea harengus. Marine Biology 140: 1241-1247.

Kurokawa T, Suzuki T, Andoh T (2000) Development of cholecystokinin and pancreatic polypeptide endocrine systems during the larval stage of Japanese flounder, Paralichthys olivaceus. General and Comparative Endocrinology 120: 8-16.

Kurokawa T, Suzuki T, Hashimoto H (2003) Identification of gastrin and multiple cholecystokinin genes in teleost. Peptides 24: $227-235$.

Kurokawa T, Uji S, Suzuki T (2004) Molecular cloning of multiple chitinase genes in Japanese flounder, Paralichthys olivaceus. Comparative Biochemistry and Physiology B 138: 255-264.

Kvåle A, Yúfera M, Nygård E, Aursland K, Harboe T, Hamre K (2006) Leaching properties of three different micropaticulate diets and preference of the diets in cod (Gadus morhua L.) larvae. Aquaculture 251: 402-415.

Kvåle A, Mangor-Jensen A, Moren M, Espe M, Hamre K (2007) Development and characterisation of some intestinal enzymes in Atlantic cod (Gadus morhua L.) and Atlantic halibut (Hippoglossus hippoglossus L.) larvae. Aquaculture 264: 457-468.

Lamarre SG, Le Francois NR, Lemieux H, Falk-Petersen I-B, Blier PU (2007) The digestive and metabolic enzyme activity profiles of a nonmetamorphic marine fish species: effects of 
feed type and feeding level. Canadian Journal of Fisheries and Aquatic Sciences 64: 849-856.

Lauff M, Hofer R (1984) Proteolytic-enzymes in fish development and the importance of dietary enzymes. Aquaculture 37: 335-346.

Lazo JP, Holt GJ, Arnold CR (2000) Ontogeny of pancreatic enzymes in larval red drum Sciaenops ocellatus. Aquaculture Nutrition 6: 183-192.

Lazo JP, Mendoza R, Holt GJ, Aguilera C, Arnold CR (2007) Characterization of digestive enzymes during larval development of red drum (Sciaenops ocellatus). Aquaculture 265: 194 205.

Levy E, Ménard D, Delvin E et al. (2001) The polymorphism at codon 54 of the FABP2 gene increases fat absorption in human intestinal explants. Journal of Biological Chemistry 276: 39679-39684.

Liddle RA (1997) Cholecystokinin cells. Annual Review of Physiology 59: 221-242.

Lie Ø, Lambertsen G (1985) Digestive lipolytic enzymes in cod (Gadus morhua) - fatty-acid specificity. Comparative Biochemistry and Physiology B 80: 447-450.

Lie $\varnothing$, Lied E, Lambertsen G (1987) Lipid digestion in cod (Gadus morhua). Comparative Biochemistry and Physiology B 88: 697-700.

Lied E, Solbakken R (1984) The course of protein digestion in Atlantic cod (Gadus morhua). Comparative Biochemistry and Physiology A 77: 503-506.

Lin XW, Volkoff H, Narnaware Y, Bernier NJ, Peyon P, Peter RE (2000) Brain regulation of feeding behavior and food intake in fish. Comparative Biochemistry and Physiology A 126: $415-434$.

Lo M-J, Weng C-F (2006) Developmental regulation of gastric pepsin and pancreatic serine protease in larvae of the euryhaline teleost, Oreochromis mossambicus. Aquaculture 261: 1403 1412.

Lodish H, Berk A, Zipursky SL, Matsudaira P, Darnell J (2000) Molecular Cell Biology, 4th edn. W.H. Freeman and Company, New York.

Lopez-Alvarado J, Langdon CJ, Teshima S-I, Kanazawa A (1994) Effects of coating and encapsulation of crystalline amino acids on leaching in larval feeds. Aquaculture 122: 335-346.

Luizi FS, Gara B, Shields RJ, Bromage NR (1999) Further description of the development of the digestive organs in Atlantic halibut (Hippoglossus hippoglossus) larvae, with notes on differential absorption of copepod and Artemia prey. Aquaculture 176: 101-116.

Ma P, Sivaloganathan B, Reddy PK, Chan WK, Lam TJ (2001) Ontogeny of $\alpha$-amylase gene expression in sea bass larvae (Lates calcarifer). Marine Biotechnology 3: 463-469.

Ma HM, Cahu C, Zambonino J et al. (2005) Activities of selected digestive enzymes during larval development of large yellow croaker (Pseudosciaena crocea). Aquaculture 245: 239248.

Ma AJ, Liu XZ, Xu YJ, Liang Y, Zhuang ZM (2006) Feeding rhythm and growth in the tongue sole, Cnoglossus semilaevis
Günther, during its early life stages. Aquaculture Research 37: 586-593.

Mackenzie BR, Ueberschär B, Basford B, Heath M, Gallego A (1999) Diel variability of feeding activity in haddock (Melanogrammus aeglefinus) larvae in the East Shetland area, North Sea. Marine Biology 138: 361-368.

Mai K, Yu H, Ma H et al. (2005) A histological study on the development of the digestive system of Pseudosciaena crocea larvae and juveniles. Journal of Fish Biology 67: 1094-1106.

Mana RR, Kawamura G (2002) A comparative study on morphological differences in the olfactory system of red sea bream (Pagrus major) and black sea bream (Acanthopagrus schlegeli) from wild and cultured stocks. Aquaculture 209: 285-306.

Mansbach CM (2000) Triacylglycerol movement in enterocytes. In: Mansbach CM, Tso P, Kuksis A (eds) Intestinal Lipid Metabolism, pp. 215-229. Kluwer Academic/Plenum Publishers, New York.

Margulies D (1993) Assessment of the nutritional condition of larval and early juvenile tuna and Spanish mackerel (Pisces: Scombridae) in the Panamá Bight. Marine Biology 115: 317330.

Márquez L, Robles R, Morales GA, Moyano FJ (2012) Gut pH as a limiting factor for digestive proteolysis in cultured juveniles of gilthead sea bream (Sparus aurata). Fish Physiology and Biochemistry 38: 859-869.

Marsh-Armstrong N, McCaffery P, Gilbert W, Dowling JE, Dräger UC (1994) Retinoic acid is necessary for development of ventral retina in zebrafish. Proceedings of the National Academic of Science USA 91: 7286-7290.

Martínez I, Moyano FJ, Fernández-Díaz C, Yúfera M (1999) Digestive enzyme activity during larval development of Senegal sole (Solea senegalensis). Fish Physiology and Biochemistry 21: 317-323.

Marui T, Caprio J (1992) Teleost gustation. Fish and Fisheries Series 6: 171-198.

Marza E, Barthe C, André M, Villeneuve L, Hélou C, Babin PJ (2005) Developmental expression and nutritional regulation of a zebrafish gene homologous to mammalian microsomal triglyceride transfer protein large subunit. Developmental Dynamics 232 (2): 506-518.

Mazurais D, Darias M, Zambonino-Infante JL, Cahu CL (2011) Transcriptomics for understanding marine fish larval development. Canadian Journal of Zoology 89: 599-611.

McLaren IA, Avendano P (1995) Prey field and diet of larval cod on Western Bank, Scotian Shelf. Canadian Journal of Fishery and Aquatic Sciences 52: 448-463.

Micale V, Garaffo M, Genovese L, Spedicato MT, Muglia U (2006) The ontogeny of the alimentary tract during larval development in common pandora Pagellus erythrinus L. Aquaculture 251: 354-365.

Micale V, Di Giancamillo A, Domeneguini C et al. (2008) Ontogeny of the digestive tract during in the sharpsnout sea bream Diplodus puntazzo (Cetti, 1777). Histology and Histopathology 23: 1077-1091. 
Micale V, Levanti MB, Germana A, Guerrera MC, Kurokawa T, Muglia U (2010) Ontogeny and distribution of cholecystokinin-immuno reactive cells in the digestive tract of sharpsnout sea bream, Diplodus puntazzo (Cetti, 1777), during larval development. General and Comparative Endocrinology 169: 23-27.

Morais S, Conceição LEC, Dinis MT, Rønnestad I (2004a) A method for radiolabeling Artemia with applications in studies of food intake, digestibility, protein and amino acid metabolism in larval fish. Aquaculture 231: 469-487.

Morais S, Lacuisse M, Conceição LEC, Dinis MT, Rønnestad I (2004b) Ontogeny of the digestive capacity of (Solea senegalensis), with respect to and metabolism of amino acids from Senegalese sole digestion, absorption Artemia. Marine Biology 145: 243-250.

Morais S, Conceição LEC, Rønnestad I et al. (2007) Dietary neutral lipid level and source in marine fish larvae: effects on digestive physiology and food intake. Aquaculture 268: 106122.

Moyano FJ, Díaz M, Alarcón FJ, Sarasquete MC (1996) Characterization of digestive enzyme activity during larval development of gilthead seabream (Sparus aurata). Fish Physiology and Biochemistry 15: 121-130.

Mukai Y, Yoshikawa H, Kobayashi H (1994) The relationship between the length of the cupulae of free neuromasts and feeding ability in larvae of the willow shiner Gnathopogon elongatus caerulescens (Teleostei, Cyprinidae). Journal of Experimental Biology 197: 399-403.

Mukai Y, Tuzan AD, Lim LS, Wahid N, Sitti Raehanah MS, Senoo S (2008) Development of sensory organ in larvae of African catfish Clarias gariepinus. Journal of Fish Biology 73: 1648-1661.

Murakami M, Kudo I (2002) Phospholipase A2. Journal of Biochemistry 101: 285-292.

Murashita K, Jordal A-EO, Nilsen TO et al. (2011) Leptin reduces Atlantic salmon growth through the central proopiomelanocortin pathway. Comparative Biochemistry and Physiology A 158: 79-86.

Murray HM, Gallant JW, Perez-Casanova JC, Johnson SC, Douglas SE (2003) Ontogeny of lipase expression in winter flounder. Journal of Fish Biology 62: 816-833.

Murray HM, Perez-Casanova JC, Gallant JW, Johnson SC, Douglas SE (2004) Trypsinogen expression during the development of the exocrine pancreas in winter flounder (Pleuronectes americanus). Comparative Biochemistry and Physiology A 138: 53-59.

Murray HM, Gallant JW, Johnson SC, Douglas SE (2006) Cloning and expression analysis of three digestive enzymes from Atlantic halibut (Hippoglossus hippoglossus) during early development: predicting gastrointestinal functionality. Aquaculture 252: 394-408.

Myrberg AA Jr, Fuiman LA (2002) The sensory world of coral reef fishes. In: Sale PF (ed.) Coral Reef Fishes, pp. 123-148. Elsevier Press, Academic Press, NY.
Narawane S (2011) Exploring the role of cationic amino acid transporters in zebrafish organogenesis. PhD Thesis. University of Bergen, Bergen, Norway.

Ng A, Dejongcurtain T, Mawdsley D et al. (2005) Formation of the digestive system in zebrafish: III. Intestinal epithelium morphogenesis. Developmental Biology 286: 114-135.

Nielsen CU, Brodin B (2003) Di/tri-peptide transporters as drug delivery targets: regulation of transport under physiological and patho-physiological conditions. Current Drug Targets 4: 373-388.

Noakes DLG, Godin JGJ (1988) Ontogeny of behaviour and concurrent development changes in sensory systems in teleost fishes. In: Hoar WS, Randall DJ (eds) Fish Physiology XIB. Viviparity and Posthatching Juveniles, pp. 345-395. Academic Press, New York.

Nordgreen A, Tonheim S, Hamre K (2009) Protein quality of larval feed with increased concentration of hydrolysed protein: effects of heat treatment and leaching. Aquaculture Nutrition 15: 525-536.

O'Connell CP (1981) Development of organ systems in the northern anchovy Engraulis mordax and other teleosts. American Zoologist 21: 429-446.

Olsen AI, Attramadal Y, Reitan KI, Olsen Y (2000) Food selection and digestion characteristics of Atlantic halibut (Hippoglossus hippoglossus) larvae fed cultivated prey organisms. Aquaculture 181: 293-310.

Olsson C, Holmberg A, Holmgren S (2008) Development of enteric and vagal innervation of the zebrafish (Danio rerio) gut. Journal of Comparative Neurology 508: 756-770.

Önal U, Langdon C, Çelik Í (2008) Ontogeny of the digestive tract of larval percula clownfish, Amphypriom percula (Lacépède 1802): a histological perspective. Aquaculture Research 39: 1077-1086.

Oozeki Y, Bailey KM (1995) Ontogenic development of digestive enzyme-activities in larval walleye pollock, Theragra chalcogramma. Marine Biology 122: 177-186.

Ortiz-Delgado JB, Darias MJ, Cañavate JP, Yúfera M, Sarasquete C (2003) Organogenesis of the digestive tract in the white seabream, Diplodus sargus. Histological and histochemical approaches. Histology and Histopathology 18: 1141-1154.

Osse JWM, van den Boogaart JGM (1999) Dynamic morphology of fish larvae, structural applications of friction forces in swimming, feeding and ventilation. Journal of Fish Biology 55 (Suppl. A): 156-174.

Ostaszewska T, Dabrowski K, Hliwa P, Gomółka P, Kwasek K (2008) Nutritional regulation of intestine morphology in larval cyprinid fish, silver bream (Vimba vimba). Aquaculture Research 39: 1268-1278.

Ostaszewska T, Kamaszewski M, Grochowski P et al. (2010) The effect of peptide absorption on PepT1 gene expression and digestive system hormones in rainbow trout (Oncorhynchus mykiss). Comparative Biochemistry and Physiology A 156: 107114. 
Østergaard P, Munk P, Janekarn V (2005) Contrasting feeding patterns among species of fish larvae from the tropical Andaman sea. Marine Biology 146: 595-606.

Ou Y, Luo J, Li J (2011) Distribution and cryopreservation of alkaline phosphatase(AKP) and acid phosphatase (ACP) in Trachinotus ovatus. South China Fisheries Science 7 (2): 49-54. doi:10.3969/j.issn.2095-0780.2011.02.008.

Oxley A, Jutfelt F, Sundell K, Olsen RE (2007) Sn-2-monoacylglycerol, not glycerol, is preferentially utilised for triacylglycerol and phosphatidylcholine biosynthesis in Atlantic salmon (Salmo salar L.) intestine. Comparative Biochemistry and Physiology B 146: 115-123.

Pankhurst PM (2008) Mechanoreception. In: Finn RN, Kapoor BG (eds) Fish Larval Physiology, pp. 305-329. Science Publisher, Enfield, NH.

Pavlov DV, Kasumyan AO (1990) Study of fish behavior and sensory systems in Russia. Journal of Ichthyology 34: 1-26.

Pedersen BH, Andersen KP (1992) Induction of trypsinogen secretion in herring larvae (Clupea harengus). Marine Biology 112: 559-565.

Pedersen BH, Hjelmeland K (1988) Fate of trypsin and assimilation efficiency in larval herring (Clupea harengus) following digestion of copepods. Marine Biology 97: 467-476.

Péres A, Zambonino-Infante JL, Cahu C (1998) Dietary regulation of activities and mRNA levels of trypsin and amylase in sea bass (Dicentrarchus labrax) larvae. Fish Physiology and Biochemistry 19: 145-152.

Perez-Casanova JC, Murray HM, Gallant JW, Ross NW, Douglas SE, Johnson SC (2004) Bile salt-activated lipase expression during larval development in the haddock (Melanogrammus aeglefinus). Aquaculture 235: 601-617.

Perez-Casanova JC, Murray HM, Gallant JW, Ross NW, Douglas SE, Johnson SC (2006) Development of the digestive capacity in larvae of haddock (Melanogrammus aeglefinus) and Atlantic cod (Gadus morhua). Aquaculture 251: 377-401.

Pinto W, Rønnestad I, Jordal A-E, Gomes AS, Dinis M, Aragão C (2012) Cloning, tissue and ontogenetic expression of the taurine transporter in the flatfish Senegalese sole (Solea senegalensis). Amino Acids 42: 1317-1327.

Poling KR, Fuiman LA (1998) Sensory development and its relation to habitat change in three species of sciaenids. Brain, Behavior and Evolution 52: 270-284.

Polo A, Yúfera M, Pascual E (1992) Feeding and growth of gilthead seabream (Sparus aurata, L.) larvae in relation to the size of the rotifer strain used as food. Aquaculture 103: 45-54.

Puvanendran V, Salies K, Laurel B, Brown JA (2004) Sizedependent foraging on larval Atlantic cod (Gadus morhua). Canadian Journal of Zoology 82: 1380-1389.

Qin JG, Hillier T (2000) Live food and feeding ecology of larval snapper (Pagrus auratus). Hatchery Feeds: Proceedings of a Workshop, Cairns, pp. 63-68.

Ramalho-Santos M, Melton DA, McMahon AP (2000) Hedgehog signals regulate multiple aspects of gastrointestinal development. Development 127: 2763-2772.
Rathore RM, Kumar S, Chakrabarti R (2005) Digestive enzyme patterns and evaluation of protease classes in Catla catla (Family: Cyprinidae) during early developmental stages. Comparative Biochemistry and Physiology B 142: 98-106.

Rawdon BB (2001) Morphogenesis of gut and distribution of the progenitors of gut endocrine cells at cranial somite levels of the chick embryo. Developmental Dynamics 222: 153-164.

Reitan KI, Rainuzzo JR, Øie G, Olsen Y (1997) A review of the nutritional effects of algae in marine fish larvae. Aquaculture 155: 207-221.

Ribeiro L, Zambonino-Infante JL, Cahu C, Dinis MT (1999) Development of digestive enzymes in larvae of Solea senegalensis, Kaup 1858. Aquaculture 179: 465-473.

Ribeiro L, Zambonino-Infante JL, Cahu C, Dinis MT (2002) Digestive enzyme profile of Solea senegalesis post-larvae fed Artemia and compound diet. Fish Physiology and Biochemistry 27: 61-69.

Ribeiro L, Couto A, Olmedo M, Álvarez-Blázquez B, Linares F, Valente LMP (2008) Digestive enzyme activity at different developmental stages of blackspot seabream, Pagellus bogaraveo (Brunnich 1768). Aquaculture Research 39: 339-346.

Ribeiro L, Hubbert F, Rodrigues V et al. (2009) Live food replacement with compound diet during Solea senegalensis development: consequences on the digestive process. European Aquaculture Society, Special Publication 38: 362-365.

Richmond BL, Boileau AC, Zheng SQ et al. (2001) Compensatory phospholipid digestion is required for cholesterol absorption in pancreatic phospholipase $\mathrm{A}(2)$-deficient mice. Gastroenterology 120: 1193-1202.

Rocha RJ, Ribeiro L, Costa R, Dinis MT (2008) Does the presence of microalgae influence fish larvae prey capture? Aquaculture Research 39: 362-369.

Rodríguez C, Pérez JA, Badia P, Izquierdo MS, Fernández-Palacios H, Hernández AL (1998) The n-3 highly unsaturated fatty acids requirements of gilthead seabream (Sparus aurata L.) larvae when using an appropriate DHA/EPA ratio in the diet. Aquaculture 169: 9-23.

Rojas-García CR, Rønnestad I (2002) Cholecystokinin and tryptic activity in the gut and body of developing Atlantic halibut larvae: evidence for participation in the regulation of protein digestion. Journal of Fish Biology 61: 973-986.

Rojas-García CR, Rønnestad I (2003) Assimilation of dietary free amino acids, peptides and protein in post-larval Atlantic halibut (Hippoglossus hippoglossus). Marine Biology 142: 801-808.

Rojas-García CR, Rønnestad I, Ueberschar B (2001) Combined sensitive analytical methods for cholecystokinin levels and tryptic activity in individual fish larvae. Journal of Experimental Marine Biology and Ecology 265: 101-115.

Rojas-García CR, Morais S, Rønnestad I (2011) Cholecystokinin (CCK) in Atlantic herring (Clupea harengus L.) - Ontogeny and effects of feeding and diurnal rhythms. Comparative Biochemistry and Physiology A 158: 455-460. 
Rombout JHWM, Stroband HWJ, Taverne-Thiele JJ (1984) Proliferation and differentiation of intestinal epithelial cells during development of Barbus conchonius (Teleostei, Cyprinidae). Cell and Tissue Research 236: 207-216.

Romero-Romero S, Yúfera M (2012) Contribution of gut content to the nutritional value of Brachionus plicatilis used as prey in larviculture. Aquaculture 364-365: 124-129.

Rønnestad I (2002) Control and efficiency of digestive function of marine fish larvae. In: Cruz-Suárez LE, Ricque-Marie D, Tapia-Salazar M, Gaxiola-Cortés MG, Simoes N (eds) Avances en Nutrición Acuícola, pp. 152-165. Cancún, Quintana Roo, México.

Rønnestad I, Conceição LEC (2005) Aspects of protein and amino acid digestion and utilization by marine fish larvae. In: Starck JM, Wang T (eds) Physiological and Ecological Adaptations to Feeding in Vertebrates, pp. 389-416. Science Publishers, Enfield, NH.

Rønnestad I, Conceição LEC (2012) Artemia protein is processed very fast in Solea senegalensis larvae: a dynamic simulation model. Aquaculture 350: 154-161.

Rønnestad I, Morais SJ (2008) Digestion. In: Finn RN, Kapoor BG (eds) Fish Larval Physiology, pp. 201-262. Science Publisher, Enfield, NH.

Rønnestad I, Thorsen A, Finn RN (1999) Fish larval nutrition: a review of recent advances in the roles of amino acids. Aquaculture 177: 201-216.

Rønnestad I, Conceição LEC, Aragão C, Dinis MT (2000a) Free amino acids are absorbed faster and assimilated more efficiently than protein in postlarval Senegal sole (Solea senegalensis). Journal of Nutrition 130: 2809-2812.

Rønnestad I, Dominguez RP, Tanaka M (2000b) Ontogeny of digestive tract functionality in Japanese flounder, Paralichthys olivaceus studied by in vivo microinjection: $\mathrm{pH}$ and assimilation of free amino acids. Fish Physiology and Biochemistry 22: 225-235.

Rønnestad I, Rojas-García CR, Skadal J (2000c) Retrograde peristalsis; a possible mechanism for filling the pyloric caeca? Journal of Fish Biology 56: 216-218.

Rønnestad I, Conceição LEC, Aragão C, Dinis MT (2001a) Assimilation and catabolism of dispensable and indispensable free amino acids in post-larval Senegal sole (Solea senegalensis). Comparative Biochemistry and Physiology $C$ 130: 461-466.

Rønnestad I, Rojas-García CR, Tonheim SK, Conceição LEC (2001b) In vivo studies of digestion and nutrient assimilation in marine fish larvae. Aquaculture 201: 161-175.

Rønnestad I, Tonheim SK, Fyhn HJ et al. (2003) The supply of amino acids during early feeding stages of marine fish larvae: a review of recent findings. Aquaculture 227: 147-164.

Rønnestad I, Gavaia PJ, Viegas CSB et al. (2007a) Oligopeptide transporter PepT1 in Atlantic cod (Gadus morhua L.): cloning, tissue expression and comparative aspects. Journal of Experimental Biology 210: 3883-3896.

Rønnestad I, Kamisaka Y, Conceição LEC, Morais S, Tonheim SK (2007b) Digestive physiology of marine fish larvae: hor- monal control and processing capacity for proteins, peptides and amino acids. Aquaculture 268: 82-97.

Rønnestad I, Murashita K, Kottra G et al. (2010) Molecular cloning and functional expression of Atlantic salmon peptide transporter 1 in Xenopus oocytes reveals efficient intestinal uptake of lysine-containing and other bioactive di- and tripeptides in teleost fish. Journal of Nutrition 140: 893-900.

Russo T, Boglione C, De Marzi P, Cataudella S (2009) Feeding preferences of the dusky grouper (Epinephelus marginatus, Lowe 1834) larvae reared in semi-intensive conditions: a contribution addressing the domestication of this species. Aquaculture 289: 289-296.

Rust MB, Hardy RW, Stickney RR (1993) A new method for force-feeding larval fish. Aquaculture 116: 341-352.

Saavedra M, Pousão-Ferreira P, Yúfera M, Dinis MT, Conceição LEC (2009) A balanced amino acid diet improves Diplodus sargus larval quality and reduces nitrogen excretion. Aquaculture Nutrition 15: 217-524.

Sæle Ø, Nordgreen A, Olsvik PA, Hamre K (2010) Characterization and expression of digestive neutral lipases during ontogeny of Atlantic cod (Gadus morhua). Comparative Biochemistry and Physiology A 157: 252-259.

Sæle Ø, Nordgreen A, Olsvik PA, Hamre K (2011) Characterisation and expression of secretory phospholipase A2 group IB during ontogeny of Atlantic cod (Gadus morhua). British Journal of Nutrition 105: 228-237.

Saenz de Rodrigañez MA, Gander B, Alaiz M, Moyano FJ (2011) Physico-chemical characterization and in vitro digestibility of commercial feeds used in weaning of marine fish. Aquaculture Nutrition 17: 429-440.

Salhi M, Hernandez-Cruz CM, Bessonart M, Izquierdo MS, Fernandez-Palacios H (1999) Effect of different dietary polar lipid levels and different n-3 HUFA content in polar lipids on gut and liver histological structure of gilthead seabream (Sparus aurata) larvae. Aquaculture 179: 253-263.

Sánchez-Amaya MI, Ortiz-Delgado JB, García-López A, Cárdenas S, Sarasquete C (2007) Larval ontogeny of redbanded seabream Pagrus auriga Valenciennes, 1843 with special reference to digestive system. A histological and histochemical approach. Aquaculture 263: 259-279.

Sánchez-Amaya MI, Yúfera M, Martínez-Rodríguez G (2009) Cloning and expression of digestives enzymes precursors during ontogeny in gilthead seabream (Sparus aurata) under different feeding conditions. European Aquaculture Society, Special Publication 38: 388-391.

Sangaletti R, Terova G, Peres A, Bossi E, Corà S, Saroglia M (2009) Functional expression of the oligopeptide transporter PepT1 from the sea bass (Dicentrarchus labrax). Pflügers Archives-European Journal of Physiology 459: 47-54.

Santamaría CA, Marín de Mateo M, Traveset R et al. (2004) Larval organogenesis in common dentex Dentex dentex L. (Sparidae): histological and histochemical aspects. Aquaculture 237: 207-228.

Sanz A, Llorente JI, Furné M et al. (2011) Digestive enzyme during ontogeny of the sturgeon Acipenser nacarii: intestine 
and pancreas development. Journal of Applied Ichthyology 27: 1139-1146.

Sarasquete MC, Polo A, Yúfera M (1993) Histochemistry of proteins, lipids and carbohydrates in the yolk constituents of oocytes, eggs and larvae of Sparus aurata L. In: Walther BT, Fyhn HJ (eds) Physiological and Biochemical Aspects of Fish Development, pp. 309-314. University of Bergen, Bergen.

Sarasquete MC, Polo A, Yúfera M (1995) Histology and histochemistry of the development of the digestive system of larval gilthead seabream Sparus aurata L. Aquaculture 130: 79-92.

Schreiber AM, Cai L, Brown DD (2005) Remodeling of the intestine during metamorphosis of Xenopus laevis. Proceedings of the National Academy of Sciences 102: 3720-3725.

Schreiber AM, Mukhi S, Brown DD (2009) Cell-cell interactions during remodeling of the intestine at metamorphosis in Xenopus laevis. Developmental Biology 331: 89-98.

Shand J, Hart NS, Thomas N, Partridge JC (2002) Developmental changes in the cone visual pigments of black bream Acanthopagrus butcheri. Journal of Experimental Biology 205: 3661-3667.

Sharma MK, Denovan-Wright EM, Degrave A, Thisse C, Thisse B, Wright JM (2004) Sequence, linkage mapping and early developmental expression of the intestinal-type fatty acidbinding protein gene (fabp2) from zebrafish (Danio rerio). Comparative Biochemistry and Physiology B 138: 391-398.

Shepherd I, Eisen J (2011) Development of the zebrafish enteric nervous system. In: Detrich HW, Westerfield M, Zon LI (eds) Methods in Cell Biology, Vol 101: Zebrafish: Cellular and Developmental Biology, 3rd edn, pp. 143-160. Elsevier Academic Press Inc, San Diego.

Shi Y-B, Ishizuya-Oka A (2001) Thyroid hormone regulation of apoptotic tissue remodeling: implications from molecular analysis of amphibian metamorphosis. Progress in Nuclei Acid Research and Molecular Biology 65: 53-100.

Shi YB, Hasebe T, Fu L, Fujimoto K, Ishizuya-Oka A (2011) The development of the adult intestinal stem cells: insights from studies on thyroid hormone-dependent amphibian metamorphosis. Cell and Biosciences 1: 30.

Shields RJ, Bell JG, Luizi FS, Gara B, Bromage NR, Sargent JR (1999) Natural copepods are superior to enriched Artemia nauplii as feed for halibut larvae (Hippoglossus hippoglossus) in terms of survival, pigmentation and retinal morphology: relation to dietary essential fatty acids. Journal of Nutrition 129: 1186-1194.

Shirota A (1970) Studies on the mouth size of fish larvae. Bulletin of the Japanese Society of Scientific Fisheries 36: 353-368.

Shoji J, Maehara T, Oiyama M, Fujimoto H, Iwamoto A, Tanaka M (2001) Daily ration of Japanese Spanish mackerel Scomberomorus niphonius larvae. Fisheries Science 67: 238-245.

Silverthorn DU (2004) Human Physiology: An Integrated Approach. Pearson Education Inc. Benjamin Cummings, San Francisco, CA.

Srivastava AS, Kurokawa T, Suzuki T (2002) mRNA expression of pancreatic enzyme precursors and estimation of protein digestibility in first feeding larvae of the Japanese flounder,
Paralichthys olivaceus. Comparative Biochemistry and Physiology A 132: 629-635.

Stroband HWJ, Debets FMH (1978) The ultrastructure and renewal of the intestinal epithelium of the juvenile grasscarp, Ctenopharyngodon idella (Val). Cell and Tissue Research 187: 181-200.

Strøttrup JG, Norsker NH (1997) Production and use of copepods in marine larviculture. Aquaculture 155: 231-247.

Suzer C, Saka S, Firat K (2006) Effects of illumination on early life development and digestive enzyme activities in common pandora Pagellus erythrinus L. larvae. Aquaculture 260: 8693.

Suzer C, Aktülün S, Çoban D et al. (2007a) Digestive enzyme activities in sharpsnout seabream (Diplodus puntazzo) larvae. Comparative Biochemistry and Physiology 148: 470-477.

Suzer C, Kamacı HO, Çoban D, Saka Ş, Fırat K, Ozkara B et al. (2007b) Digestive enzyme activity of the red porgy (Pagrus pagrus, L.) during larval development under culture conditions. Aquaculture Research 38: 1778-1785.

Suzer C, Firat K, Saka S, Karacoaglan A (2007c) Effect of early weaning on growth and digestive enzyme activity in larvae of sea bass (Dicentrarchus labrax L.). Israeli Journal of Aquaculture-Bamidgeh 59: 81-90.

Tanaka M (1969) Studies on the structure and function of the digestive system in teleost larvae-II. Characteristics of the digestive system in larvae at the stage of first feeding. Japanese Journal of Ichthyology 16: 41-49.

Tanaka M (1971) Studies on the structure and function of the digestive system in teleost larvae-III. Development of the digestive system during postlarval stage. Japanese Journal of Ichthyology 18: 164-174.

Tanaka M (1973) Studies on the structure and function of the digestive system of teleost larvae, PhD Thesis. Kyoto University, Kyoto.

Tanaka Y, Mukai Y, Takii K, Kumai H (1991) Chemoreception and vertical movement in planktonic yolk-sac larvae of red sea bream Pagrus major. Journal of Applied Ichthyology 7: 129135.

Tanaka M, Kaji T, Nakamura Y, Takahashi Y (1996) Developmental strategy of scombrid larvae: high growth potential related to food habits and precocious digestive system development. In: Watanabe Y, Yamashita Y, Oozeki AA (eds) Survival Strategies in Early Life Stages of Marine Resources, pp. 125-139. Balkema, Rotterdam.

Terova G, Corà S, Verri T, Rimoldi S, Bernardini G, Saroglia M (2009) Impact of food availability on PepT1 mRNA expression levels in sea bass (Dicentrarchus labrax). Aquaculture 294: 288-299.

Tesser MB, Terjesen BF, Zhang Y, Portella MC, Dabrowski K (2005) Free- and peptide-based dietary arginine supplementation for the South American fish pacu (Piaractus mesopotamicus). Aquaculture Nutrition 11: 443-453.

Theise ND (2005) Stem cell plasticity: tools for investigation and repair. Journal of Pediatric Gastroenterology and Nutrition 40: S48-S49. 
Tocher DR, Bendiksen EA, Campbell PJ, Bell JG (2008) The role of phospholipids in nutrition and metabolism of teleost fish. Aquaculture 280: 21-34.

Tonheim SK, Espe M, Raae AJ, Darias MJ, Rønnestad I (2004) In vivo incorporation of [U]C-14-amino acids: an alternative protein labelling procedure for use in examining larval digestive physiology. Aquaculture 235: 553-567.

Tonheim SK, Espe M, Hamre K, Rønnestad I (2005) Pre-hydrolysis improves utilisation of dietary protein in the larval teleost Atlantic halibut (Hippoglossus hippoglossus L.). Journal of Experimental Marine Biology and Ecology 321: 19-34.

Tonheim SK, Nordgreen A, Høgøy I, Hamre K, Rønnestad I (2007) In vitro digestibility of water-soluble and water-insoluble protein fractions of some common fish larval feeds and feed ingredients. Aquaculture 262: 426-435.

Ueberschär B (1993) Measurement of proteolytic enzyme activity: significance and application in larval fish research. In: Walther BT, Fyhn HJ (eds) Physiological and Biochemical Aspects of Fish Development. University of Bergen, Norway.

Ueberschär B (1995) The use of tryptic enzyme activity measurement as a nutritional condition index: laboratory calibration data and field application. ICES Journal of Marine Science Symposia 201: 119-129.

Ueberschär B (2006) Critical times for fish larvae - measurement of tryptic activity in order to assess the nutritional condition of fish larvae from laboratory rearing and from field samples - an overview. Verhandlungen der Gesellschaft fuer Ichthyologie (GfI) e V, 5: 193-229.

Ueberschär B, Pedersen BH, Hjelmeland K (1992) Quantification of trypsin with a radioimmunoassay in herring larvae (Clupea harengus) compared with a highly sensitive fluorescence technique to determine tryptic enzyme activity. Marine Biology (Berlin) 13: 468-473.

Uematsu K, Kitano M, Morita M, Iijima N (1992) Presence and ontogeny of intestinal and pancreatic phospholipase A2-like proteins in the Red Sea Bream, Pagrus major, An immunocytochemical study. Fish Physiology and Biochemistry 9: 427438.

Vadstein O, Bergh Ø, Gatesoupe F-J et al. (2012) Microbiology and immunology of fish larvae. Reviews in Aquaculture. In press. doi: 10.1111/j.1753-5131.2012.01082.x

Valentinčič T (2005) Olfactory discrimination in fishes. In: Reutter K, Kapoor BG (eds) Fish Chemosenses, pp. 65-85. Science Publishers, Inc. Enfield, NH.

Vegetti A, Mascarello F, Scapolo PA, Rowlerson A (1990) Hyperplastic and hypertrophic growth of lateral muscle in Dicentrarchus labrax (L.): an ultrastructural and morphometric study. Anatomy and Embryology 182: 1-10.

Verreth JAJ, Torreele E, Spazier E et al. (1992) The development of a functional digestive system in the African catfish Clarias gariepinus (Burchell). Journal of the World Aquaculture Society 23: 286-298.

Verri T, Kottra G, Romano A et al. (2003) Molecular and functional characterisation of the zebrafish (Danio rerio) PEPT1type peptide transporter. FEBS Letters 549: 115-122.
Verri T, Romano A, Barca A, Kottra G, Daniel H, Storelli C (2010) Transport of di- and tripeptides in teleost fish intestine. Aquaculture Research 41: 641-653.

Verri T, Terova G, Dabrowski K, Saroglia M (2011) Peptide transport and animal growth: the fish paradigm. Biology Letters 7: 597-600.

Villamizar N, García-Alcazar A, Sánchez-Vázquez FJ (2009) Effect of light spectrum and photoperiod on the growth, development and survival of European sea bass (Dicentrarchus labrax) laevae. Aquaculture 292: 80-86.

Villeneuve LAN, Gistbert E, Moriceau J, Cahu CL, ZamboninoInfante JL (2006) Intake of high level of vitamin A and polyunsaturated fatty acids during different developmental periods modifies the expression of morphogenesis genes in European sea bass (Dicentrarchus labrax). British Journal of Nutrition 95: 677-687.

Volkoff H (2006) The role of neuropeptide Y, orexins, cocaine and amphetamine-related transcript, cholecystokinin, amylin and leptin in the regulation of feeding in fish. Comparative Biochemistry and Physiology A 144: 325-331.

Volkoff H, Canosa LF, Unniappan S et al. (2005) Neuropeptides and the control of food intake in fish. General and Comparative Endocrinology 142: 3-19.

Volkoff H, Xu MY, MacDonald E, Hoskins L (2009) Aspects of the hormonal regulation of appetite in fish with emphasis on goldfish, Atlantic cod and winter flounder: notes on actions and responses to nutritional, environmental and reproductive changes. Comparative Biochemistry and Physiology A 153: 8-12.

Volkoff H, Hoskins LJ, Tuziak SM (2010) Influence of intrinsic signals and environmental cues on the endocrine control of feeding in fish: potential application in aquaculture. General and Comparative Endocrinology 167: 352-359.

Walford J, Lam TJ (1993) Development of digestive tract and proteolytic enzyme activity in seabass (Lates calcarifer) larvae and juveniles. Aquaculture 109: 187-205.

Wallace KN, Pack M (2003) Unique and conserved aspects of gut development in zebrafish. Developmental Biology 255: 12-29.

Wallace KN, Akhter S, Smith EM, Lorent K, Pack M (2005) Intestinal growth and differentiation in zebrafish. Mechanisms of Development 122: 157-173.

Wang Y, Hu M, Wang W et al. (2008) Transpositional feeding rhythm of loach Misgurnus anguillicaudatus from larvae to juveniles and its ontogeny under artificial rearing conditions. Aquaculture International 16: 539-549.

Watanabe Y (1984) An ultrastructural-study of intracellular digestion of horseradish-peroxidase by the rectal epitheliumcells in larvae of a fresh-water cottid fish Cottus-nozawae. Bulletin of The Japanese Society of Scientific Fisheries 50: 409-416.

Webb JF (1989) Neuromast morphology and lateral line trunk canal ontogeny in two species of cichlids: an SEM study. Journal of Morphology 202: 53-68.

Webb KA (2008) Cholecystokinin and the ontogeny of digestion in the red drum (Sciaenops ocellatus), PhD Thesis. The University of Texas at Austin, Austin, TX. 
Webb K, Rønnestad I (2011) Regulation of digestive processes. In: Holt J (ed.) Larval Fish Nutrition, pp. 265-282. John Wiley \& Sons, Chichester.

Webb PW, Weihs D (1986) Functional locomotor morphology of early life history stages of fishes. Transations of the American Fisheries Society 115: 115-127.

Webb KA, Khan IA, Nunez BS, Rønnestad I, Holt GJ (2010) Cholecystokinin: molecular cloning and immunohistochemical localization in the gastrointestinal tract of larval red drum, Sciaenops ocellatus (L.). General and Comparative Endocrinology 166: 152-159.

Werner RG, Blaxter JHS (1980) Growth and survival of larval herring (Clupea harengus) in relation to prey density. Canadian Journal of Fisheries and Aquatic Sciences 37: 1063-1069.

Werner RG, Blaxter JHS (1981) The effect of prey density on mortality, growth and food consumption in larval herring (Clupea harengus L.). Rapports et Proces-Verbaux des Reunions Conseil International pour l'Exploration de la Mer 178: 405-408.

Wu X, Washio Y, Aritaki M et al. (2011) Staging of initial pepsinogen and chitinase expression and complete gastric gland development within the larval stomach of Japanese flounder, spotted halibut, seven-band grouper and greater amberjack. Aquaculture 314: 165-172.

Wullur S, Sakakura Y, Hagiwara A (2009) The minute monogonont rotifer Proales similis de Beauchamp: culture and feeding to small mouth marine fish larvae. Aquaculture 293: 62-67.

Xiong DM, Xie CX, Zhang HJ, Liu HP (2011) Digestive enzymes along digestive tract of a carnivorous fish Glyptosternum maculatum (Sisoridae, Siluriformes). Journal of Animal Physiology and Animal Nutrition 95: 56-64.

Yoseda K, Yamamoto K, Asami K, Chimura M, Hashimoto K, Kosaka S (2008) Influence of light intensity on feeding, growth, and early survival of leopard coral grouper (Plectropomus leopardus) larvae under mass-scale rearing conditions. Aquaculture 279: 55-62.

Youson JH, Horbert WR (1982) Transformation of the intestinal epithelium of the larval anadromous sea lamprey Petromyzon marinus L. during metamorphosis. Journal of Morphology 171: 89-117.

Yúfera M, Darias MJ (2007a) The onset of feeding in marine fish larvae. Aquaculture 268: 53-63.

Yúfera M, Darias MJ (2007b) Changes in the gastrointestinal pH from larvae to adult in Senegal sole (Solea senegalensis). Aquaculture 267: 94-99.

Yúfera M, Pascual E, Polo A, Sarasquete MC (1993) Effect of starvation on the feeding ability of gilthead seabream (Sparus aurata L.) larvae at first feeding. Journal of Experimental Marine Biology and Ecology 169: 259-272.

Yúfera M, Fernández-Díaz C, Pascual E (1995) Feeding rates of gilthead seabream, Sparus aurata, larvae on microcapsules. Aquaculture 134: 257-268.

Yúfera M, Fernández-Díaz C, Vidaurreta A, Cara JB, Moyano FJ (2004) Gastrointestinal pH and development of the acid digestion in larvae and early juveniles of Sparus aurata (Pisces: Teleostei). Marine Biology 144: 863-869.

Yúfera M, Halm S, Beltran S, Fusté B, Planas JV, MartínezRodríguez G (2012a) Transcriptomic characterization of the larval stage in gilthead seabream (Sparus aurata) by 454 pyrosequencing. Marine Biotechnology 14: 423-435.

Yúfera M, Moyano FJ, Astola A, Pousão-Ferreira P, MartínezRodríguez G (2012b) Acidic Digestion in a teleost: postprandial and circadian pattern of gastric $\mathrm{pH}$, pepsin activity, and pepsinogen and proton pump mRNAs expression. PLoS ONE 7 (3): e33687.

Zabielski R, Godlewski MM, Guilloteau P (2008) Control of development of gastrointestinal systems of neonates. Journal of Physiology and Pharmacology 59: 35-54.

Zaiss MM, Papadakis IE, Maingot E, Divanach P, Mylonas CC (2006) Ontogeny of the digestive tract in shi drum (Umbrina cirrosa L.) reared using the mesocosm larval rearing system. Aquaculture 260: 357-368.

Zambonino Infante JL, Cahu CL, Peres A (1997) Partial substitution of di- and tripeptides for native proteins in sea bass diet improves Dicentrarchus labrax larval development. Journal of Nutrition 127: 608-614.

Zambonino-Infante JL, Cahu CL (2001) Ontogeny of the gastrointestinal tract of marine fish larvae. Comparative Biochemistry and Physiology C 130: 477-487.

Zambonino-Infante JL, Gisbert E, Sarasquete S, Navarro I, Gutiérrez J, Cahu CL (2008) Ontogeny and physiology of the digestive system of marine fish larvae. In: Cyrino JEP, Bureau D, Kapoor BG (eds) Feeding and Digestive Functions in Fishes, pp. 281-348. Science Publishers, Enfield, NH.

Zhang Y, Dabrowski K, Hliwa P, Gomulka P (2006) Indispensable amino acid concentrations decrease in tissues of stomachless fish, common carp in response to free amino acid- or peptide-based diets. Amino Acids 31: 165-172.

Zouiten D, Ben Khemis I, Besbes R, Cahu C (2008) Ontogeny of the digestive tract of thick lipped grey mullet (Chelon labrosus) larvae reared in 'mesocosm'. Aquaculture 279: 166-172. 